\title{
Genetics of anophthalmia and microphthalmia Part 1: Non-syndromic anophthalmia/microphthalmia
}

\author{
Plaisancié $\mathrm{J}^{1,2,3}$, Ceroni $\mathrm{F}^{4}$, Holt $\mathrm{R}^{4}$, Zazo Seco $\mathrm{C}^{3}$, Calvas $\mathrm{P}^{1,2,3}$, Chassaing $\mathrm{N}^{1,2,3}$, Ragge $\mathrm{NK}^{4,5, *}$ \\ ${ }^{1}$ Service de Génétique Médicale, Hôpital Purpan, CHU Toulouse, Toulouse, France \\ ${ }^{2}$ Centre de référence des Anomalies Rares en Génétique Ophtalmologique (CARGO) \\ ${ }^{3}$ INSERM U1056, Université Toulouse III, Toulouse, France \\ ${ }^{4}$ Faculty of Health and Life Sciences, Oxford Brookes University, Oxford, UK \\ ${ }^{5}$ West Midlands Regional Genetics Service, Birmingham Women and Children's NHS Foundation Trust, \\ Birmingham, UK
}

\section{*Corresponding author:}

Professor Nicola K Ragge, West Midlands Regional Genetics Service, Birmingham Women and Children's NHS Foundation Trust, Birmingham, UK; Oxford Brookes University, Oxford UK

E-mail:n.ragge@nhs.net

Tel: +441865484413

Fax: +44 1865742177

Conflict of Interest: The authors declare that they have no conflict of interest.

\section{Acknowledgements}

We would like to thank the patients and their families for their participation. We gratefully acknowledge Dr Dorine Bax for assisting with the coordination of the UK projects. Our work is supported by funding from Baillie Gifford, Microphthalmia, Anophthalmia, Coloboma Support (MACS) (www.macs.org.uk), Oxford Brookes University Central Research Fund, Fondation Maladies Rares, Fondation de France (Berthe Fouassier), Retina France, Rares Diseases Cohorts (RaDiCo) program funded by the French National Research Agency under the specific program "Investments for the Future" (Cohort grant agreement ANR-10-COHO-0003). 


\section{ABSTRACT}

Eye formation is the result of coordinated induction and differentiation processes during embryogenesis. Disruption of any one of these events has the potential to cause ocular growth and structural defects, such as anophthalmia and microphthalmia (A/M). A/M can be isolated or occur with systemic anomalies, when they may form part of a recognizable syndrome. Their etiology includes genetic and environmental factors; several hundred genes involved in ocular development have been identified in humans or animal models. In humans, around 30 genes have been repeatedly implicated in $\mathrm{A} / \mathrm{M}$ families, although many other genes have been described in single cases or families, and some genetic syndromes include eye anomalies occasionally as part of a wider phenotype. As a result of this broad genetic heterogeneity, with one or two notable exceptions, each gene explains only a small percentage of cases. Given the overlapping phenotypes, these genes can be most efficiently tested on panels or by whole exome/genome sequencing for the purposes of molecular diagnosis. However, despite whole exome/genome testing more than half of patients currently remain without a molecular diagnosis. The proportion of undiagnosed cases is even higher in those individuals with unilateral or milder phenotypes. Furthermore, even when a strong gene candidate is available for a patient, issues of incomplete penetrance and germinal mosaicism make diagnosis and genetic counselling challenging. In this review, we present the main genes implicated in nonsyndromic human $\mathrm{A} / \mathrm{M}$ phenotypes and, for practical purposes, classify them according to the most frequent or predominant phenotype each is associated with. Our intention is that this will allow clinicians to rank and prioritize their molecular analyses and interpretations according to the phenotypes of their patients.

Keywords: anophthalmia, microphthalmia, coloboma, eye development, genetics. 


\section{I - INTRODUCTION}

\section{Early eye development}

The formation of the eye is complex, requiring coordinated interactions between a variety of tissues of different embryonic origins. These include the neuroepithelium, the surface ectoderm and the extraocular mesenchyme, the latter originating from the neural crest and the mesoderm (Fuhrmann 2010). Eye morphogenesis is highly conserved among vertebrates. It begins during gastrulation, when the eye-forming region (the eye field) is induced within the anterior part of the neural plate. In humans, this corresponds to the 4 th week of gestation/embryonic development. During neurulation, the whole eye-forming region evaginates laterally, splitting the eye field into right and left optic vesicles. The optic vesicles interact with the overlying surface ectoderm, inducing its infolding, which ultimately gives rise to the lens and part of the cornea. Extension of the optic vesicle leads to the invagination of its distal surface into proximal and distal territories, forming the optic stalk and optic cup, respectively. The two layers of the optic cup form the neural and pigmented retina. This invagination is asymmetric and a furrow develops from the ventral side of the optic cup into the optic stalk, called the optic fissure. This transient opening enables the entry of the hyaloid artery to supply the developing eye. The inferior and most proximal invagination leads to the formation of the optic stalk, which allows the axons of the optic nerve to reach the brain. The nasal and temporal edges of the optic fissure subsequently fuse to close the layers of the eye during the 7th week of development in humans, establishing the basic structure of the eye (Mann 1953).

This process of eye formation is directed by a network of genes, and any disruption of these morphogenetic events by genetic or environmental influences can potentially cause growth and structural defects, such as anophthalmia, microphthalmia and coloboma.

\section{Hypotheses for disruptive mechanisms}

The pathophysiological mechanisms responsible for anophthalmia/microphthalmia $(A / M)$ (absence or reduced growth of the ocular globe, respectively) remain poorly understood. Mann proposed that A/M may result from a lack of induction at the level of the primitive neural tube or a failure of the optic pit to enlarge and form the optic vesicle (Mann 1953). Later suggestions included secondary regression of an ocular structure during development (rather than primary optic vesicle aplasia), explaining the variable presence of buried ocular vestigial tissue in human anophthalmic sockets seen on histological examination (Fitzpatrick and van Heyningen 2005). Additional suggestions have included that anophthalmia can occur following failure of lens induction (Inoue et al. 2007), early retinal differentiation or disruption of the extensive cell movements that are integral to optic vesicle 
invagination (Loosli et al. 2003; Stigloher et al. 2006; Winkler et al. 2000). Asymmetric involvement is common, suggesting differences in robustness and buffering mechanisms between the two sides.

\section{Definitions}

Anophthalmia and microphthalmia are the most severe developmental eye abnormalities and are frequently responsible for severe visual impairment, accounting for approximately $3 \%$ to $12 \%$ of visual impairment in children (Llorente-Gonzalez et al. 2011; Verma and Fitzpatrick 2007) and up to 20\% when including coloboma (Shah et al. 2011b). They can be unilateral or bilateral, and when unilateral, the contralateral eye may be normal or have various ocular anomalies, including cataract or coloboma.

Anophthalmia corresponds to the total absence of any tissue of the eye or its associated structures. However, the term 'clinical anophthalmia' is used when visible ocular structures are absent, although a remnant may be histologically detectable. Therefore, there is a fine line dividing 'clinical anophthalmia' and 'extreme microphthalmia', although in the latter visible (rather than buried) ocular structures are present.

Microphthalmia refers to a decreased size of the eye. Although the diagnosis may be clear by observation, this can be clinically confirmed if the axial length of the eye is more than 2 standard deviations (SD) below the age-adjusted population mean; $<21 \mathrm{~mm}$ in adults and $<14 \mathrm{~mm}$ in newborns (Verma and Fitzpatrick 2007). Microphthalmia is classed as severe if the corneal diameter is $<4 \mathrm{~mm}$ and is associated with a total axial length $<10 \mathrm{~mm}$ at birth or $<12 \mathrm{~mm}$ after 1 year of age (Verma and Fitzpatrick 2007; Warburg 1993).

In addition, microphthalmia can be classified as simple or complex. Simple microphthalmia refers to an eye with reduced size, but which is anatomically intact. In contrast, when microphthalmia is associated with abnormalities of the anterior segment (Axenfeld-Rieger anomaly, Peters' anomaly, sclerocornea and cataract) or of the posterior segment (persistence of primitive vitreous, chorioretinal coloboma and retinal dysplasia), it is defined as complex. When microphthalmia is combined with an optic fissure closure defect, it is referred to as colobomatous microphthalmia. A coloboma is easily visible if it presents as a ventral gap in the iris, but it may also affect other more posterior structures of the eye, including the retina, choroid and optic nerve.

Nanophthalmia is a particular form of reduced eye size characterized by extreme hyperopia, microcornea and frequently glaucoma.

Posterior microphthalmia is an uncommon subtype of microphthalmia affecting only the posterior segment of the eye and is thus defined by a reduced total axial length in the presence of normal anterior segment dimensions, including corneal diameter, anterior chamber depth and anteroposterior length of the lens. This condition is frequently associated with high hyperopia and 
abnormal retinal folds. The short distance between the lens and retina in eyes with posterior microphthalmia or nanophthalmia causes hyperopia with refractive errors ranging between +8.00 to +25.00 diopters.

Microphthalmia can also occur in association with primary congenital aphakia. This condition, resulting from a developmental arrest between the 4th and 5th weeks of gestation, is characterized by the absence of the lens. Aphakia can also be associated with other severe ocular abnormalities, such as sclerocornea or microcornea.

$\mathrm{A} / \mathrm{M}$ can be detected prenatally using high-resolution ultrasound during the second or third trimester. Nevertheless, even experienced ultrasonographers can miss ocular anomalies, and routine anomaly scans often do not include detailed ocular evaluation. After birth, $A / M$ is usually diagnosed by clinical ophthalmic examination. The detailed evaluation may include ultrasound to assess axial length and internal structure as well as electrodiagnostic testing to assess vision. The ophthalmologist will provide advice on early management of $A / M$ and the socket(s), which may include referral to an appropriate specialist centre (Ragge et al. 2007). Systemic evaluation is important to delineate any associated conditions or identifiable syndrome (Slavotinek 2018). The visual consequences are highly dependent on the particular anomalies, therapeutic options available and whether the anomalies are unilateral or bilateral. For example, Shah et al. (Shah et al. 2011a) reported that $81 \%$ of microphthalmic eyes and 93\% of microphthalmic eyes with coloboma had reduced vision.

\section{Epidemiology}

Several descriptive epidemiological studies have ascertained the prevalence of $A / M$. Most are based on national malformation registries and give a prevalence of around 1 to 3 per 10,000 live births (Bermejo and Martinez-Frias 1998; Busby et al. 1998; Chambers et al. 2018; Dolk et al. 1998; Kallen et al. 1996; Lowry et al. 2005; Morrison et al. 2002; Roos et al. 2016; Shah et al. 2011a; Spagnolo et al. 1994). Additional anomalies of other organ systems are present in $32-93 \%$ of $\mathrm{A} / \mathrm{M}$ cases (Chambers et al. 2018; Roos et al. 2016; Shah et al. 2011a; Slavotinek 2011; Spagnolo et al. 1994; Tucker et al. 1996) and $20 \%$ of children with $\mathrm{A} / \mathrm{M}$ and/or a coloboma have delayed psychomotor milestones (Morrison et al. 2002).

\section{Etiologies}

The etiology of $A / M$ can include environmental and/or genetic factors. Environmental factors are believed to represent only a small proportion of the causes of A/M (Bermejo and Martinez-Frias 1998), the best known examples being certain infectious agents (e.g. rubella, CMV and toxoplasmosis) (Duszak 2009; Kava and Nagarajan 2009; Suhardjo et al. 2003), toxic substances (e.g. alcohol), and drugs (e.g. retinoids and thalidomide) with most of the epidemiological studies relating to an era 
before the identification of genes for A/M (Lammer et al. 1985; Stromland 2004; Stromland et al. 1991; Stromland and Miller 1993). Although little is known about an association between smoking and A/M, maternal smoking in early pregnancy appears to be associated with an increase in the risk of $A / M$ in the absence of a coloboma (Kallen and Tornqvist 2005).

Genetic alterations are now known to be a major cause of developmental eye anomalies. A/M can be isolated or associated with extraocular anomalies, when they may form part of a recognizable syndrome (Slavotinek et al. 2018). In recent work, Chambers (2018) reported 1,262 live births with $A / M$ in Texas from a population of $4,207,898$ during a ten year period. Approximately half $(N=608$, 48.2\%) were syndromic (i.e. occurred with a chromosome abnormality, malformation syndrome, or complex). The most common chromosome abnormality was trisomy 13 ( $N=124,20 \%)$.

Many chromosomal abnormalities have been associated with $\mathrm{A} / \mathrm{M}$. These may be visible on a standard karyotype or identified by array comparative genomic hybridization $(\mathrm{aCGH})$, SNP array or whole genome sequencing (WGS) techniques. The rate of detection of chromosomal anomalies in patients with syndromic ocular involvement is 7-15\% using conventional cytogenetics (Kallen and Tornqvist 2005; Roos et al. 2016). These include aneuploidy (mainly trisomy 13 and 18), triploidy and certain microdeletion or microduplication syndromes, such as 4p-syndrome (MIM\#194190) or duplication of $3 q, 4 p$ or $10 q$ regions. The introduction of aCGH has made it possible to identify cryptic chromosomal abnormalities in $10-15 \%$ of patients with syndromic ocular involvement and normal karyotyping (Balikova et al. 2011; Delahaye et al. 2012). However, in non-syndromic A/M the frequency of chromosomal abnormalities identified by aCGH is low (Raca et al. 2011). In a registry study of children born with anophthalmia, microphthalmia and coloboma, Roos et al. (Roos et al. 2016) reported chromosome microarray analysis had been performed on around $9 \%$ with a possibly pathogenic copy number variant observed in almost half of cases. Another study performed SNP array screening of 60 individuals with isolated $(n=25)$ or syndromic $A / M(n=35)$ and identified four causative and six potentially causative copy number variants in ten cases (17\%) (Schilter et al. 2013). In addition to chromosomal abnormalities, structural and sequence alterations of a highly heterogeneous collection of single genes have been found to play a role in $A / M$, and interactions between these genes are beginning to reveal networks controlling eye morphogenesis. Overall, genetic variants seem to be the predominant cause of both syndromic and non-syndromic A/M.

The main causative genes encode i) transcription factors: SOX2 (MIM*184429), OTX2 (MIM*600037), PAX6 (MIM*607108), RAX (MIM*601881), VSX2 (MIM*142993), FOXE3 (MIM*601094), VAX1 (MIM*604294), ATOH7 (MIM*609875), SALL2 (MIM*602219), SALL4 (MIM*607343), MAF (MIM*177075), HMGB3 (MIM*300193), SIX3 (MIM*603714), SIX6 (MIM*606326), PAX2 (MIM*167409), PAX3 (MIM*606597), MITF (MIM* 156845), TFAP2A (MIM* 107580), SOX10 (MIM*602229) ii) expression regulators: YAP1 (MIM*606608), BCOR (MIM*300485), CHD7 (MIM*608892) or iii) proteins involved in signaling pathways: BMP4 (MIM*112262), BMP7 
(MIM*112267), SHH (MIM*600725), PTCH1 (MIM*601309), GDF3 (MIM*606522), GDF6 (MIM*601147), MFRP (MIM*606227), LRP2 (MIM*600073). Recently, mutations in genes involved in the metabolism of retinoic acid, STRA6 (MIM*610745), ALDH1A3 (MIM*600463), RARB (MIM*180220) and RBP4 (MIM*180250), have also been identified in patients with $\mathrm{A} / \mathrm{M}$. Nevertheless, many genes are involved which do not fall into these categories, for example: PORCN (MIM*300651), COL4A1 (MIM*120130), NAA10 (MIM*300013), FRAS1 (MIM*607830), FREM1 (MIM*608944), PXDN (MIM*605158), PRSS56 (MIM*613858), ABCB6 (MIM*605452), ACTG1 (MIM*102560), ACTB (MIM*102630), MAB21L2 (MIM*604357), SMOC1 (MIM*608488), HCCS (MIM*300056), COX7B (MIM*300885), C12ORF57 (MIM*615140), TMX3 (MIM*616102), FNBP4 (MIM*615265), TENM3 (MIM*610083) and TMEM98 (MIM*615949), RAB3GAP2 (MIM*609275), RAB3GAP1 (MIM*602536), RAB18 (MIM*602207), TBC1D20 (MIM*611663), SMCHD1 (MIM*614982), OLFM2 (MIM*617492).

\section{II - DIAGNOSTIC STRATEGY}

Recent advances in DNA sequencing technologies have significantly increased our knowledge of the genes underlying A/M (Plaisancie et al. 2016b). The importance of an accurate genetic diagnosis cannot be underestimated in terms of management, screening for associated conditions, genetic counselling and prenatal diagnosis. Although hundreds of genes have been suggested as being involved in eye development, around 30 of them have been repeatedly implicated in non-syndromic A/M families. In addition, some syndromic eye malformation genes have variants associated with only an eye phenotype (Slavotinek 2018). Overall, mutations in each gene explain only a small percentage of cases. According to the 2015 revision of GeneReviews (https://www.ncbi.nlm.nih.gov/books/NBK1116/), the major gene responsible for $A / M$ is SOX2, accounting for $10-15 \%$ of affected individuals, usually those with a severe $\mathrm{A} / \mathrm{M}$ phenotype. The next most frequent genetic causes are alterations in OTX2 (2-5\% of cases), RAX (3\% of cases), FOXE3 ( $2.5 \%$ of cases) and PAX6 ( $2 \%$ of cases). Overall, the genetic cause is currently only determined in around $20-30 \% \mathrm{~A} / \mathrm{M}$ patients, although this figure is higher in cases of severe and/or bilateral A/M (Chassaing et al. 2014; Gerth-Kahlert et al. 2013). For instance, in our series of $150 \mathrm{~A} / \mathrm{M}$ patients of mixed severity (Chassaing et al. 2014) screened for mutations in SOX2, OTX2, RAX, FOXE3, PAX6, GDF6 and VSX2 by direct sequencing and semi-quantitative multiplex PCR, causative mutations were detected in $21 \%$ of patients. The proportion of individuals for which mutations were detected was higher in anophthalmic patients (54\%) compared to those with unilateral microphthalmia (10\%). Since this publication, mutations in other genes have been identified in an additional $10 \%$ of our patients (unpublished data), increasing the detection rate to about $30 \%$. In another series including 51 probands with A/M (Gerth-Kahlert et al. 2013), aCGH and screening of a limited number of genes (SOX2, OTX2, RAX, FOXE3, PAX6, BMP4, SMOC1 and STRA6) resulted in a diagnostic rate of $75 \%$ in patients with bilateral and severe forms of $A / M$ and $20 \%$ in patients with unilateral and less severe forms. Gene screening alone allowed the identification of the genetic cause in around $30 \%$ of patients with severe phenotypes and around $10 \%$ for unilateral or less severe ones. In addition to the major genes listed above, other genes are also believed to explain a significant 
proportion of cases. For example, based on their series of $75 \mathrm{~A} / \mathrm{M}$ index cases and including a case they had previously reported (Yahyavi et al. 2013), Abouzeid et al. (Abouzeid et al. 2014) suggested that mutations in ALDH1A3 are a frequent cause of $\mathrm{A} / \mathrm{M}$ and responsible for approximately $10 \%$ of cases in consanguineous pedigrees. Of note, mutations in $A L D H 1 A 3$ have mainly been identified in consanguineous pedigrees.

Only a few studies have determined the mutation detection rate using whole exome sequencing (WES) in ocular developmental disorders. Slavotinek et al. (Slavotinek et al. 2015) screened 28 patients with A/M using WES, leading to a reliable molecular diagnosis in 4 individuals (14\%). Deml et al. (Deml et al. 2016) performed WES for $28 \mathrm{~A} / \mathrm{M}$ probands known not to carry mutations in SOX2 or FOXE3. This data was analyzed prioritizing 83 known $\mathrm{A} / \mathrm{M}$ genes and resulted in the identification of causative mutations in 3 individuals (11\%). More recently, WES was applied to a cohort of 14 patients with bilateral A/M (Matias-Perez et al. 2018). As expected, given the bilaterality and severity of ocular phenotype, the mutation detection rate in this cohort was almost $60 \%(8 / 14)$, the majority carrying alterations in well-known eye genes (7/8). Thus, WES studies resulted in a detection rate similar to that obtained by the targeted sequencing of a panel of the main known genes. However, an advantage of WES over panel sequencing is the opportunity to identify new causal genes in particular pedigrees (Chassaing et al. 2016b; Matias-Perez et al. 2018; Patel et al. 2018; Srour et al.2013).

Even if, theoretically, WES approaches were considered the best strategy to identify causative mutations (since $90 \%$ of pathogenic mutations are estimated to be located in coding sequences), there is an increasing recognition of the involvement of gene regulatory regions in pathological processes. Indeed, many studies have shown that variants in non-coding regions of the genome can cause ocular disorders (Bhatia et al. 2013; Chatterjee and Pal 2009; Cipriani et al. 2017; Conte et al. 2015; Davidson et al. 2016; Small et al. 2016; Volkmann et al. 2011). Although ocular genetic diseases generally follow a Mendelian pattern of inheritance, mutations in the non-coding regions of the genome (as well as some coding regions) have also been associated with non-Mendelian inheritance (Medina-Trillo et al. 2016). Variants in non-coding regions ( $98 \%$ of the genome) represent almost $2 \%$ of known gene disruptions responsible for human inherited disease according to the Human Gene Mutation Database (http://www.hgmd.cf.ac.uk/ac/index.php). However, it is likely that their involvement is underestimated, since regulatory mutations are not currently prioritized in genetic analyses. Increasing the use of WGS in patients will allow for a more comprehensive evaluation of the proportion of variants in regulatory sequences that cause human pathologies.

Although no studies investigating $\mathrm{A} / \mathrm{M}$ using WGS have been published to date, we hypothesize that they would demonstrate a much higher mutation detection rate than WES approaches due to their ability to analyze the regulatory regions of known A/M genes. WGS would also avoid biases specific to WES techniques, such as exon capture failings. 
Therefore, WGS technologies provide increased opportunities for variant identification in both coding and non-coding regions of known and new $\mathrm{A} / \mathrm{M}$ genes. However, the question of how these variants are interpreted and classified is of fundamental importance in providing reliable molecular diagnoses and appropriate genetic counselling. While genetic variants, whether sequence changes or CNVs, are generally easy to detect, the understanding of functional consequences and determination of causality is far more laborious. Furthermore, interpreting the deleterious effects of mutations in non-coding regions (deep intronic, promoter and cis-regulatory sequences) remains challenging.

The thorough interpretation of the impact of genetic variants has two key aspects. First is to predict the molecular impact of a variant. Guidelines for such predictions have been provided by the American College of Medical Genetics and Genomics (ACMG) and the Association for Molecular Pathology (Richards et al. 2015). These establish five classes of variants: benign, likely benign, of uncertain significance, likely pathogenic and pathogenic. In cases of variants of uncertain significance, additional in vitro or in vivo analyses can be undertaken to further establish their pathogenicity.

Second, but no less important, is the clinical knowledge of the phenotypes associated with specific $\mathrm{A} / \mathrm{M}$ genes and mutations, and therefore the potential genotype-phenotype correlations. The causality of a pathogenic variant is relatively straightforward to assign when the phenotype of the case is distinctive and matches that of other individuals with mutations in the same gene, and where the variant segregates according to the expected inheritance pattern for the disorder. However, a molecular diagnosis is harder to provide when i) a variant is of uncertain pathogenicity, ii) a second mutant allele is not found in cases of recessively inherited phenotypes, iii) the genotype is unexpected given the phenotype, iv) no segregation pattern can be established e.g. in singleton cases or v) the variant (if heterozygous in the case of a dominant phenotype) is inherited from an unaffected parent. In such situations, a precise phenotypic description will assist in interpreting the molecular data. Indeed, where specific phenotypes are associated with particular genes, such precise descriptions can guide further genetic analyses, such as by extending analyses to include RNA studies in the case of splice site variants, or functional studies for regulatory region variants.

\section{III - GENES IMPLICATED IN DISTINCTIVE OCULAR PHENOTYPES (Table 1)}

\section{Anophthalmia and severe microphthalmia}

Anophthalmia and severe microphthalmia are at the most severe end of the $A / M$ and coloboma spectrum and the genes responsible for the majority of these phenotypes are presented in the following section. Therefore, screening of these genes should be prioritized in patients with these phenotypes, especially as they also represent the genes most frequently involved in A/M and coloboma in general. 


\section{SOX2 (SRY [sex-determining region Y]-box 2)}

SOX2 codes for a transcription factor which is highly expressed during ocular development (Fantes et al. 2003; Hever et al. 2006; Ragge et al. 2005b; Williamson et al. 2006). Its involvement in A/M was initially demonstrated in a patient with a $\sim 740 \mathrm{~kb}$ deletion on chromosome 3 that included SOX2 (Fantes et al. 2003). Subsequently, heterozygous point variants in this gene were identified in additional patients (Fantes et al. 2003; Ragge et al. 2005b). It has since been found that heterozygous SOX2 pathogenic variants, including whole gene deletions, are present in $10-15 \%$ of all $\mathrm{A} / \mathrm{M}$ patients (Bakrania et al. 2007; Gerth-Kahlert et al. 2013) making it the most common genetic cause for these disorders.

More than 100 different truncating and missense variants of this single-exon gene have been described [LOVD-SOX2]. Deletions of SOX2 are also frequent and account for $25-50 \%$ of pathogenic variants identified in this gene (Bakrania et al. 2007; Chassaing et al. 2014). It is also of interest that most of the intragenic variants are private, having only been identified in individual families (Ragge et al. 2005b). The initial phenotypes associated with SOX2 mutations included ocular anomalies (typically severe and bilateral), psychomotor delay, seizures, periventricular heterotopias, hippocampal and pituitary anomalies, growth retardation, genital and renal abnormalities, and some minor craniofacial findings (Ragge et al. 2005b). It was later shown that SOX2 variants can also cause a syndromic form of $A / M$, Anophthalmia-Esophageal-Genital (AEG) syndrome (Williamson et al. 2006) (MIM\#206900), and the same variant can be responsible for AEG syndrome or other SOX2 phenotypes (Bakrania et al. 2007). Various other anomalies have also rarely been associated with these variants (Chassaing et al. 2007; Kelberman et al. 2006).

The spectrum of ocular anomalies associated with SOX2 variants has progressively widened, with patients also displaying less severe phenotypes, including iris and retinal coloboma and iris hypoplasia (Chassaing et al. 2007; Wang et al. 2008), and in some cases no ocular anomalies. For example, one patient with a truncating mutation showed no overt or microscopic eye involvement (Chassaing et al. 2007). Also, one individual with a nonsense variant had non-syndromic hypogonadotropic hypogonadism and a seizure disorder, but no ocular abnormalities except for decreased thickness of the retinal nerve fiber layer (Shima et al. 2017). A further three individuals from a cohort with intellectual disability/developmental delay, but without anophthalmia or microphthalmia, were also shown to harbour point mutations or microdeletions of SOX2 (Dennert et al. 2017) and in one case with a superior chorioretinal defect involving the optic disc and macula associated with a retinal dystrophy on normal sized ocular globes (Bakrania et al. 2007). Individuals with SOX2 mutations may show later neurodegeneration, as indicated by a single case report (Ragge et al.2013).

In summary, the ocular features associated with SOX2 mutations are classically bilateral and severe (anophthalmia in the majority of patients). The most common extraocular features are psychomotor delay (mild to severe impairment), cerebral involvement (ventriculomegaly, hypoplasia of the corpus 
callosum), hypogonadism and growth retardation, possibly related to pituitary anomalies, and renal anomalies. Rarely patients may also display esophageal atresia (Chassaing et al. 2014), sometimes as part of the AEG syndrome. A genotype-phenotype correlation has been suggested (Schneider et al. 2009), however patients with similar mutations have variable ocular and extraocular involvement and intra-familial clinical variability has also been frequently noted (Chassaing et al. 2007; Kelberman et al. 2006; Mihelec et al. 2009; Zenteno et al. 2006). In addition, the ocular features can be significantly asymmetrical between both eyes of the same patient, making attempts at genotype-phenotype correlations difficult. SOX2-related anophthalmia syndrome is transmitted in an autosomal dominant pattern, with the vast majority of patients having de novo variants. However, reported cases of germinal mosaicism (Chassaing et al. 2007; Faivre et al. 2006; Schneider et al. 2009) should be taken into account when providing genetic counselling.

\section{OTX2 (orthodenticle homeobox 2)}

OTX2 encodes a transcription factor involved in the formation of multiple ocular structures and is particularly expressed during the differentiation of the retina (Hever et al. 2006). The involvement of OTX2 in A/M was demonstrated by Ragge et al. (Ragge et al. 2005a) using a positional candidate gene approach leading to the identification of variants in this gene in $8 \mathrm{~A} / \mathrm{M}$ families. OTX2 is now estimated to underlie $0.7-10 \%$ of A/M (Gerth-Kahlert et al. 2013; Henderson et al. 2009; Ragge et al. 2005a; Schilter et al. 2011; Wyatt et al. 2008). More than 70 different genetic alterations have been described (Human Gene Mutation Database [HGMD ${ }^{\circledR}$ ], Stenson et al. 2017), including pathogenic truncating and missense variants, and gene deletions (Chassaing et al. 2014; Chassaing et al. 2012; Gerth-Kahlert et al. 2013), the latter representing $30-40 \%$ of variants in this gene (Chassaing et al. 2014; Wyatt and Ragge 2009).

The ocular phenotype of patients with pathogenic OTX2 variants is highly variable even within the same family. It is often severe and ranges from bilateral anophthalmia (Fig. 1a) or Leber congenital amaurosis through to no ocular malformation (Chassaing et al. 2014; Ragge et al. 2005a), making genetic counseling very challenging. Other anomalies may include colobomas (iris and/or retinal), cataract and sclerocornea. The presence of extraocular anomalies is inconsistent, but can include intellectual deficiency, growth retardation and pituitary involvement, and deafness (Ragge et al. 2005a; Schilter et al. 2011; Wyatt et al. 2008). Mutations of OTX2 have also been described in some patients with isolated hypopituitarism (Tajima et al. 2013). Furthermore, pathogenic variants in this gene have been identified in agnathia, a major malformation of the mandible during embryonic development (Chassaing et al. 2012; Patat et al. 2013).

The pattern of inheritance related to phenotypes caused by OTX2 mutations is autosomal dominant. However, penetrance is incomplete and clinical variability common (Somashekar et al. 2017). 
Mutations can be inherited or occur de novo (approximately $50 \%$ of cases). Cases of germinal mosaicism are also well described (Ragge et al. 2005a; Wyatt et al. 2008).

\section{RAX (retina and anterior neural fold homeobox)}

$R A X$ encodes a transcription factor whose role in ocular development has been studied in a variety of vertebrate models (Bailey et al. 2004). The gene is expressed early in the eye primordia and plays animportant role in the establishment and/or proliferation of retinal progenitor cells (Mathers et al. 1997).

Biallelic mutations have been identified in 7 families with a bilateral and severe ocular A/M phenotype (Abouzeid et al. 2012; Chassaing et al. 2014; Lequeux et al. 2008; Voronina et al. 2004) and in 1 family with isolated unilateral coloboma and retinoschisis (Huang et al. 2017). These mutations are of varying nature (missense, nonsense, frameshift and splicing mutations, and a gene deletion), but all act through a "loss-of-function" mechanism. In our experience, biallelic RAX variants are identified in approximately $3 \%$ of A/M patients (4/150) (Chassaing et al. 2014). Associated extra-ocular phenotypes are also varied. Intellectual disability was described in 3 patients from the 8 families described above. In comparison, in a separate study, no extra-ocular phenotype was reported in two patients, apart from frontal and sphenoid sinus abnormalities (Abouzeid et al. 2012).

Heterozygous mutations of RAX have been described in patients with chorioretinal coloboma (London et al. 2009) and A/M (Gonzalez-Rodriguez et al. 2010). However, for these patients the segregation pattern is unknown, and the link between these mutations and the ocular phenotype remains unclear. Heterozygous carriers of $R A X$ mutations in $\mathrm{A} / \mathrm{M}$ families with biallelic affected individuals lack any ocular phenotype. While it is difficult to exclude the possibility of dominant mutations, current evidence indicates that genetic counseling should tend towards considering $R A X$ mutations as acting through an autosomal recessive mode of inheritance.

\section{VSX2 (visual system homeobox 2)}

VSX2, also known as CHX10, encodes a transcription factor that plays a major role in the development of mammalian eyes (Liu et al. 1994). VSX2 is expressed during optic vesicle formation, and its expression in retinal progenitors allows their proliferation and differentiation into neuroretinal cells (Liu et al. 1994). The first mutations of VSX2 were described in microphthalmic patients by Ferda Percin et al. (Ferda Percin et al. 2000). Since then, VSX2 mutations (both missense and truncating) have been described in several other families with eye anomalies (Ammar et al. 2017; Burkitt Wright et al. 2010; Chassaing et al. 2014; Iseri et al. 2010; Khan et al. 2013; Reis et al. 2011a; Ullah et al. 2016). The 
phenotype associated with mutations in VSX2 is typically bilateral $A / M$, frequently associated with coloboma and sometimes with cataract, glaucoma and retinal dystrophy. Atypical ocular involvement has been described in one patient: his phenotype included subluxation of the lens, retinal dystrophy and severe myopia (Khan et al. 2013). Associations with delayed development and autistic spectrum disorder have occasionally been reported. However, extraocular involvement is uncommon. The $A / M$ phenotype attributable to VSX2 mutations is typically recessively inherited. However, interestingly one family had affected carrier parents with a semidominant inner retinal dystrophy, more severely affected offspring with severe microphthalmia and coloboma and a homozygous VSX2 frameshift mutation (c.249delG p.[Leu84SerfsTer57], NM_182894) (Iseri et al. 2010).

\section{STRA6 (stimulated by retinoic acid 6)}

Four genes in the retinoic acid synthesis pathway are known to be involved in the $A / M$ phenotype: STRA6, RARB, ALDH1A3 and RBP4. Both loss and gain of retinoic acid signaling cause structural defects of organs, such as the eye, heart, lung, diaphragm and limbs, indicating that this pathway is vital for the development of these structures (Cunningham and Duester 2015).

STRA6 codes for a transmembrane receptor that mediates the cellular uptake of Vitamin A (retinol). Biallelic mutations in STRA6 were first described in Matthew-Wood syndrome (Chassaing et al. 2009; Pasutto et al. 2007; Seller et al. 1996), later referred to as PDAC to reflect its major phenotypic components: (Pulmonary agenesis or hypoplasia, Diaphragmatic hernia, Anophthalmia/ microphthalmia and Cardiac defects) (Chitayat et al. 2007). However, in 2011 Casey et al. (Casey et al. 2011) demonstrated the contribution of biallelic STRA6 mutations to isolated forms of microphthalmia, a finding later confirmed by Slavotinek et al. (Slavotinek et al. 2015). Ocular involvement is a constant feature of the phenotype associated with biallelic STRA6 mutations. This can manifest as unilateral microphthalmia or anophthalmia, sometimes with contralateral eye defects, such as coloboma (Casey et al. 2011). Nevertheless, when present, microphthalmia is typically severe and bilateral. Interestingly, the phenotypic spectrum has been further broadened with the report of 3 patients with contractures and camptodactyly, in addition to PDAC (Marcadier et al.2016).

STRA6-related eye disorders are inherited in an autosomal recessive manner. Nevertheless, ocular anomalies have been described in heterozygous carriers of some families. These include one with congenital cataract (Chassaing et al. 2013), one with bilateral coloboma of the iris and the retina (Golzio et al. 2007) and one with a right optic disc coloboma and left microphthalmia with iris coloboma (Ng et al. 2013). In addition, a heterozygous STRA6 missense mutation was identified in a patient with bilateral microphthalmia and coloboma, unilateral retinal detachment, right-sided aortic arch, vascular ring and intellectual disability. This mutation was inherited from their mother, who also had bilateral microphthalmia and did not carry a second mutation (Slavotinek et al. 2015). 


\section{RARB (retinoic acid receptor beta)}

RARB is a thyroid-steroid hormone receptor and part of a superfamily of nuclear transcriptional regulators. In 2013, Srour et al. (Srour et al. 2013) reported a non-consanguineous family containing 4 siblings with bilateral microphthalmia and variable additional features of the PDAC spectrum (Chitayat et al. 2007). One of the affected individuals was known to lack mutations in STRA6. WES identified biallelic truncating mutations in RARB that segregated with the disease (c.355C > T p. [Arg119Ter] and c.1201_1202insCT p.[lle403SerfsTer15], NM_000965). Sanger sequencing of RARB in an additional cohort (15 subjects) with $\mathrm{A} / \mathrm{M}$ and at least one other feature of the PDAC syndrome identified de novo missense mutations (c.1159C $>$ T p.[Arg387Cys] and c.1159C $>$ A p.[Arg387Ser], NM_000965) in 3 additional sporadic cases (Srour et al. 2013). Targeted and exome sequencing have since resulted in the identification of one of these missense variants (p. [Arg387Cys]) and a further two de novo missense mutations (c.887G>C p.[Gly296Ala] and c.638T>C p.[Leu213Pro], NM_000965) in a total of 10 additional individuals (Slavotinek et al. 2015; Srour et al. 2016). Thus, to date there is only one family with a PDAC phenotype related to biallelic RARB mutations. Therefore, Srour et al. (Srour et al. 2016; Srour et al. 2013) suggest that RARB could underlie both recessive and dominant forms of the PDAC phenotype, with the de novo missense variants in RARB acting through a "gain-of-function" mechanism. Concerning the de novo cases, the microphthalmia phenotype was bilateral in 11/13 subjects. In addition, most subjects had sclerocornea (10/11) and coloboma (7/10) (Srour et al. 2016). However, in contrast to STRA6 (Casey et al. 2011), there is currently no report of an isolated A/M phenotype associated with mutations in RARB. For example, Srour et al. (Srour et al. 2013) sequenced $R A R B$ in 11 cases with isolated bilateral $\mathrm{A} / \mathrm{M}$, but did not find any mutation. Moreover, in addition to the PDAC spectrum of anomalies, all the subjects described by Srour et al. (Srour et al. 2016) who survived beyond the neonatal period also manifested severe global developmental delay combined with a progressive motor impairment and associated spasticity and/or dystonia (with or without chorea).

\section{ALDH1A3 (aldehyde dehydrogenase 1 family member A3)}

$A L D H 1 A 3$ encodes a retinaldehyde dehydrogenase, an enzyme involved in the metabolism of Vitamin A to retinoic acid (Cunningham and Duester 2015; Cvekl and Wang 2009). Fares-Taie et al. (Fares-Taie et al. 2013) described the first biallelic mutations of this gene in $3 \mathrm{~A} / \mathrm{M}$ consanguineous families. The proband (II.3) from family 3 reported in this study (carrying the ALDH1A3 splice site mutation c.475+1G>T, NM_000693) is shown in Fig. 1b. Since then, ALDH1A3 has been implicated in many reports of recessive forms of A/M (Abouzeid et al. 2014; Alabdullatif et al. 2017; Aldahmesh et al. 2013b; Dehghani et al. 2017; Lin et al. 2018; Liu et al. 2017b; Mory et al. 2013; Roos et al. 2013; Semerci et al. 2014; Ullah et al. 2016; Yahyavi et al. 2013). Mutations in ALDH1A3 are a frequent cause of $A / M$ in consanguineous pedigrees (Abouzeid et al. 2014), representing approximately $10 \%$ of cases. Of note, mutations in $A L D H 1 A 3$ have been reported mainly in consanguineous pedigrees. Different types of 
mutations have been described (missense, nonsense and splice site variants) and appear to act through a "loss-of-function" mechanism. The ocular defects are generally severe (anophthalmia or severe microphthalmia) and bilateral. For patients also presenting with extraocular findings, neurocognitive and behavioral features are quite frequent, notably the presence of autistic features. There are also rare descriptions of systemic anomalies, such as Dandy Walker malformation (Semerci et al. 2014), pulmonary stenosis and atrial septal defects (Fares-Taie et al. 2013). Incomplete penetrance of biallelic ALDH1A3 mutations has been reported in one family (Plaisancie et al. 2016a).

\section{MAB21L2 (male abnormal gene family 21, C. elegans, homolog-like 2)}

In 2014, a WES study identified 4 different missense variants in MAB21L2 in 5 unrelated families with bilateral clinical anophthalmia or microphthalmia and coloboma, with or without rhizomelic skeletal dysplasia and learning disability (Rainger et al. 2014). The first family had autosomal dominant bilateral colobomatous microphthalmia, and carried a heterozygous MAB21L2 mutation (c.152G>A p.[Arg51His], NM_006439) that segregated with the disease. The other MAB21L2 heterozygous variants identified by this study were found in 3 sporadic cases. Among these, one patient carried a de novo variant (c.151C>T p.[Arg51Cys], NM_006439) and presented with bilateral anophthalmia, macrocephaly, intellectual disability and generalized skeletal dysplasia. The same variant was also found de novo in a second unrelated patient with more severe rhizomelic skeletal dysplasia associated with bilateral anophthalmia. A third individual, who had bilateral colobomatous microphthalmia and minor skeletal anomalies, harbored a heterozygous variant (c.145G>A p.[Glu49Lys], NM_006439) for which segregation analysis was not possible. Finally, they also identified 2 consanguineous sibs with bilateral retinal coloboma, one with additional unilateral microphthalmia, whose asymptomatic parents were both carriers. Both siblings had a homozygous missense mutation, located in a different domain of MAB21L2 (c.740G>A p.[Arg247GIn], NM_006439). Their parents were heterozygous and asymptomatic, indicating an autosomal recessive mode of inheritance. Interestingly, the authors noted that these two homozygous siblings were more mildly affected than individuals with autosomal dominant mutations of the gene. Therefore, they suggested that the monoallelic mutations may act via a "dominant negative" mechanism (Rainger et al. 2014). A recent study analyzing the effect of these missense variants using the 3D structure of MAB21L1, another MAB21 protein, showed how all the missense mutations reported by Rainger et al. (Rainger et al. 2014) are predicted to destabilize the protein (de Oliveira Mann et al. 2016). Horn (Horn et al. 2015) described in more detail the skeletal involvement in patients with the p.(Arg51Cys) variant, consisting of severe, pre- and postnatal short stature, rhizomelic limbs with a specific humero-femoral dysplasia and multiple joint contractures. Another interesting observation is that the three monoallelic variants identified by Rainger et al. affected neighbouring residues (p.Glu49 and p.Arg51). Another study (Deml et al. 2015) has reported a third heterozygous missense mutation affecting arginine 51 (c.151C>G p.[Arg51Gly], NM_006439), identified in a 3-generation family with coloboma, microcornea, cataracts and skeletal dysplasia. This 
variant segregated with the disease and was not found in public variant databases. Taken together, these data show that the region of the protein where these monoallelic missense variants occur seems to be a mutational hotspot which may have a crucial role for the function of the protein in eye and skeletal development.

Recently Patel and colleagues (Patel et al. 2018) reported the first heterozygous MAB21L2 nonsense mutation (c.840C >G p.[Tyr280Ter], NM_006439) in a patient with isolated colobomatous microphthalmia. Unfortunately, the segregation pattern for this sporadic case is unknown. The mechanism by which MAB21L2 exerts its effects is still unknown and the identification of additional mutations will help to elucidate this.

MAB21L2 is a member of the gene family Male-abnormal 21 and is able to antagonize BMP4 signaling which is known to be important in eye development (Bakrania et al. 2008), in particular via interaction with SMAD1 (Baldessari et al. 2004). Work in several species suggests that the Mab-21 genes play key roles in early developmental processes such as gastrulation, neural tube closure and eye formation (Chow et al. 1995; Kudoh and Dawid 2001; Lau et al. 2001; Wong and Chow 2002; Yamada et al. 2003).

Deml et al. (2015) generated zebrafish models homozygous for a frameshift truncating mutation and an in-frame deletion in mab21/2. The phenotype of the former included microphthalmia with small or absent lenses in all embryos, and coloboma and shortened body/curved tail in $76 \%$ and $56 \%$ of fish, respectively. For the homozygous in-frame deletion mutants, the abnormal phenotype was milder and consisted of severe ocular coloboma in all embryos and corneal defects in almost half of them, while lenses and eye size appeared to be only mildly affected. Finally, wildtype, but not mutant, MAB21L2 mRNA was able to efficiently rescue the ocular anomalies present in zebrafish embryos with a homozygous mab21/2 frameshift mutation (68\% versus $14 \%$ ).

\section{BMP7 (bone morphogenetic protein 7)}

BMP7 encodes a bone morphogenetic protein (BMP), a family of proteins involved in multiple processes within the cell and in the specification and patterning of the early embryo. Despite these important roles, little is known regarding the specific roles of individual BMPs in human disease due to their overlapping functions. In the mouse, $B m p 7$ is expressed in the optic cup and surface ectoderm of the developing eye (Dudley and Robertson 1997) playing a crucial role in optic fissure formation and in the early steps of lens development. Bmp7 null mice display severe eye defects, including $A / M$, skeletal and renal anomalies, and die shortly after birth (Dudley et al. 1995; Luo et al. 1995; Wawersik et al. 1999; Zouvelou et al. 2009). Interestingly, in the mouse the ocular defects exhibit reduced penetrance and variable expressivity, ranging from anophthalmia to normal sized eyes (Dudley et al. 1995; Luo et al. 1995; Wawersik et al. 1999) and are influenced by genetic background. 
After screening 279 patients with an A/M and coloboma phenotype, Wyatt et al. (Wyatt et al. 2010) identified 3 cases with heterozygous BMP7 variants of different types (frameshift, missense and Kozak sequence mutations). The phenotypes of the 3 patients were i) bilateral anophthalmia with various anomalies (c.513delA, NM_001719.2), ii) unilateral anophthalmia with AEG syndrome (c.-1G>T, NM_001719.2) and iii) unilateral microphthalmia, chorioretinal and optic disc coloboma with learning disability (c.593T>C, NM_001719.2). All three variants were maternally inherited, one from an unaffected mother (c.513delA, NM_001719.2) and the remaining two from mothers with no documented phenotype. As the segregation of these alleles is not fully known their significance may become clearer as more data is generated for this gene.

\section{GDF3 and GDF6 (growth differentiation factor 3 and 6)}

The Growth Differentiation Factors (GDFs) are members of the BMP sub-family of transforming growth factor-beta (TGF- $\beta$ ) signaling ligands, known to regulate patterning during development (Herpin et al. 2004).

All of the pathogenic variants reported to date for GDF3 and GDF6 are heterozygous missense changes with affected individuals exhibiting either ocular or skeletal anomalies, or a combination of the two. Variants in these genes account for $1.7 \%$ and $1 \%$ of $\mathrm{A} / \mathrm{M}$ and coloboma patients screened for GDF3 or GDF6 mutations, respectively (Asai-Coakwell et al. 2007; Asai-Coakwell et al. 2009; Ye et al. 2010). The range of ocular phenotypes extends from bilateral anophthalmia (GDF6 variant) to unilateral coloboma (GDF3 variant). In addition to A/M and coloboma, potential pathogenic missense variants in GDF6 have been recently reported in 3 unrelated patients with isolated primary glaucoma, two with dominant forms and one sporadic case (Huang et al. 2015).

Monoallelic variants in GDF3 and GDF6 are associated with both high intra- and interfamilial variability. For example, the GDF3 variant reported in the case with unilateral coloboma (Ye et al. 2010) was inherited from the mother who was diagnosed with a familial Klippel-Feil syndrome (MIM\#118100), a rare skeletal disorder mainly characterized by the fusion of cervical vertebrae. An example of interfamilial variability is provided by a de novo missense variant in GDF6 identified in one patient with bilateral anophthalmia, but also in 3 unrelated cases with coloboma, microphthalmia, post-axial polydactyly and Klippel-Feil syndrome (Asai-Coakwell et al. 2009). Beside this clinical variability, nonpenetrance also seems to be a reasonably common occurrence associated with GDF3 and GDF6 variants (Asai-Coakwell et al. 2009; Bardakjian et al. 2017; Patel et al. 2018; Ye et al. 2010). This relatively frequent non-penetrance could be due to an additive effect of multiple variants in several BMP ligands contributing to the ocular or skeletal phenotypes (Ye et al. 2010). For instance, a patient with severe microphthalmia, bilateral iris coloboma and optic nerve hypoplasia had both GDF3 and GDF6 heterozygous variants, with only the former being inherited from their affected mother, who 
presented with mild microphthalmia, iris coloboma and normal optic discs [Ye et al. 2010]. Documented skeletal features associated with mutations in these genes include post-axial polydactyly, hemifacial hypoplasia, hemi-vertebrae, rib anomalies and spondylothoracic dysostosis (Asai-Coakwell et al. 2009). Additional features that have been observed include orofacial clefting, small pituitary gland with growth hormone deficiency, hydrocephalus and talipes (den Hollander et al. 2010).

\section{VAX1 (ventral anterior homeobox 1)}

VAX1 is a homeodomain transcription factor important for eye and brain development and its role has been studied in several animal models (Bertuzzi et al. 1999; Hallonet et al. 1999; Take-uchi et al. 2003). Mice lacking Vax1 died perinatally, although some survived after birth (Bertuzzi et al. 1999; Hallonet et al. 1999), exhibiting cleft palate and coloboma due to the failure of optic fissure closure. In addition, these animals were unable to develop the optic chiasm and presented with axon guidance defects in the form of retinal ganglion cells whose axons were unable to properly localize within the brain (Kim et al. 2014). Kim et al. (2014) suggested that, in addition to its function as a transcription factor, Vax1 may also work as a secreted protein to promote the growth of retinal ganglion cells towards the brain. To date, only one patient has been reported whose A/M phenotype is due to an alteration of VAX1 (Slavotinek et al. 2012). The patient, identified during the screening of 70 cases with an $A / M$ phenotype, had bilateral severe microphthalmia and optic nerve hypoplasia, global developmental delay, hippocampal anomalies, agenesis of the pineal gland and corpus callosum, growth retardation and bilateral cleft lip and palate. This individual carried two adjacent homozygous substitutions (c.453G>A and c.454C>A, NM_001112704.1) resulting in a missense change located in the VAX1 homeodomain (p.[Arg152Ser]). Both parents were unaffected carriers of the variant.

\section{Colobomatous microphthalmia}

Simple microphthalmia refers to an anatomically intact eye with a reduced axial length, without abnormalities of the anterior or posterior segments. However, this ocular growth restriction is frequently associated with optic fissure closure defects. The question of whether optic fissure closure defects are the consequence or the cause of abnormalities in ocular growth and differentiation/specification remains unknown, making the classification of microphthalmia and coloboma genes according to mechanism challenging. Therefore, the genes described in the following section are those that have been linked to ocular growth defects through identification of mutations in patients with simple microphthalmia and/or coloboma, although the distinction may be somewhat arbitrary. 


\section{TENM3 (teneurin transmembrane protein 3)}

TENM3 is a member of the Tenm/Odz (teneurin) family, which comprises four type II transmembrane molecules. These proteins consist of at least five functional units: a N-terminal cytoplasmic region, a transmembrane domain, a linker region, a dimerization (EGF) unit and a large globular C-terminal domain (Feng et al. 2002). In addition to their transmembrane role, it has been shown that the intracellular domains of at least two teneurins can undergo proteolytic cleavage and translocate to the nucleus where they regulate transcriptional activity (Young and Leamey 2009). Genetic studies of fly Tenm/Odz demonstrate a crucial role of teneurin during segmentation. Furthermore, both in vitro and in vivo studies suggest that teneurins are able to promote neurite outgrowth and cell adhesion (Young and Leamey 2009). Moreover, multiple lines of evidence support the involvement of TENM3 in vertebrate eye development. It is expressed multiple regions of the developing eye, including the optic stalk (Ben-Zur et al. 2000). Knockout mouse models have significantly impaired binocular vision as a result of abnormalities in the mapping of ipsilateral projections in the optic pathway (Leamey et al. 2007). Moreover, zebrafish tenm3 knockdown models have phenotypes including errors of both stratification and targeting of dendrites and axons within a subset of retinal ganglion cells (RGCs). This indicates that the gene plays a role in wiring subsets of functionally defined visual circuits (Antinucci et al. 2013). However, it is important to note that none of these animal models presented with overt ocular malformations.

By combining linkage and WES analysis, a homozygous mutation (c.2083dup p.[Thr695Asnfs] NM_001080477) in TENM3 (historically ODZ3) was identified in two children with isolated colobomatous microphthalmia from a consanguineous family (Aldahmesh et al. 2012). More recently, we and others (Chassaing et al. 2016b; Patel et al. 2018) confirmed the involvement of this gene in autosomal recessive colobomatous microphthalmia by describing consanguineous families in whom genetic studies identified TENM3 homozygous mutations, including a splicing variant (c.2968-2A>T, NM_001080477) and the frameshift variant reported by Aldahmesh et al. (2012).

\section{C12orf57 (chromosome 12 open reading frame 57)}

Although the structure and function of its product are not known, biallelic variants in C12orf57 have been identified in familial and sporadic cases of microphthalmia with bilateral iris and/or chorioretinal coloboma (Patel et al. 2018; Platzer et al. 2014; Zahrani et al. 2013), unilateral iris or chorioretinal coloboma and posterior staphyloma (Salih et al. 2013), and microcornea with corneal opacity and dense cataract (Salih et al. 2013). Additional neurologic features have been observed, such as global developmental delay and epilepsy, corpus callosum anomalies and behavioral difficulties, consistent with Temtamy syndrome (MIM\#218340). Temtamy syndrome is a rare neurological disorder characterized by agenesis/hypoplasia of corpus callosum with developmental abnormalities that 
includes ocular, skeletal and craniofacial abnormalities (Temtamy et al. 1996). In a cohort of 27 consanguineous families with corpus callosum hypoplasia, C12orf57 screening revealed 10 patients from 4 families homozygous for the same variant (c.1A>G p.[Met1?], NM_138425) affecting the initiator methionine codon (Akizu et al. 2013). Haplotype analysis was consistent with a founder effect. Two out of the 10 patients had visual abnormalities (optic disc atrophy and colobomatous microphthalmia). A recent review of 56 cases with Temtamy syndrome carrying biallelic C12orf57 mutations (23 previously unpublished cases and 33 cases from the literature) has shown that microphthalmia was present in $16.4 \%$ of the cases and coloboma in $14.5 \%$ of the cases (Alrakaf et al. 2018).

\section{YAP1 (yes associated protein 1)}

YAP1 encodes a transcriptional coactivator that represents one of the major effectors of the Hippo pathway, and plays a role in development, growth, repair and homeostasis. It is also noteworthy that SOX2 is able to directly regulate YAP1 (Seo et al. 2013). YAP1 protein has an AKT phosphorylation/143-3-binding site, followed by a WW domain, a transcription activation domain and a C-terminal PDZbinding motif (Komuro et al. 2003).

In affected members of two unrelated families with optic fissure closure defects, Williamson et al. (Williamson et al. 2014) identified two heterozygous nonsense mutations in YAP1. The first mutation (c.370C>T p.[Arg124Ter], NM_001130145.2) was present in a family (4 individuals) with isolated bilateral ocular coloboma. The second variant (c.1066G>T p.[Glu356Ter], NM_001130145.2), was identified in a family previously reported by Ravine et al. (Ravine et al. 1997) with microphthalmia ranging from mild to severe bilateral, iris and/or chorioretinal coloboma and extraocular anomalies including hearing loss, intellectual disability, orofacial clefting and hematuria. The presence of an alternative transcription start site (TSS) in intron 1 of YAP1 may explain the more restricted phenotype in the first family. The p.(Glu356Ter) mutation in the family with the syndromic phenotype is present in the coding sequence of all transcripts from either the canonical or alternative TSS. In contrast, the p.(Arg124Ter) mutation in the family with isolated ocular coloboma is located in the $5^{\prime}$ UTR of the alternative transcript. Therefore, according to the authors, this phenotypic difference might be explained by a partial rescue of YAP1 haploinsufficiency by alternative transcripts, which they supported by demonstrating that both YAP1 TSSs were used in every developmental and adult tissue examined (human fetal brain and mouse embryonic brain, eye, kidney, whole embryo, and various adult tissues).

In addition, Holt et al. (Holt et al. 2017) screened YAP1 for variants in a cohort of 258 patients with $\mathrm{A} / \mathrm{M}$ and coloboma phenotypes and identified a frameshift mutation (c.1160delA p.[Asn387ThrfsTer16], NM_001130145.2) in a patient with bilateral microphthalmia with chorioretinal 
coloboma and Asperger's syndrome (Fig. 2). This variant is located in the coding region (exon 7) of all YAP1 transcripts and is predicted to result in the loss of the transactivation domain. However, sequencing of cDNA from the patient showed the variant does not result in nonsense mediated decay. This novel frameshift mutation was also inherited from an asymptomatic parent. Several hypotheses for the difference in phenotype between the patient and parent can be proposed, including incomplete penetrance, modifying mutations in the index case or parental mosaicism. Furthermore, Oatts et al. (Oatts et al. 2017) reported a novel heterozygous missense mutation (c.284T>C p.[Phe95Ser], NM_001130145.2) in a family with dominant isolated ocular coloboma and evidence of incomplete penetrance.

Further evidence supporting the role of YAP1 in human ocular defects is provided by zebrafish yap1 mutants, which exhibit coloboma and loss of retinal pigment epithelium in a fully penetrant fashion, but with varying extent and localization (Miesfeld et al. 2015).

\section{SALL2 (spalt like transcription factor 2)}

SALL2 is a member of the spalt-like family of zinc finger transcription factors. Humans have 4 spalt-like genes, each with one $\mathrm{N}$-terminal $\mathrm{C} 2 \mathrm{HC}$ Zinc finger and 3 or $4 \mathrm{C} 2 \mathrm{H} 2$ Zinc finger domains for interactions with DNA or proteins. SALL2 appears to be mammalian-specific. Kelberman et al. (Kelberman et al. 2014) identified a homozygous nonsense mutation in SALL2 in a consanguineous family with isolated iris and retinal coloboma. They subsequently generated Sall2-null mice and, although no overt phenotypic abnormalities were observed, histological analysis of the eyes revealed a colobomatous phenotype, but with no evidence of microphthalmia. Of note, Ullah et al. (Ullah et al. 2017) recently identified by WES two missense variants in SALL4, another member of the spalt-like genes family, inherited in trans in a patient with unilateral microphthalmia and coloboma, bilateral optic nerve hypoplasia, cardiac defects and growth delay. Haploinsufficiency of SALL4 as a result of truncating mutations is linked to acro-reno-ocular syndrome (Okihiro syndrome, Duane-radial ray syndrome) (MIM\#607323), the features of which include Duane syndrome, eye anomalies, as well as radial ray and renal anomalies (Kohlhase et al. 2005).

\section{ABCB6 (ATP binding cassette subfamily B member 6)}

$A B C B 6$ codes for a protein belonging to the $B$ subfamily of ATP-binding cassette ( $A B C$ ) transporters. Heterozygous variants in $A B C B 6$ were first identified in a Chinese three generation family with autosomal dominant isolated iris and chorioretinal coloboma, where a $A B C B 6$ missense variant (c.2431C>G p.[Leu811Val], NM_005689) was found to segregate with the phenotype (Wang et al. 2012). Following this, Wang et al. (Wang et al. 2012) also identified another heterozygous variant (c.169G>A p.[Ala57Thr], NM_005689) in three Indian sporadic cases of colobomatous microphthalmia 
with no parental data available. The same study showed that a morpholino knockdown of $a b c b 6$ in zebrafish resulted in coloboma and delayed development. These phenotypes could be rescued using wildtype $A B C B 6$ mRNA, but not by injection of human mRNA containing the mutations identified in their patients. Prokudin et al. (Prokudin et al. 2014) also later reported an ABCB6 heterozygous variant in a patient with bilateral iris and fundus coloboma inherited from the unaffected father. In addition, heterozygous $A B C B 6$ nonsynonymous variants have been identified in familial and sporadic cases with dyschromatosis universalis hereditaria (MIM\#615402) (Cui et al. 2013; Liu et al. 2014; Zhang et al. 2013). In humans, skin tissue and melanocytes express $A B C B 6$ (Zhang et al. 2013). Knockdown of the gene in zebrafish resulted in the reduction of the number of mature melanocytes, supporting its role in dyschromatosis universalis hereditaria. Liu et al. (Liu et al. 2014) apparently found ocular anomalies in some patients with this condition, although the clinical description ('abnormal pitting lack of iris' (sic)) is not clear, and no pictures are available. Therefore, these reports may highlight common mechanisms underlying both pigmentary dyschromatosis universalis hereditaria and ocular coloboma.

Finally, several individuals with the Langereis (-) blood group phenotype (MIM\#111600) were found to have biallelic truncating and missense mutations in $A B C B 6$. However, there were no reports of coloboma or eye defects in these individuals (Helias et al. 2012; Saison et al. 2013).

\section{Complex microphthalmia and aphakia}

Complex microphthalmia refers to an eye with a reduced axial length and abnormalities of the anterior and/or posterior segment of the eye. As with previous sections, the following describes the genes implicated in this phenotype through identification in cases with complex microphthalmia. This section includes genes responsible for aniridia, anterior segment dysgenesis and aphakia.

\section{PAX6 (paired box 6)}

PAX6 is one of the nine members of the paired box gene family, the primary function of which is to regulate transcription in order to promote correct brain and eye morphogenesis (Hever et al. 2006). It was the first gene to be associated with $\mathrm{A} / \mathrm{M}$ in a patient who had compound heterozygous mutations and severe eye and brain anomalies (Glaser et al. 1994). However, individuals with compound heterozygous mutations of PAX6 rarely survive due to the severity of their brain anomalies (Glaser et al. 1994; Schmidt-Sidor et al. 2009; Solomon et al. 2009) and those with heterozygous mutations only rarely display A/M (Chassaing et al. 2014; Dansault et al. 2007; Hever et al. 2006). In our cohort, we recently identified a de novo heterozygous PAX6 missense variant (c.160A>C p.[Ser54Arg], NM_000280) in a boy with clinical anophthalmia (unpublished data, Fig. 3a). The typical phenotype associated with heterozygous variants of this gene is aniridia (absence of the iris) with associated 
manifestations in other ocular structures, for example foveal hypoplasia, and corneal opacification (Hall et al. 2018). Atypical presentations include Peters' anomaly, corectopia, isolated foveal hypoplasia, optic nerve malformations (hypoplasia and coloboma), cataract and nystagmus (usually related to reduced visual function) (Hever et al. 2006; Tzoulaki et al. 2005). In total, more than 500 different mutations have been described $\left(\underline{(H G M D}^{\oplus}\right)$ including amino acid substitutions, premature termination codons or C-terminal extension, splicing alterations either in coding or non-coding exons (Hingorani et al. 2012; Plaisancie et al. 2018b). In addition to point mutations, chromosome 11p13 deletions have also been described in patients with aniridia. These can include the entirety of PAX6 and neighbouring genes or can just affect the downstream 3' regulatory region essential for PAX6 expression and act through a "position effect" (Ansari et al. 2016; Fantes et al. 1995). Deletions spanning PAX6 and WT1 are the cause of a contiguous gene syndrome that includes Wilms tumor, Aniridia, Genital abnormalities and mental Retardation (WAGR syndrome, OMIM \#194072).

Transmission of PAX6 mutations is autosomal dominant with strong penetrance, but variable expressivity. In about one third of the cases the mutations occur de novo (Vincent et al. 2003).

\section{FOXE3 (forkhead box E3)}

FOXE3 is a single-exon gene encoding a transcription factor of 319 amino acids with a DNA-binding domain, called forkhead domain, located from amino acid 71 to 165 (Ormestad et al. 2002). FOXE3 is specifically expressed during lens development in humans, mouse and zebrafish (Blixt et al. 2000; Iseri et al. 2009; Semina et al. 2001; Shi et al. 2006). It participates in lens vesicle formation and allows the maintenance of the lens cells in a proliferative state, thus preventing their early differentiation into lens fiber cells (Blixt et al. 2000; Landgren et al. 2008). FOXE3 is known to be one of the PAX6 master gene targets (Dimanlig et al. 2001) and recently, Khan et al. (Khan et al. 2016) demonstrated that its function is mediated via transcriptional regulation of DNAJB1, which is vital for development of the lens and the maintenance of its transparency. We and others have shown that truncating and missense FOXE3 mutations are involved in a recessive phenotype of primary congenital aphakia, microphthalmia and sclerocornea (Ali et al. 2010; Anjum et al. 2010; Chassaing et al. 2014; Garcia-Montalvo et al. 2014; Iseri et al. 2009; Islam et al. 2015; Jimenez et al. 2011; Khan et al. 2016; Pantoja-Melendez et al. 2013; Plaisancie et al. 2018a; Reis et al. 2010; Saboo et al. 2017; Ullah et al. 2016; Valleix et al. 2006). Dominant forms of variable ocular anomalies, including anterior segment dysgenesis, blue dot lens opacities and microphthalmia, have been reported with heterozygous FOXE3 mutations (BremondGignac et al. 2010; Doucette et al. 2011; Iseri et al. 2009; Semina et al. 2001). In a recent review, we show correlations between mutation type, inheritance pattern and the severity of the phenotype (Plaisancie et al. 2018a). Complex microphthalmia and/or primary aphakia is present in all patients carrying biallelic FOXE3 mutations with at least one truncating mutation, except for one familial case 
of Peters' anomaly (Khan et al. 2016). Extraocular features, such as global developmental delay and various malformations (Arnold-Chiari malformation, ventricular septal defect, polycystic ovary syndrome, hypertrichosis) have been variably described in individuals with truncating mutations. Isolated severe ocular phenotypes (microphthalmia and/or primary aphakia) are also observed in around $75 \%$ patients with biallelic missense mutations. Dominant forms are associated with the presence of mutations leading to a C-terminal extension of the protein and are responsible for isolated anterior segment dysgenesis, sclerocornea and congenital cataract (Plaisancie et al. 2018a).

\section{PITX3 (paired like homeodomain 3)}

The pituitary homeobox (PITX) family of genes encodes transcription factors that contain two functional domains, the homeobox and the OAR (otp, aristaless, rax), that function in DNA-binding and potentially transactivation, respectively. Individuals with pathogenic heterozygous variants in PITX3 manifest isolated and syndromic congenital cataract, anterior segment disorders, such as Peters' anomaly, posterior embryotoxon and sclerocornea (Aldahmesh et al. 2011a; Berry et al. 2004; Bidinost et al. 2006; Burdon et al. 2006; Finzi et al. 2005; Liu et al. 2017a; Semina et al. 1998; Summers et al. 2008; Verdin et al. 2014). Of note, one patient has been reported with a heterozygous variant in PITX3 and complex microphthalmia associated with autism and teeth anomalies (Zazo Seco et al. 2018). Most reported mutations are frameshifts, except for one apparently recurrent missense mutation in exon 2 (c.38G>A p.[Ser13Asn], NM_005029.3) in a patient with congenital cataract (Semina et al. 1998) and in a dominant family with Peters' anomaly (Zazo Seco et al. 2018). Interestingly, all the frameshift variants reported to date are located in exon 4 (upstream from the OAR domain) and none so far within the homeodomain or the OAR domain-coding regions. Of note, homozygous frameshift mutations of PITX3 have been identified in four consanguineous individuals (Aldahmesh et al. 2011a; Bidinost et al. 2006; Zazo Seco et al. 2018). Three of them presented with a more severe ocular phenotype (complex microphthalmia) than the heterozygous family members (from no ocular phenotype to cataract) (Aldahmesh et al. 2011a; Bidinost et al. 2006). The two affected siblings with homozygous variants reported by Bidinost et al. (Bidinost et al. 2006) had additional neurological features characterized by intellectual deficiency, choreiform movements and increased muscle tone, and decreased deep tendon reflexes of the lower extremities.

\section{PTCH1 (patched, drosophila, homolog of, 1)}

PTCH1 is a transmembrane receptor for the secreted hedgehog ligands $(\mathrm{SHH}, \mathrm{IHH}, \mathrm{DHH})$, which functions as part of a dosage-sensitive pathway resulting in the activation of downstream target genes. Hedgehog signaling is important in embryonic development and tumorigenesis. Heterozygous 
mutations of this gene have been associated with basal cell nevus syndrome, also called Gorlin syndrome (MIM\#109400) and holoprosencephaly (Ming et al. 2002).

Eye anomalies have occasionally been reported in patients with Gorlin syndrome. However, attention was drawn to the occurrence of severe eye anomalies in one patient with unilateral microphthalmia with orbital cyst who developed a medulloblastoma and was subsequently diagnosed with a PTCH1 mutation (c.1402delG, NM_000264), confirming a diagnosis of Gorlin syndrome (Ragge et al. 2005c).

A recent study has shown that $P T C H 1$ seems also to be a more significant contributor to congenital ocular malformations, given the identification of likely pathogenic heterozygous PTCH1 variants in $10 \%$ of the cohort (Chassaing et al. 2016a). First, in a cohort of 22 patients with various ocular developmental anomalies, Chassaing et al. identified 4 unrelated patients with heterozygous variants predicted to be deleterious by in silico analysis: one patient (P5) with microphthalmia, cataract and sclerocornea had a frameshift deletion (c.4delG p.[Glu2AsnfsTer9], NM_001083603), one patient (P20) with bilateral Peters' anomaly had a missense mutation (c.3947A>G p.[Tyr1316Cys], NM_000264) and two patients (P8 and P15) with colobomatous microphthalmia, corpus callosum abnormality and atrial septal defects had missense mutations (c.3191C>T p.[Thr1064Met] and c.3241G>A p.[Val1081Met] respectively, NM_000264). With the exception of P5, for whom the authors were unable to perform segregation analysis, the mutations were inherited from asymptomatic parents, suggesting incomplete penetrance. Screening for mutations in PTCH1 in additional cohorts identified three further cases: i) a patient (P17) with Axenfeld-Rieger anomaly who had a heterozygous PTCH1 missense mutation (c.3889C>T p.[Arg1297Trp], NM_000264) inherited from an asymptomatic parent, ii) a patient (CC10) with bilateral Peters' anomaly and a variant (c.2695A>G p. [Ile899Val], NM_000264) also inherited from an asymptomatic parent and iii) a patient (CC44) with a familial form of dominant $\mathrm{A} / \mathrm{M}$ and anterior segment dysgenesis with a variant (c.2332A>C p.[Thr778Pro], NM_000264) for which segregation analysis has not been performed. Zebrafish models demonstrated that these missense mutations identified in humans had a deleterious effect and that in vivo suppression of ptch1 results in microphthalmia (Chassaing et al. 2016a).

Given the critical role of the SHH pathway in eye morphogenesis (Cavodeassi et al. 2018), PTCH1 involvement in ocular developmental defects would not be surprising. However, there have been no other reports of PTCH1 mutations in developmental eye anomalies. This may be due to the difficulty in interpreting the identified variants as pathogenic, since most were missense variants inherited from asymptomatic parents, requiring complex in vivo functional studies to validate their pathogenicity. 


\section{MAF (maf bZIP transcription factor $V$ )}

MAF encodes a basic-leucine zipper domain (bZip) transcription factor, which acts as a homo- or hetero-dimer. Depending on the binding site and binding partner, it can function as a transcriptional activator or repressor (Kataoka 2007). Heterozygous mutations have been reported in 80 individuals who exhibit cataract of various types, but can also present with other ocular defects such as iris coloboma, glaucoma, microcornea, Peters' anomaly and microphthalmia (Anand et al. 2018). Heterozygous mutations in MAF can also be associated with Ayme-Gripp syndrome (MIM\#601088), which presents with congenital cataract, craniofacial features, brachycephaly, deafness, intellectual disability and seizures (Niceta et al. 2015). With the exception of one translocation event (Jamieson et al. 2002), all reported MAF mutations are missense changes. A genotype-phenotype correlation appears to exist since a significant proportion of the mutations associated with eye defects are located within the basic-leucine zipper domain. In contrast, no mutations have been identified so far within the transactivation domain in humans, although such a mutation has been reported in the mouse model with congenital cataract (Perveen et al. 2007). In addition, several mutations within the Nterminal region upstream of the transactivation domain are associated with the Ayme-Gripp syndrome.

\section{PXDN (peroxidasin)}

PXDN is a peroxidase which is secreted into, and involved in the formation of, the extracellular matrix. In mice, peroxidasin protein ( $P x d n$ ) is localized in the corneal and lens epithelium (Khan et al. 2011). A WES study performed in a non-consanguineous family containing two siblings with anterior segment dysgenesis, sclerocornea, microphthalmia and neurodevelopmental delay identified compound heterozygous PXDN mutations in both sibs, with one variant inherited from each parent (Choi et al. 2015). They also reported two additional compound heterozygous PXDN mutations in a singleton male with bilateral microphthalmia, cataract and anterior segment dysgenesis, one inherited from each parent (Choi et al. 2015). Homozygous changes in PXDN have been identified in two families with nonsyndromic A/M by Patel et al. (2018). Biallelic mutations in PXDN have been shown to be responsible for congenital cataracts, microcornea, sclerocornea and developmental glaucoma in three families (Khan et al. 2011) and recently for developmental glaucoma in one family (Micheal et al. 2016). A mouse model with a homozygous truncating mutation in the peroxidase domain demonstrated severe anterior segment dysgenesis and microphthalmia, resembling the phenotypes of patients (Yan et al. 2014). 


\section{GJA8 (gap junction protein alpha 8)}

GJA8 encodes gap junction protein alpha 8, also known as connexin 50 (Cx50). Connexins are transmembrane proteins that oligomerise to form gap junction channels (GJCs), which mediate the passage of ions and small molecules between adjacent cells and therefore play an important role in intercellular communications. The first link between GJA8 and cataractogenesis emerged from linkage analysis of an 8-generation family diagnosed with zonular pulverulent cataract (Renwick and Lawler 1963; Shiels et al. 1998). Since then, GJA8 has been investigated mainly in individuals with congenital or early-onset cataracts. These studies have progressively expanded the spectrum of GJA8 variants associated with these developmental anomalies.

Although most individuals initially described with GJA8 variants had isolated cataract, a recent study (Ma et al. 2016) identified a de novo heterozygous missense mutation (c.151G>A p.[Asp51Asn], NM_005267.4) in a patient with a more severe phenotype, including microphthalmia and sclerocornea. To investigate further the role of GJA8 in A/M, Ceroni et al. (Ceroni et al. 2018) analyzed a large cohort of individuals presenting with a wide range of developmental eye anomalies, mainly $A / M$ and coloboma. This study identified 6 likely pathogenic sequence variants in 7 independent families, including the variant previously reported by Ma et al. (Ma et al. 2016). Interestingly, in all 6 families where segregation analysis could be performed, these variants co-segregated with both early onset cataracts and microphthalmia, supporting the hypothesis that the gene may be involved a broader range of human developmental eye anomalies. The missense variant p.(Gly94Arg) (c.280G>A, NM_005267.4) for which segregation analysis could not be performed was identified in a child with congenital aphakia, sclerocornea, microphthalmia and coloboma (Ceroni et al. 2018) (Fig. 3b,c). This, in combination with two recently reported de novo mutations involving the same amino acid (c.280G $>\mathrm{C}$ p.[Gly94Arg] and c.281G>A p.[Gly94Glu], NM_005267.4), in singleton cases with severe lens developmental abnormalities, sclerocornea and microcornea (Ma et al. 2018), supports a more fundamental role for GJA8 in human lens development. Moreover, these findings suggest that specific variants in GJA8 give rise to phenotypes overlapping with those caused by genetic variants of FOXE3 (Plaisancie et al. 2018a).

The involvement of GJA8 in lens and ocular growth is also supported by animal studies. Mice with Gja8 homozygous deletions or heterozygous missense mutations exhibit microphthalmia, smaller lenses, and cataract, indicating that this connexin is important not only for lens formation and the maintenance of its transparency, but also for the control of eye morphogenesis. Taken together, these studies underline the importance of screening GJA8 more widely and in particular in individuals diagnosed with cataracts and microphthalmia or with lens defects.

In humans, GJA8 mutations are predominantly heterozygous missense variants, with the exception being a few homozygous variants (mainly frameshift) reported in consanguineous families. Therefore, the mode of inheritance is typically autosomal dominant and this should be taken into account when providing genetic counselling. 


\section{SIX6 (sine oculis homeobox 6)}

SIX6 belongs to the sine oculis homeobox (SIX) protein family, a group of evolutionarily conserved transcription factors (Kumar 2009). In Drosophila this family includes three genes, two of which (sine oculis and optix) are required for the correct development of the visual system (Cheyette et al. 1994; Serikaku and O'Tousa 1994). SIX6 was mapped to chromosome $14 q 22.3 q 23$ by Gallardo et al. (Gallardo et al. 1999). Deletions in this region had been previously reported in three individuals with bilateral clinical anophthalmia and pituitary anomalies (Bennett et al. 1991; Elliott et al. 1993; Lemyre et al. 1998). Gallardo et al. (Gallardo et al. 1999) demonstrated that one of these deletions (Bennett et al. 1991) included SIX6 and suggested that the ocular and pituitary phenotype of this individual could be caused by SIX6 haploinsufficiency, implicating it as a candidate gene for anophthalmia (Gallardo et al. 1999). Since this original report, three additional studies have linked SIX6 variants with developmental eye disorders. In 2004, Gallardo et al. (Gallardo et al. 2004) performed mutational analysis of SIX6 in a cohort of 73 patients with $A / M$ and identified a variant of unknown significance (c.493A>G p.[Thr165Ala], NM_007374.2) in a patient with bilateral complex microphthalmia and her asymptomatic father. Using a WES and linkage analysis strategy, Aldahmesh et al. (Aldahmesh et al. 2013a) identified a homozygous SIX6 truncating mutation (c.532_536del, NM_007374.2) in two children with isolated complex microphthalmia from a consanguineous family. Most recently, Yariz et al. (Yariz et al. 2015) reported a consanguineous family with three children who had optic disc anomalies and macular atrophy without microphthalmia or cataracts, carrying a homozygous missense mutation (c.110T>C p.[Leu37Pro], NM_007374.2). However, in a study of 173 patients with microphthalmia, clinical anophthalmia and coloboma, Aijaz et al. (Aijaz et al. 2004) found no diseasecausing mutations in this gene.

\section{ATOH7 (atonal bHLH transcription factor 7)}

$A T O H 7$, the human homolog of the Drosophila gene atonal, is a single-exon gene coding for a member of the basic helix-loop-helix (bHLH) transcription factor family. The bHLH domain, which in the human protein (NP_660161.1) spans residues 41-96, consists of a basic motif (residues 41-52) necessary for DNA binding, and a HLH domain (residues 53-96) involved in the formation of homo- or hetero-dimers with other family members. In 2011, Ghiasvand et al. (Ghiasvand et al. 2011) identified a 6,523 bp deletion located $\sim 20 \mathrm{~kb}$ from $\mathrm{ATOH} 7$ and affecting cis-regulatory elements in a large consanguineous Kurdish pedigree with autosomal recessive non-syndromic congenital retinal non-attachment (NCRNA). Subsequently, homozygous mutations affecting ATOH7 have been identified in four additional families with NCRNA, one reported by Kondo et al. (Kondo et al. 2016) and three unrelated Pakistani families reported by Keser et al. (Keser et al. 2017), two of which carried the previously described 6,523 bp deletion. Using WES and subsequent candidate-gene screening, homozygous variants in $\mathrm{ATOH7}$ (c.146A>T p.[Glu49Val] and c.53delC p.[Pro18ArgfsTer69], NM_145178.3) have also 
been identified in two consanguineous families (Pakistani and Turkish, respectively) diagnosed with microphthalmia, microcornea, corneal opacity, nystagmus and vitreoretinal dysplasia (Khan et al. 2012). The family carrying the frameshift mutation also presented with congenital cataracts, retinal detachments, hypoplasia of the optic nerves, vitreous and retinal calcifications, and persistent fetal vasculature. A homozygous mutation (c.136A>C p.[Asn46His], NM_145178.3) associated with persistent fetal vasculature has also been identified in a consanguineous Pakistani family with three affected individuals (Prasov et al. 2012).

Overall, the phenotype of individuals carrying $A T O H 7$ mutations seems to be consistent with a role in retinal neurogenesis. Expression studies and animal models have shown that Atoh7 is important for retinal ganglion cell (RGC) formation (Brown et al. 2001; Wang et al. 2001) and retinal vascular development (Edwards et al. 2012). Mice lacking Atoh7 (formerly Math5) (Brown et al. 2001) develop normal sized eyes, but exhibit a dramatic reduction (>95\%) in the number of RGCs and no optic nerve or chiasm. However, this does not exclude that mutations of specific residues might result in other severe phenotypes, as shown by Khan et al. (Khan et al. 2012). Therefore, the potential involvement of $A T O H 7$ in microphthalmia warrants further investigation.

\section{RBP4 (retinol binding protein 4)}

Vitamin A (retinol) is a liposoluble substrate necessary for the synthesis of Retinoic Acid (RA), a signaling molecule with a pivotal role in eye morphogenesis. Retinol circulates in the blood bound to a carrier, called retinol binding protein 4 (RBP4), which together with thyroxine-binding transthyretin (TTR) mediates retinol transport from its main store site, the liver, to the peripheral target tissues (Cunningham and Duester 2015; Kawaguchi et al. 2007). In most animals, retinol cannot be synthesized de novo, but is assimilated with the diet; during gestation maternal retinol is the main retinoid source for embryos of placental species. Maternal RBP4 cannot cross the maternal-fetal interface, but retinol can diffuse across the yolk sac and placenta and bind to the zygotically synthesized RBP4 (Ward et al. 1997; Ward and Morriss-Kay 1997). Once retinol-RBP4 reaches the target tissues, RBP4 binds to the transmembrane receptor STRA6, which then mediates the cellular uptake of retinol (Cunningham and Duester 2015; Kawaguchi et al. 2007), as discussed previously.

Biallelic mutations in RBP4 were first identified in pedigrees with autosomal recessive retinal dystrophy and iris coloboma (Cukras et al. 2012; Seeliger et al. 1999). Later, in a 7-generation family with autosomal dominant $\mathrm{A} / \mathrm{M}$ and/or coloboma, after genome-wide multipoint linkage analysis Chou et al. (Chou et al. 2015) identified a candidate locus on chromosome 10q23. Given the importance of vitamin $A$ in eye development, they prioritized genes in the $10 q 23$ critical region with roles in vitamin A metabolism and found a missense mutation (c.223G>A p.[Ala75Thr], NM_006744) in RBP4 in affected individuals and obligate carriers. Screening of 75 additional $A / M / c o l o b o m a$ cases revealed another heterozygous missense mutation (c.217G>A p.[Ala73Thr], NM_006744) in two unrelated 
patients (Chou et al. 2015). Functional analysis demonstrated that both these mutant retinol-binding proteins bind the STRA6 receptor with much higher affinity than the wild-type, yet carry little or no vitamin A. Consistent with these findings, all the p.(Ala73Thr) heterozygous carriers who were tested had fasting serum vitamin A levels below normal limits and plasma retinol fluorescence was also reduced. These mutations were hypothesized to have a dominant-negative effect and to compete with the wild-type copies of the protein. Maternal penetrance was significantly greater than paternal penetrance. Chou et al. (Chou et al. 2015) therefore suggested that when the RBP4 mutation is maternally transmitted, there is decreased vitamin A delivery both at the placenta, involving maternalderived RBP4, and later at the developing eye primordia, involving fetal-derived RBP4.

Recently, the role of RBP4 in $\mathrm{A} / \mathrm{M}$ was further supported by the identification of a heterozygous missense mutation (c.394T>A p.[Tyr132Asn], NM_006744) in a proband with an isolated bilateral complex microphthalmia phenotype (Riera et al. 2017). Moreover, a WES study has identified a homozygous mutation predicted to affect RBP4 splicing (c.248+1G>A, NM_006744) in a patient with unilateral microphthalmia, retinal dystrophy and bilateral iris and retinal coloboma (Khan et al. 2017).

\section{BMP4 (bone morphogenetic protein 4)}

Similar to $B M P 7, B M P 4$ encodes a member the TGF-beta superfamily of proteins. Members of this family act as ligands bind TGF-beta receptors causing the recruitment and activation of transcription factors resulting in gene regulation. Mutations affecting BMP4 are associated with ocular, digital and brain anomalies. However, large deletions spanning BMP4 necessitate careful delineation, since in some cases they can represent $14 q 22$ microdeletion syndrome, a contiguous gene deletion syndrome that can extend to include OTX2 (Bakrania et al. 2008). Since heterozygous OTX2 mutations can also be responsible for $A / M$, when both genes are involved in the deletion it is difficult to establish the contribution of each haploinsufficient gene to the phenotype. De novo deletions of BMP4 not including OTX2 have been reported in two patients. These individuals lacked a $A / M$ phenotype, instead presenting with either an isolated ocular phenotype of Rieger anomaly, microcornea, nystagmus and glaucoma (Reis et al. 2011b) or a phenotype that included sclerocornea, corneal opacity, glaucoma, brain anomalies and postaxial polysyndactyly (Hayashi et al. 2008).

Intragenic mutations in BMP4 have been described in five families with an A/M phenotype, usually complex associating with anterior and/or posterior segment anomalies (Bakrania et al. 2008; Reis et al. 2011b; Zhang et al. 2009). However, it is important to note how variable the phenotype remains even in the case of intragenic mutations. The truncating mutation (c.226_227del p.[Ser76CysfsTer29], NM_001202.5) was identified in a proband with unilateral anophthalmia and coloboma, retinal dystrophy and a small anterior segment in the contralateral eye, along with postaxial polydactyly, structural brain anomalies and learning difficulties (Bakrania et al. 2008). This variant was also 
observed in three additional family members affected with high myopia and/or polydactyly. A paternally inherited variant of unknown significance (c.278A>G p.[Glu93Gly], NM_001202.5) was identified in a proband with bilateral microphthalmia, broad hands with low-placed thumbs, brain anomalies and developmental delay, the father presenting only with mild inferior pigmentation of both retinas (Bakrania et al. 2008). However, for this proband a subsequent diagnosis of Kabuki syndrome was made as they also carried a pathogenic frameshift variant in KMT2D (Ragge, personal communication). A third missense variant (c.751C>T p.[His251Tyr], NM_001202.5), was detected in a proband with mild microphthalmia and anterior segment anomalies, as well as in his unaffected brother (Zhang et al. 2009). Reis et al. (Reis et al. 2011b) identified a nonsense mutation (c.592C>T p.[Arg198Ter], NM_001202.5) in a patient with anophthalmia, microphthalmia with sclerocornea, right-sided diaphragmatic hernia and hydrocephalus. Furthermore, they identified a frameshift mutation (c.171dupC p.[Glu58ArgfsTer17], NM_001202.5) in two half-siblings with anophthalmia/microphthalmia, discordant developmental delay, postaxial polydactyly and growth retardation, as well as in their unaffected mother. One of the affected siblings also carried an additional BMP4 missense variant (c.362A>G p.[His121Arg], NM_001202.5). Moreover, from mutational screening of genes associated with anterior segment dysgenesis, microcornea and microphthalmia performed on 257 patients with isolated primary glaucoma, two missense variants in BMP4 were identified (Huang et al. 2015). These were the previously reported variant (c.450C>G p.[Asn150Lys], NM_001202.5) (Weber et al. 2008), carried by a patient with primary angle-closure glaucoma (PACG), and the novel variant (c.502G>C p.[Gly168Arg], NM_001202.5), found in an individual with primary open-angle glaucoma (POAG).

\section{Posterior microphthalmia and nanophthalmia}

Nanophthalmia and posterior microphthalmia represent particular forms of microphthalmia characterized by extreme hyperopia. Nanophthalmia affects the whole globe and is associated with microcornea and susceptibility to angle closure glaucoma, whereas posterior microphthalmia only represents reduced growth of the posterior segment. A few genes have been found to be specifically involved in these subtypes of microphthalmia. 


\section{MFRP (membrane frizzled-related protein)}

This gene encodes a member of the frizzled-related protein family, containing a cysteine-rich domain (CRD) essential for Wnt binding and signaling (Katoh 2001). Mutations in this gene were first identified in the autosomal recessive retinal degeneration-6 (rd6) mouse model (Kameya et al. 2002; Sundin 2005). Mfrp was found to be primarily expressed in the eye (pigmentary retina and ciliary epithelium) and at lower levels in the brain (Kameya et al. 2002).

In humans, biallelic mutations in MFRP were first associated with nanophthalmia (Sundin et al. 2005). Later, additional phenotypes were also described, including posterior microphthalmia (Aldahmesh et al. 2011b; Matsushita et al. 2012; Nowilaty et al. 2013; Patel et al. 2018; Velez et al. 2017), sometimes with retinal dystrophy, foveoschisis and optic disc drusen (Ayala-Ramirez et al. 2006; Crespi et al. 2008; Mukhopadhyay et al. 2010; Wasmann et al. 2014; Zenteno et al. 2009). Isolated retinal dystrophy without the other MFRP-related ocular features has also been reported (Kannabiran et al. 2012). Interestingly, exon 5 appears to be a hotspot for MFRP mutations of various types (nonsense, frameshift and missense, as well as splice acceptor site variants). Recently, Collery et al. (Collery et al. 2016) showed that loss of $m f r p$ causes nanophthalmia and hyperopia in zebrafish models.

\section{PRSS56 (serine protease 56)}

This gene encodes a peptidase S1 domain containing protein with a trypsin-like serine protease activity. Biallelic mutations in PRSS56 (missense, nonsense and frameshift variants, as well as splice donor site variants) cause autosomal recessive posterior microphthalmia and nanophthalmia in humans (Gal et al. 2011; Nair et al. 2011; Nowilaty et al. 2013; Orr et al. 2011; Patel et al. 2018; Said et al. 2013) and posterior microphthalmia in mice (Nair et al. 2011).

\section{TMEM98 (transmembrane protein 98)}

TMEM98 was the first gene shown to cause autosomal dominant nanophthalmia (Awadalla et al. 2014). Linkage analysis of a large pedigree, followed by WES led to the identification of a missense variant (c.577G>C p.[Ala193Pro], NM_015544) in TMEM98 segregating with the affected status. This gene, which codes for a transmembrane protein, is expressed in various ocular tissues, including sclera, iris, ciliary body, choroid and retina (Awadalla et al. 2014).

Four additional heterozygous variants in TMEM98 were identified in a WES study of approximately 1200 samples from Chinese individuals with various forms of eye disorders (not specified) (Sun and Zhang 2015). None of these variants was detected in 288 unrelated healthy individuals (ethnicity not specified). Based on the gnomAD database, two of them (c.2T>C p. [Met1?] and c.149T>C p.[Ile50Thr], 
NM_015544) are novel, while the other two (c.56C>T p.[Ser19Leu] and c.398A>C p.[Lys133Thr], NM_015544) are rare, p.(Ser19Leu) being found only in European (MAF $=0.00008513$ ) and African $(\mathrm{MAF}=0.00004473)$ individuals, while $\mathrm{p} .($ Lys133Thr) is only present in East Asian individuals (MAF = $0.0002319)$. None of these patients had signs of nanophthalmia: the first 3 variants were identified in cases with high myopia, while the last was found in an individual with a cone-rod dystrophy. However, another study reported two additional heterozygous TMEM98 variants, a missense (c.587A>C p.[His196Pro], NM_15544) and a 34-bp deletion at the exon4/intron4 boundary (described as NM_015544:c.694_721del, reported as NM_015544.2:c.236_263+6del34 in ClinVar), in two unrelated pedigrees with nanophthalmia, supporting the role of TMEM98 in autosomal dominant nanophthalmia (Khorram et al. 2015).

\section{IV - MANAGEMENT}

As seen in the description of $A / M$, the distinction between isolated and syndromic forms is often imprecise. Systemic anomalies are present in 32-93\% of A/M cases (Chambers et al. 2018; Roos et al. 2016; Shah et al. 2011a; Slavotinek 2011; Spagnolo et al. 1994; Tucker et al. 1996), presumably depending on ascertainment, and predominantly affecting brain, heart, kidneys and extremities (hands and feet). The precise combination of ocular and extraocular features associated with $\mathrm{A} / \mathrm{M}$ can guide the search for genetic etiology, notwithstanding the overlap between the different syndromic forms. Given the high phenotypic variability between the different syndromes, even for variants in the same gene, it is difficult to define a priori a common management for all patients. Ophthalmological care aims to maximize the visual potential, prevent its deterioration and improve aesthetics through encouraging symmetrical socket growth and the use of prosthetics (Ragge et al. 2007). However, addressing systemic features and screening for potential complications, e.g. pituitary insufficiency, developmental delay, and kidney, heart or brain anomalies, is of paramount importance, meaning that multidisciplinary care is optimal (Ragge et al. 2007). Monitoring of growth, hearing, motor and cognitive development is essential in order to provide the best supportive care for the children, many of whom are severely visually impaired (Salt and Sargent 2014) and early intervention is critical to assist optimum development (Dale and Salt 2007). Furthermore, psychological support is essential to overcome the difficulties of life with a combination of visual, cognitive, motor and aesthetic issues. The initial assessment and an outline of ocular and extraocular management are defined for $\mathrm{A} / \mathrm{M}$ and close liaison between various specialists is essential (Ragge et al. 2007).

In the context of microphthalmia, visual function may be present, but there may be cataract, glaucoma or refractive errors that are amenable to treatment. In the case of unilateral involvement, the healthy eye must be protected (glasses are recommended, even in the absence of refractive error). Electrodiagnostic testing can detect optic nerve dysfunction, retinal dystrophy or cortical visual impairment. Visual acuity should be closely monitored in those at risk in order to detect any loss of 
vision, particularly in those at risk of a later onset retinal dystrophy (e.g. BMP4, VSX2). For severe anomalies associated with visual impairment, e.g. cataract, surgical treatment is offered. Chorioretinal coloboma can be associated with a small, but important risk of retinal detachment, which should be explained to the family, with a discussion of symptoms to look out for and an urgency to present to the specialist for assessment.

The size of the orbit is determined by the growth of the globe. Anophthalmia and severe microphthalmia are accompanied by a reduction in the size of the orbit, causing orbital asymmetry (Ragge et al. 2007). Occasionally, $A / M$ is accompanied by cyst formation, and this may compensate by encouraging orbital growth. Socket expanders (if the eye is absent or virtually absent), including either hydrophilic or solid expanders can be used from birth to encourage orbital growth, and widen the palpebral fissure, enlarge the bony orbit and stretch the conjunctival cul-de-sacs. If a formed eye is present, a clear prosthesis may be fitted in front of an existing microphthalmic eye to develop the bony socket, if asymmetry is to be avoided (Ragge et al. 2007). In this way the health of the underlying eye is still observable in the very young in case of inflammation, and any risk of further loss of vision by occlusional amblyopia is reduced. A cosmetic shell can be introduced when the risk of either of these scenarios is reduced. Expansion of the orbital volume in anophthalmic or severely microphthalmic sockets can be managed by the use of solid prostheses of increasing size throughout childhood. Generally, prostheses should be updated regularly (even every few weeks/months in the early years) until adolescence, depending on progress with socket expansion and symmetry with the contralateral side. However, they can sometimes be associated with complications, including instability, difficulty with insertion or removal, or inappropriate stimulation of growth. They are generally bespoke (molded to the shape of the socket) and hand-painted to ensure the best aesthetic result. Sometimes, an orbital implant is needed in order that a smaller prosthesis can be used; an increase in socket lining to deepen the inferior palpebral fissure (from buccal mucosa, for example) might also improve stability of the prosthesis. In adulthood, ocular prostheses are worn and do not need to be changed as frequently since orbital growth is complete.

\section{Genetic counseling}

Genetic heterogeneity and variable penetrance makes genetic diagnosis and counseling challenging in these conditions. It used to be estimated that the risk of recurrence of $A / M$ in the siblings of an affected child was 10-15\% (Verma and Fitzpatrick 2007) in the absence of a genetic diagnosis. From our experience, this overall risk is probably lower than 10\%; however this figure is incorrect in any individual case as it can range from zero to up to $50 \%$ depending on the situation. In the majority of cases where invasive prenatal diagnosis is not possible or desired, prenatal screening can be performed by detailed ultrasound scanning (although this forms an incomplete assessment) following by evaluation postnatally. The identification of a causal genetic anomaly (currently possible in 
approximately $25-60 \%$ of cases, depending on severity, bilaterality and systemic features) enables specific genetic counseling and the opportunity for pre-natal or even pre-implantation diagnosis. However, even in families where a genetic cause is identified, genetic counseling is highly complex due to the phenotypic variability observed for many of the $A / M$ genes (including within a family), the incomplete penetrance of mutations and the possibility of mosaicism. All these aspects and their implications in terms of genetic counseling should be discussed with the families by an ophthalmic geneticist experienced in managing these conditions.

\section{CONCLUSION}

This review reflects the wide clinical and genetic heterogeneity observed in patients with $A / M$, underlying the variable expressivity and incomplete penetrance that are commonly associated with these disorders. It also highlights the difficulty in establishing genotype-phenotype correlations in these conditions. The only clear conclusion, even if no statistics are yet definitive, is the more severe and bilateral the ocular lesions, the more likely it is that a causative mutation can be identified. Although hundreds of genes are implicated in eye development, we are currently able to explain the genetic bases of these defects in less than half of patients. This suggests a number of unknown genes, cellular and molecular mechanisms still remain to be elucidated in the $\mathrm{A} / \mathrm{M}$ spectrum and more widely in eye development disorders. WGS technologies will provide increased opportunities for variant identification in both coding and non-coding regions of known and new $\mathrm{A} / \mathrm{M}$ genes. However, along with this is the importance of multidisciplinary input from expert clinicians and scientists to interpret genetic variants in the light of the phenotype so that errors in interpretation of causality can be avoided. Nevertheless, beyond the genetic bases, parallel progress needs to be made in understanding the underlying cellular processes so as to distinguish between mechanisms that involve lack of development or regression. Indeed, in this review we have shown that some of the genes and mechanisms described provide clues indicating that many cases of microphthalmia are related to impairment of development of structures, such as lens or retina, or defects in optic fissure closure. Therefore, as in genetic sequences such as Pierre-Robin sequence, in which one morphogenetic cause triggers a cascade of effects, reduction in eye size may be more the consequence of a particular ocular structure development defect (lens, retina, optic fissure) than the direct result of an eye growth defect.

Informed consent: Informed consent was obtained from all relevant subjects included in this paper. Patients shown in this review article were recruited as part of a national 'Genetics of Eye and Brain anomalies' study, approved by the Cambridge East Ethics Committee (04/Q0104/129). Additional informed consent for all individuals for whom identifying information is included in this article. 


\section{REFERENCES}

Abouzeid H, Favez T, Schmid A, Agosti C, Youssef M, Marzouk I, El Shakankiry N, Bayoumi N, Munier FL, Schorderet DF (2014) Mutations in ALDH1A3 represent a frequent cause of microphthalmia/anophthalmia in consanguineous families. Hum Mutat 35: 949-53. doi: 10.1002/humu. 22580

Abouzeid H, Youssef MA, Bayoumi N, ElShakankiri N, Marzouk I, Hauser P, Schorderet DF (2012) RAX and anophthalmia in humans: evidence of brain anomalies. Mol Vis 18: 1449-56.

Aijaz S, Clark BJ, Williamson K, van Heyningen V, Morrison D, Fitzpatrick D, Collin R, Ragge N, Christoforou A, Brown A, Hanson I (2004) Absence of SIX6 mutations in microphthalmia, anophthalmia, and coloboma. Invest Ophthalmol Vis Sci 45: 3871-6. doi: 10.1167/iovs.04-0641

Akizu N, Shembesh NM, Ben-Omran T, Bastaki L, Al-Tawari A, Zaki MS, Koul R, Spencer E, Rosti RO, Scott E, Nickerson E, Gabriel S, da Gente G, Li J, Deardorff MA, Conlin LK, Horton MA, Zackai $\mathrm{EH}$, Sherr EH, Gleeson JG (2013) Whole-exome sequencing identifies mutated c12orf57 in recessive corpus callosum hypoplasia. Am J Hum Genet 92: 392-400.

Alabdullatif MA, Al Dhaibani MA, Khassawneh MY, El-Hattab AW (2017) Chromosomal microarray in a highly consanguineous population: diagnostic yield, utility of regions of homozygosity, and novel mutations. Clin Genet 91: 616-622. doi: 10.1111/cge.12872

Aldahmesh MA, Khan AO, Hijazi H, Alkuraya FS (2013a) Homozygous truncation of SIX6 causes complex microphthalmia in humans. Clin Genet 84:198-9.

Aldahmesh MA, Khan AO, Hijazi H, Alkuraya FS (2013b) Mutations in ALDH1A3 cause microphthalmia. Clin Genet 84: 128-31.

Aldahmesh MA, Khan AO, Mohamed J, Alkuraya FS (2011a) Novel recessive BFSP2 and PITX3 mutations: insights into mutational mechanisms from consanguineous populations. Genet Med 13: 978-81. doi: 10.1097/GIM.0b013e31822623d5

Aldahmesh MA, Mohammed JY, Al-Hazzaa S, Alkuraya FS (2012) Homozygous null mutation in ODZ3 causes microphthalmia in humans. Genet Med 14: 900-4. doi: 10.1038/gim.2012.71

Aldahmesh MA, Nowilaty SR, Alzahrani F, Al-Ebdi L, Mohamed JY, Rajab M, Khan AO, Alkuraya FS (2011b) Posterior microphthalmos as a genetically heterogeneous condition that can be allelic to nanophthalmos. Arch Ophthalmol 129: 805-7. doi: 10.1001/archophthalmol.2011.129

Ali M, Buentello-Volante B, McKibbin M, Rocha-Medina JA, Fernandez-Fuentes N, Koga-Nakamura W, Ashiq A, Khan K, Booth AP, Williams G, Raashid Y, Jafri H, Rice A, Inglehearn CF, Zenteno JC (2010) Homozygous FOXE3 mutations cause non-syndromic, bilateral, total sclerocornea, aphakia, microphthalmia and optic disc coloboma. Mol Vis 16: 1162-8.

Alrakaf L, Al-Owain MA, Busehail M, Alotaibi MA, Monies D, Aldhalaan HM, Alhashem A, Al-Hassnan ZN, Rahbeeni ZA, Murshedi FA, Ani NA, Al-Maawali A, Ibrahim NA, Abdulwahab FM, Alsagob M, Hashem MO, Ramadan W, Abouelhoda M, Meyer BF, Kaya N, Maddirevula S, Alkuraya FS (2018) Further delineation of Temtamy syndrome of corpus callosum and ocular abnormalities. Am J Med Genet A 176:715-721. doi: 10.1002/ajmg.a.38615.

Ammar THA, Ismail S, Mansour OAA, El-Shafey MM, Doghish AS, Kamal AM, Abdel-Salam GMH (2017) Genetic analysis of SOX2 and VSX2 genes in 27 Egyptian families with anophthalmia and microphthalmia. Ophthalmic Genet 38: 498-500. doi: 10.1080/13816810.2017.1279184

Anand D, Agrawal SA, Slavotinek A, Lachke SA (2018) Mutation update of transcription factor genes FOXE3, HSF4, MAF, and PITX3 causing cataracts and other developmental ocular defects. Hum Mutat 39: 471-494. doi: 10.1002/humu.23395

Anjum I, Eiberg H, Baig SM, Tommerup N, Hansen L (2010) A mutation in the FOXE3 gene causes congenital primary aphakia in an autosomal recessive consanguineous Pakistani family. Mol Vis 16: $549-55$. 
Ansari M, Rainger J, Hanson IM, Williamson KA, Sharkey F, Harewood L, Sandilands A, Clayton-Smith J, Dollfus H, Bitoun P, Meire F, Fantes J, Franco B, Lorenz B, Taylor DS, Stewart F, Willoughby CE, McEntagart M, Khaw PT, Clericuzio C, Van Maldergem L, Williams D, Newbury-Ecob R, Traboulsi El, Silva ED, Madlom MM, Goudie DR, Fleck BW, Wieczorek D, Kohlhase J, McTrusty AD, Gardiner C, Yale C, Moore AT, Russell-Eggitt I, Islam L, Lees M, Beales PL, Tuft SJ, Solano JB, Splitt M, Hertz JM, Prescott TE, Shears DJ, Nischal KK, Doco-Fenzy M, Prieur F, Temple IK, Lachlan KL, Damante G, Morrison DA, van Heyningen V, FitzPatrick DR (2016) Genetic Analysis of 'PAX6-Negative' Individuals with Aniridia or Gillespie Syndrome. PLoS One 11: e0153757. doi: 10.1371/journal.pone.0153757

Antinucci P, Nikolaou N, Meyer MP, Hindges R (2013) Teneurin-3 specifies morphological and functional connectivity of retinal ganglion cells in the vertebrate visual system. Cell Rep 5: 58292. doi: 10.1016/j.celrep.2013.09.045

Asai-Coakwell M, French CR, Berry KM, Ye M, Koss R, Somerville M, Mueller R, van Heyningen V, Waskiewicz AJ, Lehmann OJ (2007) GDF6, a novel locus for a spectrum of ocular developmental anomalies. Am J Hum Genet 80: 306-15.

Asai-Coakwell M, French CR, Ye M, Garcha K, Bigot K, Perera AG, Staehling-Hampton K, Mema SC, Chanda B, Mushegian A, Bamforth S, Doschak MR, Li G, Dobbs MB, Giampietro PF, Brooks BP, Vijayalakshmi P, Sauve Y, Abitbol M, Sundaresan P, van Heyningen V, Pourquie O, Underhill TM, Waskiewicz AJ, Lehmann OJ (2009) Incomplete penetrance and phenotypic variability characterize Gdf6-attributable oculo-skeletal phenotypes. Hum Mol Genet 18: 1110-21.

Awadalla MS, Burdon KP, Souzeau E, Landers J, Hewitt AW, Sharma S, Craig JE (2014) Mutation in TMEM98 in a large white kindred with autosomal dominant nanophthalmos linked to 17p12q12. JAMA Ophthalmol 132: 970-7. doi: 10.1001/jamaophthalmol.2014.946

Ayala-Ramirez R, Graue-Wiechers F, Robredo V, Amato-Almanza M, Horta-Diez I, Zenteno JC (2006) A new autosomal recessive syndrome consisting of posterior microphthalmos, retinitis pigmentosa, foveoschisis, and optic disc drusen is caused by a MFRP gene mutation. Mol Vis 12: $1483-9$.

Bailey TJ, El-Hodiri H, Zhang L, Shah R, Mathers PH, Jamrich M (2004) Regulation of vertebrate eye development by Rx genes. Int J Dev Biol 48: 761-70.

Bakrania P, Efthymiou M, Klein JC, Salt A, Bunyan DJ, Wyatt A, Ponting CP, Martin A, Williams S, Lindley V, Gilmore J, Restori M, Robson AG, Neveu MM, Holder GE, Collin JR, Robinson DO, Farndon P, Johansen-Berg H, Gerrelli D, Ragge NK (2008) Mutations in BMP4 cause eye, brain, and digit developmental anomalies: overlap between the BMP4 and hedgehog signaling pathways. Am J Hum Genet 82: 304-19.

Bakrania P, Robinson DO, Bunyan DJ, Salt A, Martin A, Crolla JA, Wyatt A, Fielder A, Ainsworth J, Moore A, Read S, Uddin J, Laws D, Pascuel-Salcedo D, Ayuso C, Allen L, Collin JR, Ragge NK (2007) SOX2 anophthalmia syndrome: 12 new cases demonstrating broader phenotype and high frequency of large gene deletions. Br J Ophthalmol 91: 1471-6.

Baldessari D, Badaloni A, Longhi R, Zappavigna V, Consalez GG (2004) MAB21L2, a vertebrate member of the Male-abnormal 21 family, modulates BMP signaling and interacts with SMAD1. BMC Cell Biol 5: 48. doi: 10.1186/1471-2121-5-48

Balikova I, de Ravel T, Ayuso C, Thienpont B, Casteels I, Villaverde C, Devriendt K, Fryns JP, Vermeesch JR (2011) High frequency of submicroscopic chromosomal deletions in patients with idiopathic congenital eye malformations. Am J Ophthalmol 151: 1087-1094 e45.

Bardakjian T, Krall M, Wu D, Lao R, Tang PL, Wan E, Kopinsky S, Schneider A, Kwok PY, Slavotinek A (2017) A recurrent, non-penetrant sequence variant, p.Arg266Cys in Growth/Differentiation Factor 3 (GDF3) in a female with unilateral anophthalmia and skeletal anomalies. Am J Ophthalmol Case Rep 7: 102-106. doi: 10.1016/j.ajoc.2017.06.006

Ben-Zur T, Feige E, Motro B, Wides R (2000) The mammalian Odz gene family: homologs of a Drosophila pair-rule gene with expression implying distinct yet overlapping developmental roles. Dev Biol 217: 107-20. doi: 10.1006/dbio.1999.9532

Bennett CP, Betts DR, Seller MJ (1991) Deletion 14q (q22q23) associated with anophthalmia, absent pituitary, and other abnormalities. J Med Genet 28: 280-1. 
Bermejo E, Martinez-Frias ML (1998) Congenital eye malformations: clinical-epidemiological analysis of 1,124,654 consecutive births in Spain. Am J Med Genet 75: 497-504.

Berry V, Yang Z, Addison PK, Francis PJ, lonides A, Karan G, Jiang L, Lin W, Hu J, Yang R, Moore A, Zhang $\mathrm{K}$, Bhattacharya SS (2004) Recurrent 17 bp duplication in PITX3 is primarily associated with posterior polar cataract (CPP4). J Med Genet 41: e109. doi:10.1136/jmg.2004.020289

Bertuzzi S, Hindges R, Mui SH, O'Leary DD, Lemke G (1999) The homeodomain protein vax1 is required for axon guidance and major tract formation in the developing forebrain. Genes Dev 13: 3092105.

Bhatia S, Bengani H, Fish M, Brown A, Divizia MT, de Marco R, Damante G, Grainger R, van Heyningen V, Kleinjan DA (2013) Disruption of autoregulatory feedback by a mutation in a remote, ultraconserved PAX6 enhancer causes aniridia. Am J Hum Genet 93: 1126-34. doi: 10.1016/j.ajhg.2013.10.028

Bidinost C, Matsumoto M, Chung D, Salem N, Zhang K, Stockton DW, Khoury A, Megarbane A, Bejjani BA, Traboulsi El (2006) Heterozygous and homozygous mutations in PITX3 in a large Lebanese family with posterior polar cataracts and neurodevelopmental abnormalities. Invest Ophthalmol Vis Sci 47: 1274-80. doi: 10.1167/iovs.05-1095

Blixt A, Mahlapuu M, Aitola M, Pelto-Huikko M, Enerback S, Carlsson P (2000) A forkhead gene, FoxE3, is essential for lens epithelial proliferation and closure of the lens vesicle. Genes Dev 14: 24554.

Bremond-Gignac D, Bitoun P, Reis LM, Copin H, Murray JC, Semina EV (2010) Identification of dominant FOXE3 and PAX6 mutations in patients with congenital cataract and aniridia. Mol Vis 16: 170511.

Brown NL, Patel S, Brzezinski J, Glaser T (2001) Math5 is required for retinal ganglion cell and optic nerve formation. Development 128: 2497-508.

Burdon KP, McKay JD, Wirth MG, Russell-Eggit IM, Bhatti S, Ruddle JB, Dimasi D, Mackey DA, Craig JE (2006) The PITX3 gene in posterior polar congenital cataract in Australia. Mol Vis 12: 367-71.

Burkitt Wright EM, Perveen R, Bowers N, Ramsden S, McCann E, O'Driscoll M, Lloyd IC, Clayton-Smith J, Black GC (2010) VSX2 in microphthalmia: a novel splice site mutation producing a severe microphthalmia phenotype. Br J Ophthalmol 94: 386-8.

Busby A, Dolk H, Collin R, Jones RB, Winter R (1998) Compiling a national register of babies born with anophthalmia/microphthalmia in England 1988-94. Arch Dis Child Fetal Neonatal Ed 79: F16873.

Casey J, Kawaguchi R, Morrissey M, Sun H, McGettigan P, Nielsen JE, Conroy J, Regan R, Kenny E, Cormican P, Morris DW, Tormey P, Chroinin MN, Kennedy BN, Lynch S, Green A, Ennis S (2011) First implication of STRA6 mutations in isolated anophthalmia, microphthalmia, and coloboma: a new dimension to the STRA6 phenotype. Hum Mutat 32: 1417-26. doi: 10.1002/humu.21590

Cavodeassi F, Creuzet S, Etchevers HC (2018) The hedgehog pathway and ocular developmental anomalies. Hum Genet. doi: 10.1007/s00439-018-1918-8

Ceroni F, Aguilera-Garcia D, Chassaing N, Bax DA, Blanco-Kelly F, Ramos P, Tarilonte M, Villaverde C, da Silva LRJ, Ballesta-Martinez MJ, Sanchez-Soler MJ, Holt RJ, Cooper-Charles L, Bruty J, Wallis Y, McMullan D, Hoffman J, Bunyan D, Stewart A, Stewart H, Lachlan K, Study DDD, Fryer A, McKay V, Roume J, Dureau P, Saggar A, Griffiths M, Calvas P, Ayuso C, Corton M, Ragge NK (2018) New GJA8 variants and phenotypes highlight its critical role in a broad spectrum of eye anomalies. Hum Genet. doi: 10.1007/s00439-018-1875-2

Chambers TM, Agopian AJ, Lewis RA, Langlois PH, Danysh HE, Weber KA, Shaw GM, Mitchell LE, Lupo PJ (2018) Epidemiology of anophthalmia and microphthalmia: Prevalence and patterns in Texas, 1999-2009. Am J Med Genet A. doi: 10.1002/ajmg.a.40352

Chassaing N, Causse A, Vigouroux A, Delahaye A, Alessandri JL, Boespflug-Tanguy O, Boute-Benejean O, Dollfus H, Duban-Bedu B, Gilbert-Dussardier B, Giuliano F, Gonzales M, Holder-Espinasse M, Isidor B, Jacquemont ML, Lacombe D, Martin-Coignard D, Mathieu-Dramard M, Odent S, Picone O, Pinson L, Quelin C, Sigaudy S, Toutain A, Thauvin-Robinet C, Kaplan J, Calvas P (2014) Molecular findings and clinical data in a cohort of 150 patients with anophthalmia/microphthalmia. Clin Genet. 
Chassaing N, Davis EE, McKnight KL, Niederriter AR, Causse A, David V, Desmaison A, Lamarre S, Vincent-Delorme C, Pasquier L, Coubes C, Lacombe D, Rossi M, Dufier JL, Dollfus H, Kaplan J, Katsanis N, Etchevers HC, Faguer S, Calvas P (2016a) Targeted resequencing identifies PTCH1 as a major contributor to ocular developmental anomalies and extends the SOX2 regulatory network. Genome Res 26: 474-85. doi: 10.1101/gr.196048.115

Chassaing N, Gilbert-Dussardier B, Nicot F, Fermeaux V, Encha-Razavi F, Fiorenza M, Toutain A, Calvas $P(2007)$ Germinal mosaicism and familial recurrence of a SOX2 mutation with highly variable phenotypic expression extending from AEG syndrome to absence of ocular involvement. Am J Med Genet A 143: 289-91.

Chassaing N, Golzio C, Odent S, Lequeux L, Vigouroux A, Martinovic-Bouriel J, Tiziano FD, Masini L, Piro F, Maragliano G, Delezoide AL, Attie-Bitach T, Manouvrier-Hanu S, Etchevers HC, Calvas P (2009) Phenotypic spectrum of STRA6 mutations: from Matthew-Wood syndrome to nonlethal anophthalmia. Hum Mutat 30: E673-81.

Chassaing N, Ragge N, Kariminejad A, Buffet A, Ghaderi-Sohi S, Martinovic J, Calvas P (2013) Mutation analysis of the STRA6 gene in isolated and non-isolated anophthalmia/microphthalmia. Clin Genet 83: 244-50.

Chassaing N, Ragge N, Plaisancie J, Patat O, Genevieve D, Rivier F, Malrieu-Eliaou C, Hamel C, Kaplan J, Calvas $P$ (2016b) Confirmation of TENM3 involvement in autosomal recessive colobomatous microphthalmia. Am J Med Genet A 170: 1895-8. doi: 10.1002/ajmg.a.37667

Chassaing N, Sorrentino S, Davis EE, Martin-Coignard D, lacovelli A, Paznekas W, Webb BD, FayePetersen O, Encha-Razavi F, Lequeux L, Vigouroux A, Yesilyurt A, Boyadjiev SA, Kayserili $H$, Loget $P$, Carles D, Sergi C, Puvabanditsin S, Chen CP, Etchevers HC, Katsanis N, Mercer CL, Calvas P, Jabs EW (2012) OTX2 mutations contribute to the otocephaly-dysgnathia complex. J Med Genet 49: 373-9.

Chatterjee S, Pal JK (2009) Role of 5'- and 3'-untranslated regions of mRNAs in human diseases. Biol Cell 101: 251-62. doi: 10.1042/BC20080104

Cheyette BN, Green PJ, Martin K, Garren H, Hartenstein V, Zipursky SL (1994) The Drosophila sine oculis locus encodes a homeodomain-containing protein required for the development of the entire visual system. Neuron 12: 977-96.

Chitayat D, Sroka H, Keating S, Colby RS, Ryan G, Toi A, Blaser S, Viero S, Devisme L, Boute-Benejean O, Manouvrier-Hanu S, Mortier G, Loeys B, Rauch A, Bitoun P (2007) The PDAC syndrome (pulmonary hypoplasia/agenesis, diaphragmatic hernia/eventration, anophthalmia/microphthalmia, and cardiac defect) (Spear syndrome, Matthew-Wood syndrome): report of eight cases including a living child and further evidence for autosomal recessive inheritance. Am J Med Genet A 143A: 1268-81. doi:10.1002/ajmg.a.31788

Choi A, Lao R, Ling-Fung Tang P, Wan E, Mayer W, Bardakjian T, Shaw GM, Kwok PY, Schneider A, Slavotinek A (2015) Novel mutations in PXDN cause microphthalmia and anterior segment dysgenesis. Eur J Hum Genet 23: 337-41. doi: 10.1038/ejhg.2014.119

Chou CM, Nelson C, Tarle SA, Pribila JT, Bardakjian T, Woods S, Schneider A, Glaser T (2015) Biochemical Basis for Dominant Inheritance, Variable Penetrance, and Maternal Effects in RBP4 Congenital Eye Disease. Cell 161: 634-646. doi: 10.1016/j.cell.2015.03.006

Chow KL, Hall DH, Emmons SW (1995) The mab-21 gene of Caenorhabditis elegans encodes a novel protein required for choice of alternate cell fates. Development 121: 3615-26.

Cipriani V, Silva RS, Arno G, Pontikos N, Kalhoro A, Valeina S, Inashkina I, Audere M, Rutka K, Puech B, Michaelides M, van Heyningen V, Lace B, Webster AR, Moore AT (2017) Duplication events downstream of IRX1 cause North Carolina macular dystrophy at the MCDR3 locus. Sci Rep. 7:7512. doi: 10.1038/s41598-017-06387-6.

Collery RF, Volberding PJ, Bostrom JR, Link BA, Besharse JC (2016) Loss of Zebrafish Mfrp Causes Nanophthalmia, Hyperopia, and Accumulation of Subretinal Macrophages. Invest Ophthalmol Vis Sci 57: 6805-6814. doi: 10.1167/iovs.16-19593

Conte I, Hadfield KD, Barbato S, Carrella S, Pizzo M, Bhat RS, Carissimo A, Karali M, Porter LF, Urquhart J, Hateley S, O'Sullivan J, Manson FD, Neuhauss SC, Banfi S, Black GC (2015) MiR-204 is responsible for inherited retinal dystrophy associated with ocular coloboma. Proc Natl Acad Sci U S A 112: E3236-45. doi: 10.1073/pnas.1401464112 
Crespi J, Buil JA, Bassaganyas F, Vela-Segarra JI, Diaz-Cascajosa J, Ayala-Ramirez R, Zenteno JC (2008) A novel mutation confirms MFRP as the gene causing the syndrome of nanophthalmos-renititis pigmentosa-foveoschisis-optic disk drusen. Am J Ophthalmol 146: 323-328. doi: 10.1016/j.ajo.2008.04.029

Cui YX, Xia XY, Zhou Y, Gao L, Shang XJ, Ni T, Wang WP, Fan XB, Yin HL, Jiang SJ, Yao B, Hu YA, Wang G, Li XJ (2013) Novel mutations of ABCB6 associated with autosomal dominant dyschromatosis universalis hereditaria. PLoS One 8: e79808. doi: 10.1371/journal.pone.0079808

Cukras C, Gaasterland T, Lee P, Gudiseva HV, Chavali VR, Pullakhandam R, Maranhao B, Edsall L, Soares S, Reddy GB, Sieving PA, Ayyagari R (2012) Exome analysis identified a novel mutation in the RBP4 gene in a consanguineous pedigree with retinal dystrophy and developmental abnormalities. PLoS One 7: e50205. doi: 10.1371/journal.pone.0050205

Cunningham TJ, Duester G (2015) Mechanisms of retinoic acid signalling and its roles in organ and limb development. Nat Rev Mol Cell Biol 16: 110-23. doi: 10.1038/nrm3932

Cvekl A, Wang WL (2009) Retinoic acid signaling in mammalian eye development. Exp Eye Res 89: 28091.

Dale N, Salt A (2007) Early support developmental journal for children with visual impairment: the case for a new developmental framework for early intervention. Child Care Health Dev 33: 684-90. doi: 10.1111/j.1365-2214.2007.00798.x

Dansault A, David G, Schwartz C, Jaliffa C, Vieira V, de la Houssaye G, Bigot K, Catin F, Tattu L, Chopin C, Halimi P, Roche O, Van Regemorter N, Munier F, Schorderet D, Dufier JL, Marsac C, Ricquier D, Menasche M, Penfornis A, Abitbol M (2007) Three new PAX6 mutations including one causing an unusual ophthalmic phenotype associated with neurodevelopmental abnormalities. Mol Vis 13: 511-23.

Davidson AE, Liskova P, Evans CJ, Dudakova L, Noskova L, Pontikos N, Hartmannova H, Hodanova K, Stranecky V, Kozmik Z, Levis HJ, Idigo N, Sasai N, Maher GJ, Bellingham J, Veli N, Ebenezer ND, Cheetham ME, Daniels JT, Thaung CM, Jirsova K, Plagnol V, Filipec M, Kmoch S, Tuft SJ, Hardcastle AJ (2016) Autosomal-Dominant Corneal Endothelial Dystrophies CHED1 and PPCD1 Are Allelic Disorders Caused by Non-coding Mutations in the Promoter of OVOL2. Am J Hum Genet 98: 75-89. doi: 10.1016/j.ajhg.2015.11.018

de Oliveira Mann CC, Kiefersauer R, Witte G, Hopfner KP (2016) Structural and biochemical characterization of the cell fate determining nucleotidyltransferase fold protein MAB21L1. Sci Rep 6: 27498. doi: 10.1038/srep27498

Dehghani M, Dehghan Tezerjani M, Metanat Z, Vahidi Mehrjardi MY (2017) A Novel Missense Mutation in the ALDH13 Gene Causes Anophthalmia in Two Unrelated Iranian Consanguineous Families. Int J Mol Cell Med 6: 131-134. doi: 10.22088/acadpub.BUMS.6.2.7

Delahaye A, Bitoun P, Drunat S, Gerard-Blanluet M, Chassaing N, Toutain A, Verloes A, Gatelais F, Legendre M, Faivre L, Passemard S, Aboura A, Kaltenbach S, Quentin S, Dupont C, Tabet AC, Amselem S, Elion J, Gressens P, Pipiras E, Benzacken B (2012) Genomic imbalances detected by array-CGH in patients with syndromal ocular developmental anomalies. Eur J Hum Genet 20: 527-33.

Deml B, Kariminejad A, Borujerdi RH, Muheisen S, Reis LM, Semina EV (2015) Mutations in MAB21L2 result in ocular Coloboma, microcornea and cataracts. PLoS Genet 11: e1005002. doi: 10.1371/journal.pgen.1005002

Deml B, Reis LM, Lemyre E, Clark RD, Kariminejad A, Semina EV (2016) Novel mutations in PAX6, OTX2 and NDP in anophthalmia, microphthalmia and coloboma. Eur J Hum Genet 24: 535-41. doi: 10.1038/ejhg.2015.155

den Hollander Al, Biyanwila J, Kovach P, Bardakjian T, Traboulsi El, Ragge NK, Schneider A, Malicki J (2010) Genetic defects of GDF6 in the zebrafish out of sight mutant and in human eye developmental anomalies. BMC Genet 11: 102. doi: 10.1186/1471-2156-11-102

Dennert N, Engels H, Cremer K, Becker J, Wohlleber E, Albrecht B, Ehret JK, Ludecke HJ, Suri M, Carignani G, Renieri A, Kukuk GM, Wieland T, Andrieux J, Strom TM, Wieczorek D, DieuxCoeslier A, Zink AM (2017) De novo microdeletions and point mutations affecting SOX2 in three individuals with intellectual disability but without major eye malformations. Am J Med Genet A 173: 435-443. doi: 10.1002/ajmg.a.38034 
Dimanlig PV, Faber SC, Auerbach W, Makarenkova HP, Lang RA (2001) The upstream ectoderm enhancer in Pax6 has an important role in lens induction. Development 128: 4415-24.

Dolk H, Busby A, Armstrong BG, Walls PH (1998) Geographical variation in anophthalmia and microphthalmia in England, 1988-94. Bmj 317: 905-9; discussion 910.

Doucette L, Green J, Fernandez B, Johnson GJ, Parfrey P, Young TL (2011) A novel, non-stop mutation in FOXE3 causes an autosomal dominant form of variable anterior segment dysgenesis including Peters anomaly. Eur J Hum Genet 19: 293-9.

Dudley AT, Lyons KM, Robertson EJ (1995) A requirement for bone morphogenetic protein-7 during development of the mammalian kidney and eye. Genes Dev 9: 2795-807.

Dudley AT, Robertson EJ (1997) Overlapping expression domains of bone morphogenetic protein family members potentially account for limited tissue defects in BMP7 deficient embryos. Dev Dyn 208: 349-62. doi: 10.1002/(SICI)1097-0177(199703)208:3<349::AID-AJA6>3.0.CO;2-I

Duszak RS (2009) Congenital rubella syndrome--major review. Optometry 80: 36-43. doi: 10.1016/j.optm.2008.03.006

Edwards MM, McLeod DS, Li R, Grebe R, Bhutto I, Mu X, Lutty GA (2012) The deletion of Math5 disrupts retinal blood vessel and glial development in mice. Exp Eye Res 96: 147-56. doi: 10.1016/j.exer.2011.12.005

Elliott J, Maltby EL, Reynolds B (1993) A case of deletion 14(q22.1-->q22.3) associated with anophthalmia and pituitary abnormalities. J Med Genet 30: 251-2.

Faivre L, Williamson KA, Faber V, Laurent N, Grimaldi M, Thauvin-Robinet C, Durand C, Mugneret F, Gouyon JB, Bron A, Huet F, Hayward C, Heyningen V, Fitzpatrick DR (2006) Recurrence of SOX2 anophthalmia syndrome with gonosomal mosaicism in a phenotypically normal mother. Am J Med Genet A 140: 636-9.

Fantes J, Ragge NK, Lynch SA, McGill NI, Collin JR, Howard-Peebles PN, Hayward C, Vivian AJ, Williamson K, van Heyningen V, FitzPatrick DR (2003) Mutations in SOX2 cause anophthalmia. Nat Genet 33: 461-3.

Fantes J, Redeker B, Breen M, Boyle S, Brown J, Fletcher J, Jones S, Bickmore W, Fukushima Y, Mannens $M$, et al. (1995) Aniridia-associated cytogenetic rearrangements suggest that a position effect may cause the mutant phenotype. Hum Mol Genet 4: 415-22.

Fares-Taie L, Gerber S, Chassaing N, Clayton-Smith J, Hanein S, Silva E, Serey M, Serre V, Gerard X, Baumann C, Plessis G, Demeer B, Bretillon L, Bole C, Nitschke P, Munnich A, Lyonnet S, Calvas P, Kaplan J, Ragge N, Rozet JM (2013) ALDH1A3 mutations cause recessive anophthalmia and microphthalmia. Am J Hum Genet 92: 265-70.

Feng K, Zhou XH, Oohashi T, Morgelin M, Lustig A, Hirakawa S, Ninomiya Y, Engel J, Rauch U, Fassler R (2002) All four members of the Ten-m/Odz family of transmembrane proteins form dimers. J Biol Chem 277: 26128-35. doi: 10.1074/jbc.M203722200

Ferda Percin E, Ploder LA, Yu JJ, Arici K, Horsford DJ, Rutherford A, Bapat B, Cox DW, Duncan AM, Kalnins VI, Kocak-Altintas A, Sowden JC, Traboulsi E, Sarfarazi M, McInnes RR (2000) Human microphthalmia associated with mutations in the retinal homeobox gene CHX10. Nat Genet 25: 397-401.

Finzi S, Li Y, Mitchell TN, Farr A, Maumenee IH, Sallum JM, Sundin O (2005) Posterior polar cataract: genetic analysis of a large family. Ophthalmic Genet 26: 125-30. doi: 10.1080/13816810500229124

Fitzpatrick DR, van Heyningen V (2005) Developmental eye disorders. Curr Opin Genet Dev 15: 348-53. Fuhrmann S (2010) Eye morphogenesis and patterning of the optic vesicle. Curr Top Dev Biol 93: 6184. doi: 10.1016/B978-0-12-385044-7.00003-5

Gal A, Rau I, El Matri L, Kreienkamp HJ, Fehr S, Baklouti K, Chouchane I, Li Y, Rehbein M, Fuchs J, Fledelius HC, Vilhelmsen K, Schorderet DF, Munier FL, Ostergaard E, Thompson DA, Rosenberg T (2011) Autosomal-recessive posterior microphthalmos is caused by mutations in PRSS56, a gene encoding a trypsin-like serine protease. Am J Hum Genet 88: 382-90. doi: 10.1016/j.ajhg.2011.02.006 
Gallardo ME, Lopez-Rios J, Fernaud-Espinosa I, Granadino B, Sanz R, Ramos C, Ayuso C, Seller MJ, Brunner HG, Bovolenta P, Rodriguez de Cordoba S (1999) Genomic cloning and characterization of the human homeobox gene SIX6 reveals a cluster of SIX genes in chromosome 14 and associates SIX6 hemizygosity with bilateral anophthalmia and pituitary anomalies. Genomics 61: 82-91. doi: 10.1006/geno.1999.5916

Gallardo ME, Rodriguez De Cordoba S, Schneider AS, Dwyer MA, Ayuso C, Bovolenta P (2004) Analysis of the developmental SIX6 homeobox gene in patients with anophthalmia/microphthalmia. Am J Med Genet A 129A: 92-4. doi: 10.1002/ajmg.a.30126

Garcia-Montalvo IA, Pelcastre-Luna E, Nelson-Mora J, Buentello-Volante B, Miranda-Duarte A, Zenteno JC (2014) Mutational screening of FOXE3, GDF3, ATOH7, and ALDH1A3 in congenital ocular malformations. Possible contribution of the FOXE3 p.VAL201MET variant to the risk of severe eye malformations. Ophthalmic Genet 35: 190-2. doi: 10.3109/13816810.2014.903983

Gerth-Kahlert C, Williamson K, Ansari M, Rainger JK, Hingst V, Zimmermann T, Tech S, Guthoff RF, van Heyningen V, FitzPatrick DR (2013) Clinical and mutation analysis of 51 probands with anophthalmia and/or severe microphthalmia from a single center. Molecular Genetics \& Genomic Medicine 1: 15-31.

Ghiasvand NM, Rudolph DD, Mashayekhi M, Brzezinski JAt, Goldman D, Glaser T (2011) Deletion of a remote enhancer near ATOH7 disrupts retinal neurogenesis, causing NCRNA disease. Nat Neurosci 14: 578-86. doi: 10.1038/nn.2798

Glaser T, Jepeal L, Edwards JG, Young SR, Favor J, Maas RL (1994) PAX6 gene dosage effect in a family with congenital cataracts, aniridia, anophthalmia and central nervous system defects. Nat Genet 7: 463-71.

Golzio C, Martinovic-Bouriel J, Thomas S, Mougou-Zrelli S, Grattagliano-Bessieres B, Bonniere M, Delahaye S, Munnich A, Encha-Razavi F, Lyonnet S, Vekemans M, Attie-Bitach T, Etchevers HC (2007) Matthew-Wood syndrome is caused by truncating mutations in the retinol-binding protein receptor gene STRA6. Am J Hum Genet 80: 1179-87.

Gonzalez-Rodriguez J, Pelcastre EL, Tovilla-Canales JL, Garcia-Ortiz JE, Amato-Almanza M, VillanuevaMendoza C, Espinosa-Mattar Z, Zenteno JC (2010) Mutational screening of CHX10, GDF6, OTX2, RAX and SOX2 genes in 50 unrelated microphthalmia-anophthalmia-coloboma (MAC) spectrum cases. Br J Ophthalmol 94: 1100-4.

Hall HN, Williamson KA, FitzPatrick DR (2018) The genetic architecture of aniridia and Gillespie syndrome. Hum Genet. doi: 10.1007/s00439-018-1934-8

Hallonet M, Hollemann T, Pieler T, Gruss P (1999) Vax1, a novel homeobox-containing gene, directs development of the basal forebrain and visual system. Genes Dev 13: 3106-14.

Hayashi S, Okamoto N, Makita Y, Hata A, Imoto I, Inazawa J (2008) Heterozygous deletion at 14q22.1q22.3 including the BMP4 gene in a patient with psychomotor retardation, congenital corneal opacity and feet polysyndactyly. Am J Med Genet A 146A: 2905-10.

Helias V, Saison C, Ballif BA, Peyrard T, Takahashi J, Takahashi H, Tanaka M, Deybach JC, Puy H, Le Gall M, Sureau C, Pham BN, Le Pennec PY, Tani Y, Cartron JP, Arnaud L (2012) ABCB6 is dispensable for erythropoiesis and specifies the new blood group system Langereis. Nat Genet 44: 170-3. doi: 10.1038/ng.1069

Henderson RH, Williamson KA, Kennedy JS, Webster AR, Holder GE, Robson AG, FitzPatrick DR, van Heyningen V, Moore AT (2009) A rare de novo nonsense mutation in OTX2 causes early onset retinal dystrophy and pituitary dysfunction. Mol Vis 15: 2442-7.

Herpin A, Lelong C, Favrel P (2004) Transforming growth factor-beta-related proteins: an ancestral and widespread superfamily of cytokines in metazoans. Dev Comp Immunol 28: 461-85. doi: 10.1016/j.dci.2003.09.007

Hever AM, Williamson KA, van Heyningen V (2006) Developmental malformations of the eye: the role of PAX6, SOX2 and OTX2. Clin Genet 69: 459-70.

Hingorani M, Hanson I, van Heyningen V (2012) Aniridia. Eur J Hum Genet 20: 1011-7. doi: 10.1038/ejhg.2012.100

Holt R, Ceroni F, Bax DA, Broadgate S, Diaz DG, Santos C, Gerrelli D, Ragge NK (2017) New variant and expression studies provide further insight into the genotype-phenotype correlation in YAP1related developmental eye disorders. Sci Rep 7: 7975. doi: 10.1038/s41598-017-08397-w 
Horn D, Prescott T, Houge G, Braekke K, Rosendahl K, Nishimura G, FitzPatrick DR, Spranger J (2015) A Novel Oculo-Skeletal syndrome with intellectual disability caused by a particular MAB21L2 mutation. Eur J Med Genet 58: 387-91. doi: 10.1016/j.ejmg.2015.06.003

Huang X, Xiao X, Jia X, Li S, Li M, Guo X, Liu X, Zhang Q (2015) Mutation analysis of the genes associated with anterior segment dysgenesis, microcornea and microphthalmia in 257 patients with glaucoma. Int J Mol Med 36: 1111-7. doi: 10.3892/ijmm.2015.2325

Huang XF, Huang ZQ, Lin D, Dai ML, Wang QF, Chen ZJ, Jin ZB, Wang Y (2017) Unraveling the genetic cause of a consanguineous family with unilateral coloboma and retinoschisis: expanding the phenotypic variability of RAX mutations. Sci Rep 7: 9064. doi: 10.1038/s41598-017-09276-0

Inoue M, Kamachi Y, Matsunami H, Imada K, Uchikawa M, Kondoh H (2007) PAX6 and SOX2-dependent regulation of the Sox 2 enhancer N-3 involved in embryonic visual system development. Genes Cells 12: 1049-61. doi: 10.1111/j.1365-2443.2007.01114.x

Iseri SU, Osborne RJ, Farrall M, Wyatt AW, Mirza G, Nurnberg G, Kluck C, Herbert H, Martin A, Hussain MS, Collin JR, Lathrop M, Nurnberg P, Ragoussis J, Ragge NK (2009) Seeing clearly: the dominant and recessive nature of FOXE3 in eye developmental anomalies. Hum Mutat 30: 1378-86.

Iseri SU, Wyatt AW, Nurnberg G, Kluck C, Nurnberg P, Holder GE, Blair E, Salt A, Ragge NK (2010) Use of genome-wide SNP homozygosity mapping in small pedigrees to identify new mutations in VSX2 causing recessive microphthalmia and a semidominant inner retinal dystrophy. Hum Genet 128: 51-60. doi: 10.1007/s00439-010-0823-6

Islam L, Kelberman D, Williamson L, Lewis N, Glindzicz MB, Nischal KK, Sowden JC (2015) Functional analysis of FOXE3 mutations causing dominant and recessive ocular anterior segment disease. Hum Mutat 36: 296-300. doi: 10.1002/humu.22741

Jamieson RV, Perveen R, Kerr B, Carette M, Yardley J, Heon E, Wirth MG, van Heyningen V, Donnai D, Munier F, Black GC (2002) Domain disruption and mutation of the bZIP transcription factor, MAF, associated with cataract, ocular anterior segment dysgenesis and coloboma. Hum Mol Genet 11: 33-42.

Jimenez NL, Flannick J, Yahyavi M, Li J, Bardakjian T, Tonkin L, Schneider A, Sherr EH, Slavotinek AM (2011) Targeted 'next-generation' sequencing in anophthalmia and microphthalmia patients confirms SOX2, OTX2 and FOXE3 mutations. BMC Med Genet 12: 172.

Kallen B, Robert E, Harris J (1996) The descriptive epidemiology of anophthalmia and microphthalmia. Int J Epidemiol 25: 1009-16.

Kallen B, Tornqvist K (2005) The epidemiology of anophthalmia and microphthalmia in Sweden. Eur J Epidemiol 20: 345-50.

Kameya S, Hawes NL, Chang B, Heckenlively JR, Naggert JK, Nishina PM (2002) Mfrp, a gene encoding a frizzled related protein, is mutated in the mouse retinal degeneration 6. Hum Mol Genet 11: 1879-86.

Kannabiran C, Singh H, Sahini N, Jalali S, Mohan G (2012) Mutations in TULP1, NR2E3, and MFRP genes in Indian families with autosomal recessive retinitis pigmentosa. Mol Vis 18:1165-74.

Kataoka K (2007) Multiple mechanisms and functions of maf transcription factors in the regulation of tissue-specific genes. J Biochem 141: 775-81. doi: 10.1093/jb/mvm105

Katoh M (2001) Molecular cloning and characterization of MFRP, a novel gene encoding a membranetype Frizzled-related protein. Biochem Biophys Res Commun 282: 116-23. doi: 10.1006/bbrc.2001.4551

Kava MP, Nagarajan L (2009) Microphthalmia and microcornea: in congenital cytomegalovirus. Indian J Ophthalmol 57: 323.

Kawaguchi R, Yu J, Honda J, Hu J, Whitelegge J, Ping P, Wiita P, Bok D, Sun H (2007) A membrane receptor for retinol binding protein mediates cellular uptake of vitamin A. Science 315: 820-5. doi: 10.1126/science.1136244

Kelberman D, Islam L, Lakowski J, Bacchelli C, Chanudet E, Lescai F, Patel A, Stupka E, Buck A, Wolf S, Beales PL, Jacques TS, Bitner-Glindzicz M, Liasis A, Lehmann OJ, Kohlhase J, Nischal KK, Sowden JC (2014) Mutation of SALL2 causes recessive ocular coloboma in humans and mice. Hum Mol Genet 23: 2511-26. doi: 10.1093/hmg/ddt643 
Kelberman D, Rizzoti K, Avilion A, Bitner-Glindzicz M, Cianfarani S, Collins J, Chong WK, Kirk JM, Achermann JC, Ross R, Carmignac D, Lovell-Badge R, Robinson IC, Dattani MT (2006) Mutations within Sox2/SOX2 are associated with abnormalities in the hypothalamo-pituitary-gonadal axis in mice and humans. J Clin Invest 116:2442-55.

Keser V, Khan A, Siddiqui S, Lopez I, Ren H, Qamar R, Nadaf J, Majewski J, Chen R, Koenekoop RK (2017) The Genetic Causes of Nonsyndromic Congenital Retinal Detachment: A Genetic and Phenotypic Study of Pakistani Families. Invest Ophthalmol Vis Sci 58: 1028-1036. doi: 10.1167/iovs.16-20281

Khan AO, Aldahmesh MA, Noor J, Salem A, Alkuraya FS (2013) Lens Subluxation and Retinal Dysfunction in a Girl with Homozygous VSX2 Mutation. Ophthalmic Genet.

Khan K, Logan CV, McKibbin M, Sheridan E, Elcioglu NH, Yenice O, Parry DA, Fernandez-Fuentes N, Abdelhamed ZI, Al-Maskari A, Poulter JA, Mohamed MD, Carr IM, Morgan JE, Jafri H, Raashid $Y$, Taylor GR, Johnson CA, Inglehearn CF, Toomes C, Ali M (2012) Next generation sequencing identifies mutations in Atonal homolog 7 (ATOH7) in families with global eye developmental defects. Hum Mol Genet 21: 776-83.

Khan K, Rudkin A, Parry DA, Burdon KP, McKibbin M, Logan CV, Abdelhamed ZI, Muecke JS, FernandezFuentes N, Laurie KJ, Shires M, Fogarty R, Carr IM, Poulter JA, Morgan JE, Mohamed MD, Jafri H, Raashid Y, Meng N, Piseth H, Toomes C, Casson RJ, Taylor GR, Hammerton M, Sheridan E, Johnson CA, Inglehearn CF, Craig JE, Ali M (2011) Homozygous mutations in PXDN cause congenital cataract, corneal opacity, and developmental glaucoma. Am J Hum Genet 89: 46473. doi: 10.1016/j.ajhg.2011.08.005

Khan KN, Carss K, Raymond FL, Islam F, Nihr BioResource-Rare Diseases C, Moore AT, Michaelides M, Arno G (2017) Vitamin A deficiency due to bi-allelic mutation of RBP4: There's more to it than meets the eye. Ophthalmic Genet 38: 465-466. doi: 10.1080/13816810.2016.1227453

Khan SY, Vasanth S, Kabir F, Gottsch JD, Khan AO, Chaerkady R, Lee MC, Leitch CC, Ma Z, Laux J, Villasmil R, Khan SN, Riazuddin S, Akram J, Cole RN, Talbot CC, Pourmand N, Zaghloul NA, Hejtmancik JF, Riazuddin SA (2016) FOXE3 contributes to Peters anomaly through transcriptional regulation of an autophagy-associated protein termed DNAJB1. Nat Commun 7: 10953. doi: 10.1038/ncomms10953

Khorram D, Choi M, Roos BR, Stone EM, Kopel T, Allen R, Alward WL, Scheetz TE, Fingert JH (2015) Novel TMEM98 mutations in pedigrees with autosomal dominant nanophthalmos. Mol Vis 21: 1017-23.

Kim N, Min KW, Kang KH, Lee EJ, Kim HT, Moon K, Choi J, Le D, Lee SH, Kim JW (2014) Regulation of retinal axon growth by secreted Vax1 homeodomain protein. Elife 3: e02671. doi: 10.7554/eLife.02671

Komuro A, Nagai M, Navin NE, Sudol M (2003) WW domain-containing protein YAP associates with ErbB-4 and acts as a co-transcriptional activator for the carboxyl-terminal fragment of ErbB-4 that translocates to the nucleus. J Biol Chem 278: 33334-41. doi: 10.1074/jbc.M305597200

Kondo H, Matsushita I, Tahira T, Uchio E, Kusaka S (2016) Mutations in ATOH7 gene in patients with nonsyndromic congenital retinal nonattachment and familial exudative vitreoretinopathy. Ophthalmic Genet 37: 462-464. doi: 10.3109/13816810.2015.1120316

Kudoh T, Dawid IB (2001) Zebrafish mab21/2 is specifically expressed in the presumptive eye and tectum from early somitogenesis onwards. Mech Dev 109: 95-8.

Kumar JP (2009) The sine oculis homeobox (SIX) family of transcription factors as regulators of development and disease. Cell Mol Life Sci 66: 565-83. doi: 10.1007/s00018-008-8335-4

Lammer EJ, Chen DT, Hoar RM, Agnish ND, Benke PJ, Braun JT, Curry CJ, Fernhoff PM, Grix AW, Jr., Lott IT, et al. (1985) Retinoic acid embryopathy. N Engl J Med 313: 837-41.

Landgren H, Blixt A, Carlsson P (2008) Persistent FoxE3 expression blocks cytoskeletal remodeling and organelle degradation during lens fiber differentiation. Invest Ophthalmol Vis Sci 49: 4269-77. doi: 10.1167/iovs.08-2243

Lau GT, Wong OG, Chan PM, Kok KH, Wong RL, Chin KT, Lin MC, Kung HF, Chow KL (2001) Embryonic XMab21/2 expression is required for gastrulation and subsequent neural development. Biochem Biophys Res Commun 280: 1378-84. doi: 10.1006/bbrc.2001.4290 
Leamey CA, Merlin S, Lattouf P, Sawatari A, Zhou X, Demel N, Glendining KA, Oohashi T, Sur M, Fassler $R$ (2007) Ten_m3 regulates eye-specific patterning in the mammalian visual pathway and is required for binocular vision. PLoS Biol 5: e241. doi:10.1371/journal.pbio.0050241

Lemyre E, Lemieux N, Decarie JC, Lambert M (1998) Del(14)(q22.1q23.2) in a patient with anophthalmia and pituitary hypoplasia. Am J Med Genet 77: 162-5.

Lequeux L, Rio M, Vigouroux A, Titeux M, Etchevers H, Malecaze F, Chassaing N, Calvas P (2008) Confirmation of RAX gene involvement in human anophthalmia. Clin Genet 74: 392-5.

Lin S, Harlalka GV, Hameed A, Reham HM, Yasin M, Muhammad N, Khan S, Baple EL, Crosby AH, Saleha $S$ (2018) Novel mutations in ALDH1A3 associated with autosomal recessive anophthalmia/microphthalmia, and review of the literature. BMC Med Genet 19: 160. doi: 10.1186/s12881-018-0678-6

Liu H, Li Y, Hung KK, Wang N, Wang C, Chen X, Sheng D, Fu X, See K, Foo JN, Low H, Liany H, Irwan ID, Liu J, Yang B, Chen M, Yu Y, Yu G, Niu G, You J, Zhou Y, Ma S, Wang T, Yan X, Goh BK, Common JE, Lane BE, Sun Y, Zhou G, Lu X, Wang Z, Tian H, Cao Y, Chen S, Liu Q, Liu J, Zhang F (2014) Genome-wide linkage, exome sequencing and functional analyses identify ABCB6 as the pathogenic gene of dyschromatosis universalis hereditaria. PLoS One 9: e87250. doi: 10.1371/journal.pone.0087250

Liu H, Liu H, Tang J, Lin Q, Sun Y, Wang C, Yang H, Khan MR, Peerbux MW, Ahmad S, Bukhari I, Zhu J (2017a) Whole Exome Sequencing Identifies a Novel Mutation in the PITX3 Gene, Causing Autosomal Dominant Congenital Cataracts in a Chinese Family. Ann Clin Lab Sci 47: 92-95.

Liu IS, Chen JD, Ploder L, Vidgen D, van der Kooy D, Kalnins VI, McInnes RR (1994) Developmental expression of a novel murine homeobox gene (Chx10): evidence for roles in determination of the neuroretina and inner nuclear layer. Neuron 13: 377-93.

Liu Y, Lu Y, Liu S, Liao S (2017b) Novel compound heterozygous mutations of ALDH1A3 contribute to anophthalmia in a non-consanguineous Chinese family. Genet Mol Biol 40: 430-435. doi: 10.1590/1678-4685-GMB-2016-0120

Llorente-Gonzalez S, Peralta-Calvo J, Abelairas-Gomez JM (2011) Congenital anophthalmia and microphthalmia: epidemiology and orbitofacial rehabilitation. Clin Ophthalmol 5: 1759-65. doi: 10.2147/OPTH.S27189

London NJ, Kessler P, Williams B, Pauer GJ, Hagstrom SA, Traboulsi El (2009) Sequence alterations in $\mathrm{RX}$ in patients with microphthalmia, anophthalmia, and coloboma. Mol Vis 15: 162-7.

Loosli F, Staub W, Finger-Baier KC, Ober EA, Verkade H, Wittbrodt J, Baier H (2003) Loss of eyes in zebrafish caused by mutation of chokh/rx3. EMBO Rep 4: 894-9.

Lowry RB, Kohut R, Sibbald B, Rouleau J (2005) Anophthalmia and microphthalmia in the Alberta Congenital Anomalies Surveillance System. Can J Ophthalmol 40: 38-44.

Luo G, Hofmann C, Bronckers AL, Sohocki M, Bradley A, Karsenty G (1995) BMP-7 is an inducer of nephrogenesis, and is also required for eye development and skeletal patterning. Genes Dev 9: 2808-20.

Ma AS, Grigg JR, Ho G, Prokudin I, Farnsworth E, Holman K, Cheng A, Billson FA, Martin F, Fraser C, Mowat D, Smith J, Christodoulou J, Flaherty M, Bennetts B, Jamieson RV (2016) Sporadic and Familial Congenital Cataracts: Mutational Spectrum and New Diagnoses Using NextGeneration Sequencing. Hum Mutat 37: 371-84. doi: 10.1002/humu.22948

Ma AS, Grigg JR, Prokudin I, Flaherty M, Bennetts B, Jamieson RV (2018) New mutations in GJA8 expand the phenotype to include total sclerocornea. Clin Genet93: 155-159. doi: 10.1111/cge.13045

Mann I (1953) The Developmental Basis of Eye Malformations. Philadelphia (PA): JB Lippincott.

Marcadier JL, Mears AJ, Woods EA, Fisher J, Airheart C, Qin W, Beaulieu CL, Dyment DA, Innes AM, Curry CJ, Care4Rare Canada C (2016) A novel mutation in two Hmong families broadens the range of STRA6-related malformations to include contractures and camptodactyly. Am J Med Genet A 170A: 11-8. doi: 10.1002/ajmg.a.37389

Mathers PH, Grinberg A, Mahon KA, Jamrich M (1997) The Rx homeobox gene is essential for vertebrate eye development. Nature 387: 603-7. 
Matias-Perez D, Garcia-Montano LA, Cruz-Aguilar M, Garcia-Montalvo IA, Nava-Valdez J, BarraganArevalo T, Villanueva-Mendoza C, Villarroel CE, Guadarrama-Vallejo C, la Cruz RV, ChaconCamacho O, Zenteno JC (2018) Identification of novel pathogenic variants and novel genephenotype correlations in Mexican subjects with microphthalmia and/or anophthalmia by next-generation sequencing. J Hum Genet 63: 1169-1180. doi: 10.1038/s10038-018-0504-1

Matsushita I, Kondo H, Tawara A (2012) Novel compound heterozygous mutations in the MFRP gene in a Japanese patient with posterior microphthalmos. Jpn J Ophthalmol 56: 396-400. doi: 10.1007/s10384-012-0145-4

Medina-Trillo C, Aroca-Aguilar JD, Mendez-Hernandez CD, Morales L, Garcia-Anton M, Garcia-Feijoo J, Escribano J (2016) Rare FOXC1 variants in congenital glaucoma: identification of translation regulatory sequences. Eur J Hum Genet 24: 672-80. doi: 10.1038/ejhg.2015.169

Micheal S, Siddiqui SN, Zafar SN, Iqbal A, Khan MI, den Hollander AI (2016) Identification of Novel Variants in LTBP2 and PXDN Using Whole-Exome Sequencing in Developmental and Congenital Glaucoma. PLoS One 11: e0159259. doi: 10.1371/journal.pone.0159259

Miesfeld JB, Gestri G, Clark BS, Flinn MA, Poole RJ, Bader JR, Besharse JC, Wilson SW, Link BA (2015) Yap and Taz regulate retinal pigment epithelial cell fate. Development 142: 3021-32. doi: 10.1242/dev.119008

Mihelec M, Abraham P, Gibson K, Krowka R, Susman R, Storen R, Chen Y, Donald J, Tam PP, Grigg JR, Flaherty M, Gole GA, Jamieson RV (2009) Novel SOX2 partner-factor domain mutation in a four-generation family. Eur J Hum Genet 17: 1417-22.

Ming JE, Kaupas ME, Roessler E, Brunner HG, Golabi M, Tekin M, Stratton RF, Sujansky E, Bale SJ, Muenke M (2002) Mutations in PATCHED-1, the receptor for SONIC HEDGEHOG, are associated with holoprosencephaly. Hum Genet 110: 297-301. doi: 10.1007/s00439-002-0695-5

Morrison D, FitzPatrick D, Hanson I, Williamson K, van Heyningen V, Fleck B, Jones I, Chalmers J, Campbell H (2002) National study of microphthalmia, anophthalmia, and coloboma (MAC) in Scotland: investigation of genetic aetiology. J Med Genet 39: 16-22.

Mory A, Ruiz FX, Dagan E, Yakovtseva EA, Kurolap A, Pares X, Farres J, Gershoni-Baruch R (2013) A missense mutation in ALDH1A3 causes isolated microphthalmia/anophthalmia in nine individuals from an inbred Muslim kindred. Eur J Hum Genet.

Mukhopadhyay R, Sergouniotis PI, Mackay DS, Day AC, Wright G, Devery S, Leroy BP, Robson AG, Holder GE, Li Z, Webster AR (2010) A detailed phenotypic assessment of individuals affected by MFRP-related oculopathy. Mol Vis 16: 540-8.

Nair KS, Hmani-Aifa M, Ali Z, Kearney AL, Ben Salem S, Macalinao DG, Cosma IM, Bouassida W, Hakim B, Benzina Z, Soto I, Soderkvist P, Howell GR, Smith RS, Ayadi H, John SW (2011) Alteration of the serine protease PRSS56 causes angle-closure glaucoma in mice and posterior microphthalmia in humans and mice. Nat Genet 43: 579-84. doi: 10.1038/ng.813

Ng WY, Pasutto F, Bardakjian TM, Wilson MJ, Watson G, Schneider A, Mackey DA, Grigg JR, Zenker M, Jamieson RV (2013) A puzzle over several decades: eye anomalies with FRAS1 and STRA6 mutations in the same family. Clin Genet 83: 162-8. doi: 10.1111/j.1399-0004.2012.01851.x

Niceta M, Stellacci E, Gripp KW, Zampino G, Kousi M, Anselmi M, Traversa A, Ciolfi A, Stabley D, Bruselles A, Caputo V, Cecchetti S, Prudente S, Fiorenza MT, Boitani C, Philip N, Niyazov D, Leoni C, Nakane T, Keppler-Noreuil K, Braddock SR, Gillessen-Kaesbach G, Palleschi A, Campeau PM, Lee BH, Pouponnot C, Stella L, Bocchinfuso G, Katsanis N, Sol-Church K, Tartaglia M (2015) Mutations Impairing GSK3-Mediated MAF Phosphorylation Cause Cataract, Deafness, Intellectual Disability, Seizures, and a Down Syndrome-like Facies. Am J Hum Genet 96: 816-25. doi: 10.1016/j.ajhg.2015.03.001

Nowilaty SR, Khan AO, Aldahmesh MA, Tabbara KF, Al-Amri A, Alkuraya FS (2013) Biometric and molecular characterization of clinically diagnosed posterior microphthalmos. Am J Ophthalmol 155: 361-372 e7. doi: 10.1016/j.ajo.2012.08.016

Oatts JT, Hull S, Michaelides M, Arno G, Webster AR, Moore AT (2017) Novel heterozygous mutation in YAP1 in a family with isolated ocular colobomas. Ophthalmic Genet 38: 281-283. doi: 10.1080/13816810.2016.1188122

Ormestad M, Blixt A, Churchill A, Martinsson T, Enerback S, Carlsson P (2002) Foxe3 haploinsufficiency in mice: a model for Peters' anomaly. Invest Ophthalmol Vis Sci 43:1350-7. 
Orr A, Dube MP, Zenteno JC, Jiang H, Asselin G, Evans SC, Caqueret A, Lakosha $H$, Letourneau L, Marcadier J, Matsuoka M, Macgillivray C, Nightingale M, Papillon-Cavanagh S, Perry S, Provost S, Ludman M, Guernsey DL, Samuels ME (2011) Mutations in a novel serine protease PRSS56 in families with nanophthalmos. Mol Vis 17: 1850-61.

Pantoja-Melendez C, Ali M, Zenteno JC (2013) An epidemiological investigation of a Forkhead box protein E3 founder mutation underlying the high frequency of sclerocornea, aphakia, and microphthalmia in a Mexican village. Mol Vis 19: 1866-70.

Pasutto F, Sticht H, Hammersen G, Gillessen-Kaesbach G, Fitzpatrick DR, Nurnberg G, Brasch F, Schirmer-Zimmermann H, Tolmie JL, Chitayat D, Houge G, Fernandez-Martinez L, Keating S, Mortier G, Hennekam RC, von der Wense A, Slavotinek A, Meinecke P, Bitoun P, Becker C, Nurnberg P, Reis A, Rauch A (2007) Mutations in STRA6 cause a broad spectrum of malformations including anophthalmia, congenital heart defects, diaphragmatic hernia, alveolar capillary dysplasia, lung hypoplasia, and mental retardation. Am J Hum Genet 80: 55060.

Patat O, van Ravenswaaij-Arts CMA, Tantau J, Corsten-Janssen N, van Tintelen JP, Dijkhuizen T, Kaplan J, Chassaing N (2013) Otocephaly-Dysgnathia Complex: description of four cases and confirmation of the role of OTX2. Molecular Syndromology 4: 302-5.

Patel N, Khan AO, Alsahli S, Abdel-Salam G, Nowilaty SR, Mansour AM, Nabil A, Al-Owain M, Sogati S, Salih MA, Kamal AM, Alsharif H, Alsaif HS, Alzahrani SS, Abdulwahab F, Ibrahim N, Hashem M, Faquih T, Shah ZA, Abouelhoda M, Monies D, Dasouki M, Shaheen R, Wakil SM, Aldahmesh MA, Alkuraya FS (2018) Genetic investigation of 93 families with microphthalmia or posterior microphthalmos. Clin Genet 93: 1210-1222. doi: 10.1111/cge.13239

Perveen R, Favor J, Jamieson RV, Ray DW, Black GC (2007) A heterozygous c-Maf transactivation domain mutation causes congenital cataract and enhances target gene activation. Hum Mol Genet 16: 1030-8. doi: 10.1093/hmg/ddm048

Plaisancie J, Bremond-Gignac D, Demeer B, Gaston V, Verloes A, Fares-Taie L, Gerber S, Rozet JM, Calvas P, Chassaing N (2016a) Incomplete penetrance of biallelic ALDH1A3 mutations. Eur J Med Genet 59: 215-8. doi: 10.1016/j.ejmg.2016.02.004

Plaisancie J, Calvas P, Chassaing N (2016b) Genetic Advances in Microphthalmia. J Pediatr Genet 5: 184-188. doi: 10.1055/s-0036-1592350

Plaisancie J, Ragge NK, Dollfus H, Kaplan J, Lehalle D, Francannet C, Morin G, Colineaux H, Calvas P, Chassaing N (2018a) FOXE3 mutations: genotype-phenotype correlations. Clin Genet 93: 837845. doi: $10.1111 /$ cge.13177

Plaisancie J, Tarilonte M, Ramos P, Jeanton-Scaramouche C, Gaston V, Dollfus H, Aguilera D, Kaplan J, Fares-Taie L, Blanco-Kelly F, Villaverde C, Francannet C, Goldenberg A, Arroyo I, Rozet JM, Ayuso C, Chassaing N, Calvas P, Corton M (2018b) Implication of non-coding PAX6 mutations in aniridia. Hum Genet 137: 831-846. doi: 10.1007/s00439-018-1940-x

Platzer K, Huning I, Obieglo C, Schwarzmayr T, Gabriel R, Strom TM, Gillessen-Kaesbach G, Kaiser FJ (2014) Exome sequencing identifies compound heterozygous mutations in C12orf57 in two siblings with severe intellectual disability, hypoplasia of the corpus callosum, chorioretinal coloboma, and intractable seizures. Am J Med Genet A 164A: 1976-80. doi: 10.1002/ajmg.a.36592

Prasov L, Masud T, Khaliq S, Mehdi SQ, Abid A, Oliver ER, Silva ED, Lewanda A, Brodsky MC, Borchert M, Kelberman D, Sowden JC, Dattani MT, Glaser T (2012) ATOH7 mutations cause autosomal recessive persistent hyperplasia of the primary vitreous. Hum Mol Genet 21: 3681-94.

Prokudin I, Simons C, Grigg JR, Storen R, Kumar V, Phua ZY, Smith J, Flaherty M, Davila S, Jamieson RV (2014) Exome sequencing in developmental eye disease leads to identification of causal variants in GJA8, CRYGC, PAX6 and CYP1B1. Eur J Hum Genet 22: 907-15. doi: 10.1038/ejhg.2013.268

Raca G, Jackson CA, Kucinskas L, Warman B, Shieh JT, Schneider A, Bardakjian TM, Schimmenti LA (2011) Array comparative genomic hybridization analysis in patients with anophthalmia, microphthalmia, and coloboma. Genet Med 13: 437-42. 
Ragge NK, Brown AG, Poloschek CM, Lorenz B, Henderson RA, Clarke MP, Russell-Eggitt I, Fielder A, Gerrelli D, Martinez-Barbera JP, Ruddle P, Hurst J, Collin JR, Salt A, Cooper ST, Thompson PJ, Sisodiya SM, Williamson KA, Fitzpatrick DR, van Heyningen V, Hanson IM (2005a) Heterozygous mutations of OTX2 cause severe ocular malformations. Am J Hum Genet 76: 1008-22.

Ragge NK, Lorenz B, Schneider A, Bushby K, de Sanctis L, de Sanctis U, Salt A, Collin JR, Vivian AJ, Free SL, Thompson P, Williamson KA, Sisodiya SM, van Heyningen V, Fitzpatrick DR (2005b) SOX2 anophthalmia syndrome. Am J Med Genet A 135: 1-7; discussion 8.

Ragge NK, Quaghebeur G, Stewart H (2013) SOX2 anophthalmia syndrome in adulthood - a neurodegenerative picture? Clin Genet 83: 482-4. doi: 10.1111/j.1399-0004.2012.01922.x

Ragge NK, Salt A, Collin JR, Michalski A, Farndon PA (2005c) Gorlin syndrome: the PTCH gene links ocular developmental defects and tumour formation. $\mathrm{Br} J$ Ophthalmol 89: 988-91. doi: 10.1136/bjo.2004.061390

Ragge NK, Subak-Sharpe ID, Collin JR (2007) A practical guide to the management of anophthalmia and microphthalmia. Eye (Lond) 21: 1290-300. doi: 10.1038/sj.eye.6702858

Rainger J, Pehlivan D, Johansson S, Bengani $H$, Sanchez-Pulido L, Williamson KA, Ture M, Barker $H$, Rosendahl K, Spranger J, Horn D, Meynert A, Floyd JA, Prescott T, Anderson CA, Rainger JK, Karaca E, Gonzaga-Jauregui C, Jhangiani S, Muzny DM, Seawright A, Soares DC, Kharbanda M, Murday V, Finch A, Uk10K, Baylor-Hopkins Center for Mendelian G, Gibbs RA, van Heyningen V, Taylor MS, Yakut T, Knappskog PM, Hurles ME, Ponting CP, Lupski JR, Houge G, FitzPatrick DR (2014) Monoallelic and biallelic mutations in MAB21L2 cause a spectrum of major eye malformations. Am J Hum Genet 94: 915-23. doi: 10.1016/j.ajhg.2014.05.005

Ravine D, Ragge NK, Stephens D, Oldridge M, Wilkie AO (1997) Dominant coloboma-microphthalmos syndrome associated with sensorineural hearing loss, hematuria, and cleft lip/palate. Am J Med Genet 72: 227-36.

Reis LM, Khan A, Kariminejad A, Ebadi F, Tyler RC, Semina EV (2011a) VSX2 mutations in autosomal recessive microphthalmia. Mol Vis 17: 2527-32.

Reis LM, Tyler RC, Schilter KF, Abdul-Rahman O, Innis JW, Kozel BA, Schneider AS, Bardakjian TM, Lose EJ, Martin DM, Broeckel U, Semina EV (2011b) BMP4 loss-of-function mutations in developmental eye disorders including SHORT syndrome. Hum Genet 130: 495-504.

Reis LM, Tyler RC, Schneider A, Bardakjian T, Stoler JM, Melancon SB, Semina EV (2010) FOXE3 plays a significant role in autosomal recessive microphthalmia. Am J Med Genet A 152A:582-90.

Renwick JH, Lawler SD (1963) Probable Linkage between a Congenital Cataract Locus and the Duffy Blood Group Locus. Ann Hum Genet 27: 67-84.

Richards S, Aziz N, Bale S, Bick D, Das S, Gastier-Foster J, Grody WW, Hegde M, Lyon E, Spector E, Voelkerding K, Rehm HL, Committee ALQA (2015) Standards and guidelines for the interpretation of sequence variants: a joint consensus recommendation of the American College of Medical Genetics and Genomics and the Association for Molecular Pathology. Genet Med 17: 405-24. doi: 10.1038/gim.2015.30

Riera M, Wert A, Nieto I, Pomares E (2017) Panel-based whole exome sequencing identifies novel mutations in microphthalmia and anophthalmia patients showing complex Mendelian inheritance patterns. Mol Genet Genomic Med 5: 709-719. doi: 10.1002/mgg3.329

Roos L, Fang M, Dali Cl, Jensen H, Christoffersen N, Wu B, Zhang J, Xu R, Harris P, Xu X, Gronskov K, Tumer $Z$ (2013) A homozygous mutation in a consanguineous family consolidates the role of ALDH1A3 in autosomal recessive microphthalmia. Clin Genet.

Roos L, Jensen H, Gronskov K, Holst R, Tumer Z (2016) Congenital Microphthalmia, Anophthalmia and Coloboma among Live Births in Denmark. Ophthalmic Epidemiol 23: 324-30. doi: 10.1080/09286586.2016.1213859

Saboo US, Penke D, Mahindrakar A, Uddaraju M, Sankurathri C, Gong X, Xing C, Mootha VV (2017) Exome sequencing reveals novel homozygous FOXE3 mutation in microphthalmos with staphylomatous malformation. Ophthalmic Genet 38: 295-297. doi: 10.1080/13816810.2016.1217549 
Said MB, Chouchene E, Salem SB, Daoud K, Largueche L, Bouassida W, Benzina Z, Ayadi H, Soderkvist P, Matri L, Hmani-Aifa M (2013) Posterior microphthalmia and nanophthalmia in Tunisia caused by a founder c.1059_1066insC mutation of the PRSS56 gene. Gene 528: 288-94. doi: 10.1016/j.gene.2013.06.045

Saison C, Helias V, Peyrard T, Merad L, Cartron JP, Arnaud L (2013) The ABCB6 mutation p.Arg192Trp is a recessive mutation causing the Lan- blood type. Vox Sang 104: 159-65. doi: 10.1111/j.14230410.2012.01650.x

Salih MA, Tzschach A, Oystreck DT, Hassan HH, AlDrees A, Elmalik SA, El Khashab HY, Wienker TF, AbuAmero KK, Bosley TM (2013) A newly recognized autosomal recessive syndrome affecting neurologic function and vision. Am J Med Genet A 161:1207-13.

Salt A, Sargent J (2014) Common visual problems in children with disability. Arch Dis Child 99: 1163-8. doi: 10.1136/archdischild-2013-305267

Schilter KF, Reis LM, Schneider A, Bardakjian TM, Abdul-Rahman O, Kozel BA, Zimmerman HH, Broeckel U, Semina EV (2013) Whole-genome copy number variation analysis in anophthalmia and microphthalmia. Clin Genet 84: 473-81. doi: 10.1111/cge.12202

Schilter KF, Schneider A, Bardakjian T, Soucy JF, Tyler RC, Reis LM, Semina EV (2011) OTX2 microphthalmia syndrome: four novel mutations and delineation of a phenotype. Clin Genet 79: $158-68$.

Schmidt-Sidor B, Szymanska K, Williamson K, van Heyningen V, Roszkowski T, Wierzba-Bobrowicz T, Zaremba J (2009) Malformations of the brain in two fetuses with a compound heterozygosity for two PAX6 mutations. Folia Neuropathol 47: 372-82.

Schneider A, Bardakjian T, Reis LM, Tyler RC, Semina EV (2009) Novel SOX2 mutations and genotypephenotype correlation in anophthalmia and microphthalmia. Am J Med Genet A 149A: 270615.

Seeliger MW, Biesalski HK, Wissinger B, Gollnick H, Gielen S, Frank J, Beck S, Zrenner E (1999) Phenotype in retinol deficiency due to a hereditary defect in retinol binding protein synthesis. Invest Ophthalmol Vis Sci 40: 3-11.

Seller MJ, Davis TB, Fear CN, Flinter FA, Ellis I, Gibson AG (1996) Two sibs with anophthalmia and pulmonary hypoplasia (the Matthew-Wood syndrome). Am J Med Genet 62: 227-29. doi: 10.1002/(SICI)1096-8628(19960329)62:3<227::AID-AJMG5>3.0.CO;2-Q

Semerci CN, Kalay E, Yildirim C, Dincer T, Olmez A, Toraman B, Kocyigit A, Bulgu Y, Okur V, SatirogluTufan L, Akarsu NA (2014) Novel splice-site and missense mutations in the ALDH1A3 gene underlying autosomal recessive anophthalmia/microphthalmia. Br J Ophthalmol 98: 832-40. doi: 10.1136/bjophthalmol-2013-304058

Semina EV, Brownell I, Mintz-Hittner HA, Murray JC, Jamrich M (2001) Mutations in the human forkhead transcription factor FOXE3 associated with anterior segment ocular dysgenesis and cataracts. Hum Mol Genet 10: 231-6.

Semina EV, Ferrell RE, Mintz-Hittner HA, Bitoun P, Alward WL, Reiter RS, Funkhauser C, Daack-Hirsch $S$, Murray JC (1998) A novel homeobox gene PITX3 is mutated in families with autosomaldominant cataracts and ASMD. Nat Genet 19: 167-70. doi: 10.1038/527

Seo E, Basu-Roy U, Gunaratne PH, Coarfa C, Lim DS, Basilico C, Mansukhani A (2013) SOX2 regulates YAP1 to maintain stemness and determine cell fate in the osteo-adipo lineage. Cell Rep 3: 2075-87. doi: 10.1016/j.celrep.2013.05.029

Serikaku MA, O'Tousa JE (1994) sine oculis is a homeobox gene required for Drosophila visual system development. Genetics 138: 1137-50.

Shah SP, Taylor AE, Sowden JC, Ragge N, Russell-Eggitt I, Rahi JS, Gilbert CE (2011a) Anophthalmos, microphthalmos, and Coloboma in the United kingdom: clinical features, results of investigations, and early management. Ophthalmology 119: 362-8.

Shah SP, Taylor AE, Sowden JC, Ragge NK, Russell-Eggitt I, Rahi JS, Gilbert CE, Surveillance of Eye Anomalies Special Interest G (2011b) Anophthalmos, microphthalmos, and typical coloboma in the United Kingdom: a prospective study of incidence and risk. Invest Ophthalmol Vis Sci 52: 558-64. doi: 10.1167/iovs.10-5263 
Shi X, Luo Y, Howley S, Dzialo A, Foley S, Hyde DR, Vihtelic TS (2006) Zebrafish foxe3: roles in ocular lens morphogenesis through interaction with pitx3. Mech Dev 123: 761-82. doi: 10.1016/j.mod.2006.07.004

Shiels A, Mackay D, lonides A, Berry V, Moore A, Bhattacharya S (1998) A missense mutation in the human connexin50 gene (GJA8) underlies autosomal dominant "zonular pulverulent" cataract, on chromosome 1q. Am J Hum Genet 62: 526-32. doi: 10.1086/301762

Shima H, Ishii A, Wada Y, Kizawa J, Yokoi T, Azuma N, Matsubara Y, Suzuki E, Nakamura A, Narumi S, Fukami M (2017) SOX2 nonsense mutation in a patient clinically diagnosed with non-syndromic hypogonadotropic hypogonadism. Endocr J 64: 813-817. doi: 10.1507/endocrj.EJ17-0078

Slavotinek A (2018) Genetics of anophthalmia and microphthalmia. Part 2: Syndromes associated with anophthalmia-microphthalmia. Hum Genet. doi: 10.1007/s00439-018-1949-1

Slavotinek AM (2011) Eye development genes and known syndromes. Mol Genet Metab 104: 448-56.

Slavotinek AM, Chao R, Vacik T, Yahyavi M, Abouzeid H, Bardakjian T, Schneider A, Shaw G, Sherr EH,

Lemke G, Youssef M, Schorderet DF (2012) VAX1 mutation associated with microphthalmia, corpus callosum agenesis, and orofacial clefting: the first description of a VAX1 phenotype in humans. Hum Mutat 33: 364-8.

Slavotinek AM, Garcia ST, Chandratillake G, Bardakjian T, Ullah E, Wu D, Umeda K, Lao R, Tang PL, Wan E, Madireddy L, Lyalina S, Mendelsohn BA, Dugan S, Tirch J, Tischler R, Harris J, Clark MJ, Chervitz S, Patwardhan A, West JM, Ursell P, de Alba Campomanes A, Schneider A, Kwok PY, Baranzini S, Chen RO (2015) Exome sequencing in 32 patients with anophthalmia/microphthalmia and developmental eye defects. Clin Genet 88: 468-73. doi: 10.1111/cge.12543

Small KW, DeLuca AP, Whitmore SS, Rosenberg T, Silva-Garcia R, Udar N, Puech B, Garcia CA, Rice TA, Fishman GA, Héon E, Folk JC, Streb LM, Haas CM, Wiley LA, Scheetz TE, Fingert JH, Mullins RF, Tucker BA, Stone EM (2016) North Carolina Macular Dystrophy is caused by dysregulation of the retinal transcription factor PRDM13. Ophthalmology 123:9-18. doi: 10.1016/j.ophtha.2015.10.006.

Solomon BD, Pineda-Alvarez DE, Balog JZ, Hadley D, Gropman AL, Nandagopal R, Han JC, Hahn JS, Blain D, Brooks B, Muenke M (2009) Compound heterozygosity for mutations in PAX6 in a patient with complex brain anomaly, neonatal diabetes mellitus, and microophthalmia. Am J Med Genet A 149A: 2543-6.

Somashekar PH, Shukla A, Girisha KM (2017) Intrafamilial variability in syndromic microphthalmia type 5 caused by a novel variation in OTX2. Ophthalmic Genet 38: 533-536. doi: 10.1080/13816810.2017.1301967

Spagnolo A, Bianchi F, Calabro A, Calzolari E, Clementi M, Mastroiacovo P, Meli P, Petrelli G, Tenconi R (1994) Anophthalmia and benomyl in Italy: a multicenter study based on 940,615 newborns. Reprod Toxicol 8: 397-403.

Srour M, Caron V, Pearson T, Nielsen SB, Levesque S, Delrue MA, Becker TA, Hamdan FF, Kibar Z, Sattler SG, Schneider MC, Bitoun P, Chassaing N, Rosenfeld JA, Xia F, Desai S, Roeder E, Kimonis V, Schneider A, Littlejohn RO, Douzgou S, Tremblay A, Michaud JL (2016) Gain-of-Function Mutations in RARB Cause Intellectual Disability with Progressive Motor Impairment. Hum Mutat 37: 786-93. doi: 10.1002/humu.23004

Srour M, Chitayat D, Caron V, Chassaing N, Bitoun P, Patry L, Cordier MP, Capo-Chichi JM, Francannet C, Calvas P, Ragge N, Dobrzeniecka S, Hamdan FF, Rouleau GA, Tremblay A, Michaud JL (2013) Recessive and dominant mutations in retinoic acid receptor beta in cases with microphthalmia and diaphragmatic hernia. Am J Hum Genet 93: 765-72. doi: 10.1016/j.ajhg.2013.08.014

Stenson PD, Mort M, Ball EV, Evans K, Hayden M, Heywood S, Hussain M, Phillips AD, Cooper DN (2017) The Human Gene Mutation Database: towards a comprehensive repository of inherited mutation data for medical research, genetic diagnosis and next-generation sequencing studies. Hum Genet. 136:665-677. doi: 10.1007/s00439-017-1779-6.

Stigloher C, Ninkovic J, Laplante M, Geling A, Tannhauser B, Topp S, Kikuta H, Becker TS, Houart C, Bally-Cuif $L$ (2006) Segregation of telencephalic and eye-field identities inside the zebrafish forebrain territory is controlled by Rx3. Development 133: 2925-35. doi: 10.1242/dev.02450 
Stromland K (2004) Visual impairment and ocular abnormalities in children with fetal alcohol syndrome. Addict Biol 9: 153-7; discussion 159-60.

Stromland K, Miller M, Cook C (1991) Ocular teratology. Surv Ophthalmol 35: 429-46.

Stromland K, Miller MT (1993) Thalidomide embryopathy: revisited 27 years later. Acta Ophthalmol (Copenh) 71: 238-45.

Suhardjo, Utomo PT, Agni AN (2003) Clinical manifestations of ocular toxoplasmosis in Yogyakarta, Indonesia: a clinical review of 173 cases. Southeast Asian J Trop Med Public Health 34: 291-7.

Summers KM, Withers SJ, Gole GA, Piras S, Taylor PJ (2008) Anterior segment mesenchymal dysgenesis in a large Australian family is associated with the recurrent $17 \mathrm{bp}$ duplication in PITX3. Mol Vis 14: 2010-5.

Sun W, Zhang Q (2015) Does the association between TMEM98 and nanophthalmos require further confirmation? JAMA Ophthalmol 133: 358-9. doi: 10.1001/jamaophthalmol.2014.4915

Sundin OH (2005) The mouse's eye and Mfrp: not quite human. Ophthalmic Genet 26: 153-5. doi: $10.1080 / 13816810500374359$

Sundin OH, Leppert GS, Silva ED, Yang JM, Dharmaraj S, Maumenee IH, Santos LC, Parsa CF, Traboulsi El, Broman KW, Dibernardo C, Sunness JS, Toy J, Weinberg EM (2005) Extreme hyperopia is the result of null mutations in MFRP, which encodes a Frizzled-related protein. Proc Natl Acad Sci U S A 102: 9553-8. doi: 10.1073/pnas.0501451102

Tajima T, Ishizu K, Nakamura A (2013) Molecular and Clinical Findings in Patients with LHX4 and OTX2 Mutations. Clin Pediatr Endocrinol 22: 15-23.

Take-uchi M, Clarke JD, Wilson SW (2003) Hedgehog signalling maintains the optic stalk-retinal interface through the regulation of Vax gene activity. Development 130: 955-68.

Temtamy SA, Salam MA, Aboul-Ezz EH, Hussein HA, Helmy SA, Shalash BA (1996) New autosomal recessive multiple congenital abnormalities/mental retardation syndrome with craniofacial dysmorphism absent corpus callosum, iris colobomas and connective tissue dysplasia. Clin Dysmorphol 5: 231-40.

Tucker S, Jones B, Collin R (1996) Systemic anomalies in 77 patients with congenital anophthalmos or microphthalmos. Eye (Lond) 10 ( Pt 3): 310-4. doi: 10.1038/eye.1996.65

Tzoulaki I, White IM, Hanson IM (2005) PAX6 mutations: genotype-phenotype correlations. BMC Genet 6: 27.

Ullah E, Nadeem Saqib MA, Sajid S, Shah N, Zubair M, Khan MA, Ahmed I, Ali G, Dutta AK, Danda S, Lao R, Ling-Fung Tang P, Kwok PY, Ansar M, Slavotinek A (2016) Genetic analysis of consanguineous families presenting with congenital ocular defects. Exp Eye Res 146: 163-71. doi: 10.1016/j.exer.2016.03.014

Ullah E, Wu D, Madireddy L, Lao R, Ling-Fung Tang P, Wan E, Bardakjian T, Kopinsky S, Kwok PY, Schneider A, Baranzini S, Ansar M, Slavotinek A (2017) Two missense mutations in SALL4 in a patient with microphthalmia, coloboma, and optic nerve hypoplasia. Ophthalmic Genet 38: 371-375. doi: 10.1080/13816810.2016.1217550

Valleix S, Niel F, Nedelec B, Algros MP, Schwartz C, Delbosc B, Delpech M, Kantelip B (2006) Homozygous nonsense mutation in the FOXE3 gene as a cause of congenital primary aphakia in humans. Am J Hum Genet 79: 358-64.

Velez G, Tsang SH, Tsai YT, Hsu CW, Gore A, Abdelhakim AH, Mahajan M, Silverman RH, Sparrow JR, Bassuk AG, Mahajan VB (2017) Gene Therapy Restores Mfrp and Corrects Axial Eye Length. Sci Rep 7: 16151. doi: 10.1038/s41598-017-16275-8

Verdin H, Sorokina EA, Meire F, Casteels I, de Ravel T, Semina EV, De Baere E (2014) Novel and recurrent PITX3 mutations in Belgian families with autosomal dominant congenital cataract and anterior segment dysgenesis have similar phenotypic and functional characteristics. Orphanet J Rare Dis 9: 26. doi: 10.1186/1750-1172-9-26

Verma AS, Fitzpatrick DR (2007) Anophthalmia and microphthalmia. Orphanet J Rare Dis 2: 47.

Vincent MC, Pujo AL, Olivier D, Calvas P (2003) Screening for PAX6 gene mutations is consistent with haploinsufficiency as the main mechanism leading to various ocular defects. Eur J Hum Genet 11: 163-9. 
Volkmann BA, Zinkevich NS, Mustonen A, Schilter KF, Bosenko DV, Reis LM, Broeckel U, Link BA, Semina EV (2011) Potential novel mechanism for Axenfeld-Rieger syndrome: deletion of a distant region containing regulatory elements of PITX2. Invest Ophthalmol Vis Sci 52: 1450-9. doi: 10.1167/iovs.10-6060

Voronina VA, Kozhemyakina EA, O'Kernick CM, Kahn ND, Wenger SL, Linberg JV, Schneider AS, Mathers $\mathrm{PH}$ (2004) Mutations in the human RAX homeobox gene in a patient with anophthalmia and sclerocornea. Hum Mol Genet 13: 315-22.

Wang L, He F, Bu J, Zhen Y, Liu X, Du W, Dong J, Cooney JD, Dubey SK, Shi Y, Gong B, Li J, McBride PF, Jia Y, Lu F, Soltis KA, Lin Y, Namburi P, Liang C, Sundaresan P, Paw BH, Li W, Li DY, Phillips JD, Yang $Z$ (2012) ABCB6 mutations cause ocular coloboma. Am J Hum Genet 90: 40-8. doi: 10.1016/j.ajhg.2011.11.026

Wang P, Liang X, Yi J, Zhang Q (2008) Novel SOX2 mutation associated with ocular coloboma in a Chinese family. Arch Ophthalmol 126: 709-13.

Wang SW, Kim BS, Ding K, Wang H, Sun D, Johnson RL, Klein WH, Gan L (2001) Requirement for math5 in the development of retinal ganglion cells. Genes Dev 15:24-9.

Warburg M (1993) Classification of microphthalmos and coloboma. J Med Genet 30: 664-9.

Ward SJ, Chambon P, Ong DE, Bavik C (1997) A retinol-binding protein receptor-mediated mechanism for uptake of vitamin A to postimplantation rat embryos. Biol Reprod 57: 751-5.

Ward SJ, Morriss-Kay GM (1997) The functional basis of tissue-specific retinoic acid signalling in embryos. Semin Cell Dev Biol 8: 429-35. doi: 10.1006/scdb.1997.0166

Wasmann RA, Wassink-Ruiter JS, Sundin OH, Morales E, Verheij JB, Pott JW (2014) Novel membrane frizzled-related protein gene mutation as cause of posterior microphthalmia resulting in high hyperopia with macular folds. Acta Ophthalmol 92: 276-81. doi: 10.1111/aos.12105

Wawersik S, Purcell P, Rauchman M, Dudley AT, Robertson EJ, Maas R (1999) BMP7 acts in murine lens placode development. Dev Biol 207: 176-88. doi: 10.1006/dbio.1998.9153

Weber S, Taylor JC, Winyard P, Baker KF, Sullivan-Brown J, Schild R, Knuppel T, Zurowska AM, CaldasAlfonso A, Litwin M, Emre S, Ghiggeri GM, Bakkaloglu A, Mehls O, Antignac C, Network E, Schaefer F, Burdine RD (2008) SIX2 and BMP4 mutations associate with anomalous kidney development. J Am Soc Nephrol 19: 891-903. doi: 10.1681/ASN.2006111282

Williamson KA, Hever AM, Rainger J, Rogers RC, Magee A, Fiedler Z, Keng WT, Sharkey FH, McGill N, Hill CJ, Schneider A, Messina M, Turnpenny PD, Fantes JA, van Heyningen V, FitzPatrick DR (2006) Mutations in SOX2 cause anophthalmia-esophageal-genital (AEG) syndrome. Hum Mol Genet 15: 1413-22.

Williamson KA, Rainger J, Floyd JA, Ansari M, Meynert A, Aldridge KV, Rainger JK, Anderson CA, Moore AT, Hurles ME, Clarke A, van Heyningen V, Verloes A, Taylor MS, Wilkie AO, Consortium UK, Fitzpatrick DR (2014) Heterozygous loss-of-function mutations in YAP1 cause both isolated and syndromic optic fissure closure defects. Am J Hum Genet 94: 295-302. doi: 10.1016/j.ajhg.2014.01.001

Winkler S, Loosli F, Henrich T, Wakamatsu Y, Wittbrodt J (2000) The conditional medaka mutation eyeless uncouples patterning and morphogenesis of the eye. Development 127: 1911-9.

Wong RL, Chow KL (2002) Depletion of Mab21l1 and Mab21/2 messages in mouse embryo arrests axial turning, and impairs notochord and neural tube differentiation. Teratology 65: 70-7. doi: 10.1002/tera.10018

Wyatt A, Bakrania P, Bunyan DJ, Osborne RJ, Crolla JA, Salt A, Ayuso C, Newbury-Ecob R, Abou-Rayyah $\mathrm{Y}$, Collin JR, Robinson D, Ragge N (2008) Novel heterozygous OTX2 mutations and whole gene deletions in anophthalmia, microphthalmia and coloboma. Hum Mutat 29: E278-83.

Wyatt AW, Osborne RJ, Stewart H, Ragge NK (2010) Bone morphogenetic protein 7 (BMP7) mutations are associated with variable ocular, brain, ear, palate, and skeletal anomalies. Hum Mutat 31: 781-7.

Wyatt AW, Ragge N (2009) MLGA: a cost-effective approach to the diagnosis of gene deletions in eye development anomalies. Mol Vis 15: 1445-8. 
Yahyavi M, Abouzeid H, Gawdat G, de Preux AS, Xiao T, Bardakjian T, Schneider A, Choi A, Jorgenson E, Baier H, El Sada M, Schorderet DF, Slavotinek AM (2013) ALDH1A3 loss of function causes bilateral anophthalmia/microphthalmia and hypoplasia of the optic nerve and optic chiasm. Hum Mol Genet 22: 3250-8.

Yamada R, Mizutani-Koseki Y, Hasegawa T, Osumi N, Koseki H, Takahashi N (2003) Cell-autonomous involvement of Mab21l1 is essential for lens placode development. Development 130: 175970.

Yan X, Sabrautzki S, Horsch M, Fuchs H, Gailus-Durner V, Beckers J, Hrabe de Angelis M, Graw J (2014) Peroxidasin is essential for eye development in the mouse. Hum Mol Genet 23: 5597-614. doi: $10.1093 / \mathrm{hmg} / \mathrm{ddu} 274$

Yariz KO, Sakalar YB, Jin X, Hertz J, Sener EF, Akay H, Ozbek MN, Farooq A, Goldberg J, Tekin M (2015) A homozygous SIX6 mutation is associated with optic disc anomalies and macular atrophy and reduces retinal ganglion cell differentiation. Clin Genet 87: 192-5. doi:10.1111/cge.12374

Ye M, Berry-Wynne KM, Asai-Coakwell M, Sundaresan P, Footz T, French CR, Abitbol M, Fleisch VC, Corbett N, Allison WT, Drummond G, Walter MA, Underhill TM, Waskiewicz AJ, Lehmann OJ (2010) Mutation of the bone morphogenetic protein GDF3 causes ocular and skeletal anomalies. Hum Mol Genet 19: 287-98. doi: 10.1093/hmg/ddp496

Young TR, Leamey CA (2009) Teneurins: important regulators of neural circuitry. Int J Biochem Cell Biol 41: 990-3. doi: 10.1016/j.biocel.2008.06.014

Zahrani F, Aldahmesh MA, Alshammari MJ, Al-Hazzaa SA, Alkuraya FS (2013) Mutations in c12orf57 cause a syndromic form of colobomatous microphthalmia. Am J Hum Genet 92: 387-91.

Zazo Seco C, Plaisancie J, Lupasco T, Michot C, Pechmeja J, Delanne J, Cottereau E, Ayuso C, Corton M, Calvas P, Ragge N, Chassaing N (2018) Identification of PITX3 mutations in individuals with various ocular developmental defects. Ophthalmic Genet 39: 314-320. doi: 10.1080/13816810.2018.1430243

Zenteno JC, Buentello-Volante B, Quiroz-Gonzalez MA, Quiroz-Reyes MA (2009) Compound heterozygosity for a novel and a recurrent MFRP gene mutation in a family with the nanophthalmos-retinitis pigmentosa complex. Mol Vis 15: 1794-8.

Zenteno JC, Perez-Cano HJ, Aguinaga M (2006) Anophthalmia-esophageal atresia syndrome caused by an SOX2 gene deletion in monozygotic twin brothers with markedly discordant phenotypes. Am J Med Genet A 140: 1899-903.

Zhang C, Li D, Zhang J, Chen X, Huang M, Archacki S, Tian Y, Ren W, Mei A, Zhang Q, Fang M, Su Z, Yin Y, Liu D, Chen Y, Cui X, Li C, Yang H, Wang Q, Wang J, Liu M, Deng Y (2013) Mutations in ABCB6 cause dyschromatosis universalis hereditaria. J Invest Dermatol 133: 2221-8. doi: 10.1038/jid.2013.145

Zhang X, Li S, Xiao X, Jia X, Wang P, Shen H, Guo X, Zhang Q (2009) Mutational screening of 10 genes in Chinese patients with microphthalmia and/or coloboma. Mol Vis 15:2911-8.

Zouvelou V, Luder HU, Mitsiadis TA, Graf D (2009) Deletion of BMP7 affects the development of bones, teeth, and other ectodermal appendages of the orofacial complex. J Exp Zool B Mol Dev Evol 312B: 361-74. doi: 10.1002/jez.b.21262 


\section{FIGURE LEGENDS}

Fig. 1 a. Facial view of a female with bilateral anophthalmia, carrying a de novo 14q22.3q23.1 deletion (chr14:57166658-5878654, hg19), including the gene OTX2. b. Facial view of a female diagnosed with bilateral anophthalmia, left cyst and hypoplastic optic chiasm, carrying a homozygous ALDH1A3 pathogenic variant (Fares-Taie et al. 2013)

1.a.

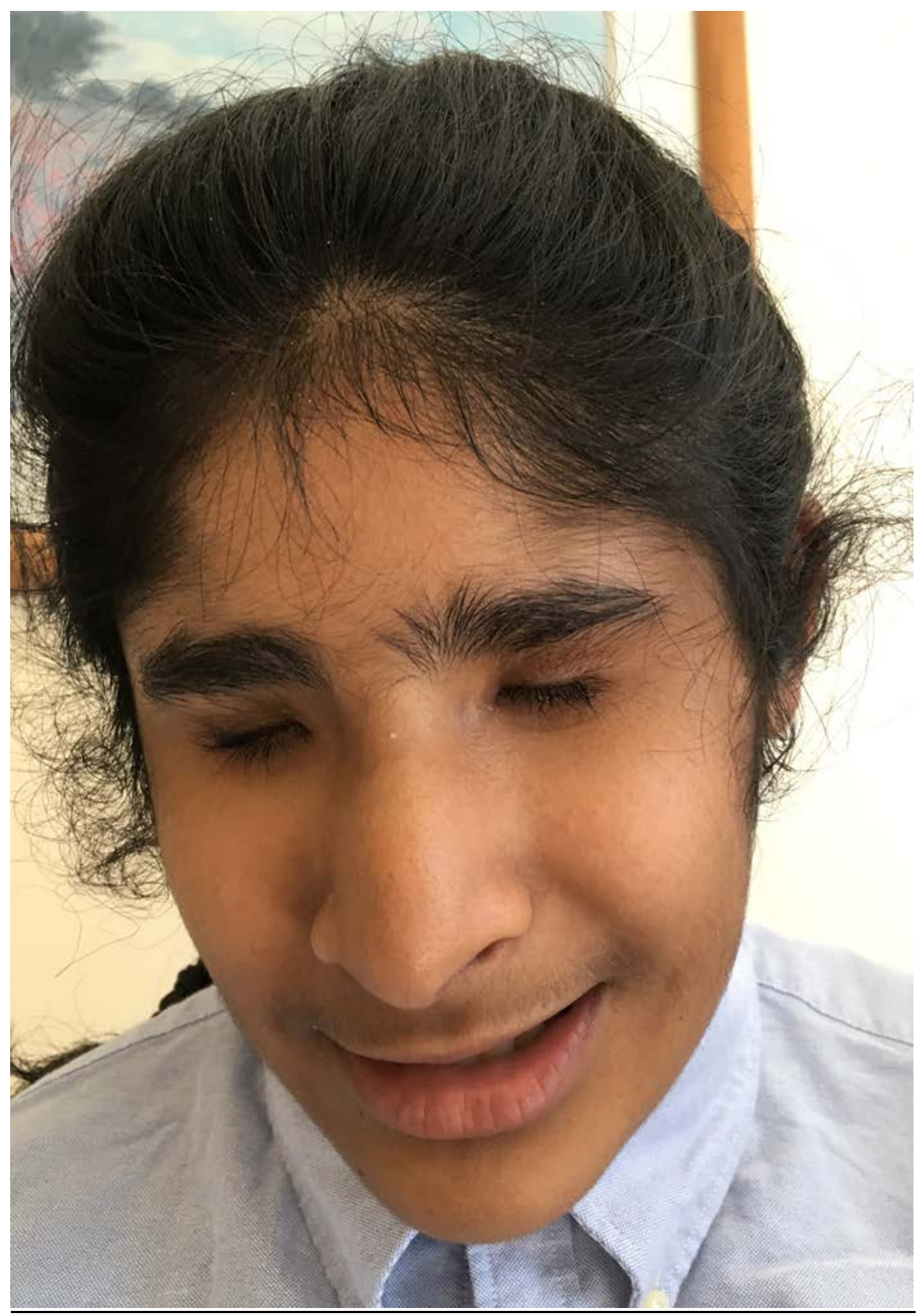


1.b.

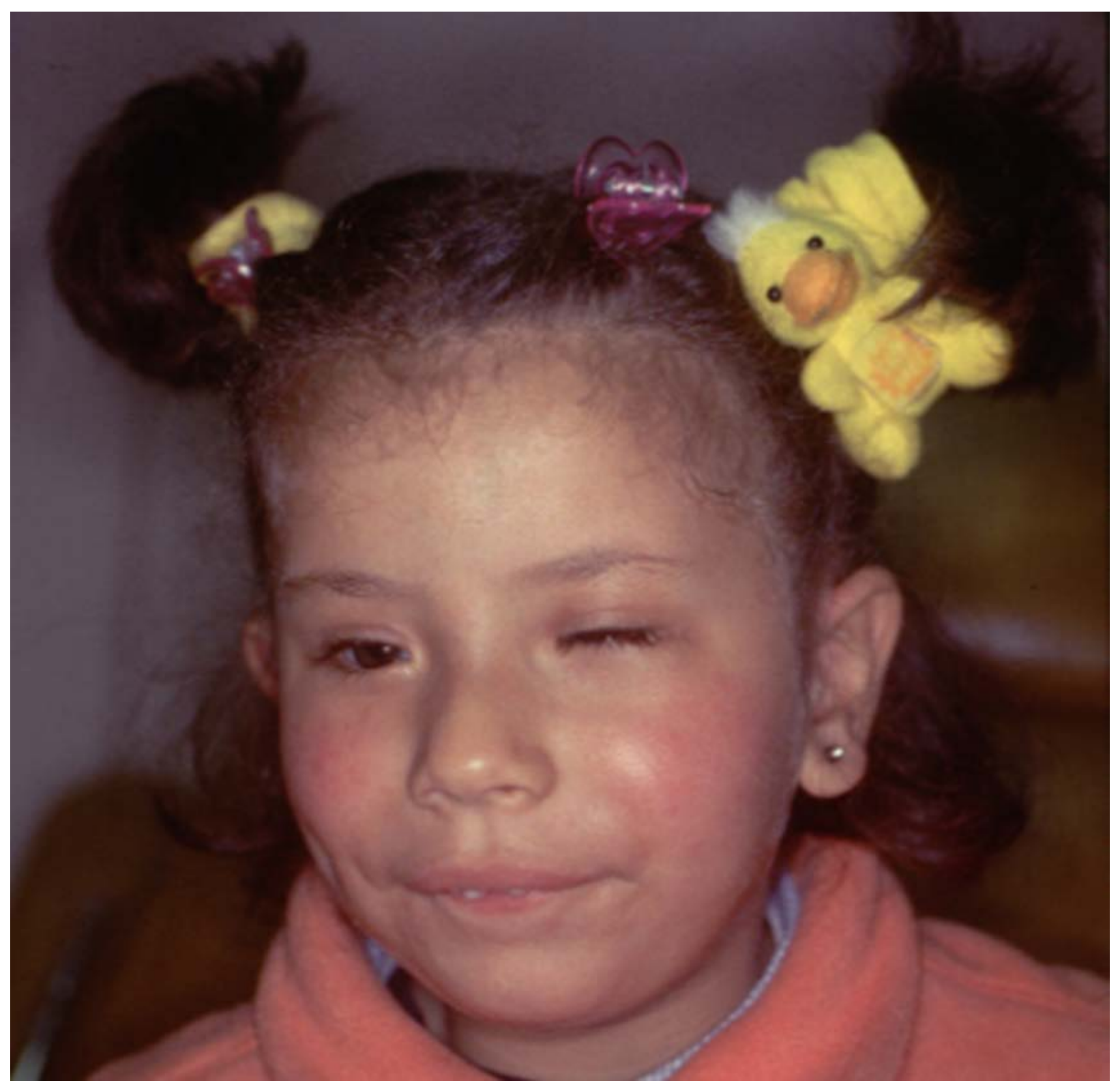


Fig. 2 a. Eyes of a male with non-syndromic bilateral colobomatous microphthalmia, with an inherited YAP1 frameshift mutation (Holt et al. 2017). b-c. Magnified view of the eyes of the same individual. The right eye (b) presents with microphthalmia with chorioretinal coloboma involving optic disc. The left eye (c) also presents with microphthalmia with chorioretinal coloboma involving optic disc, more marked than right, and small convergent squint

2.a.

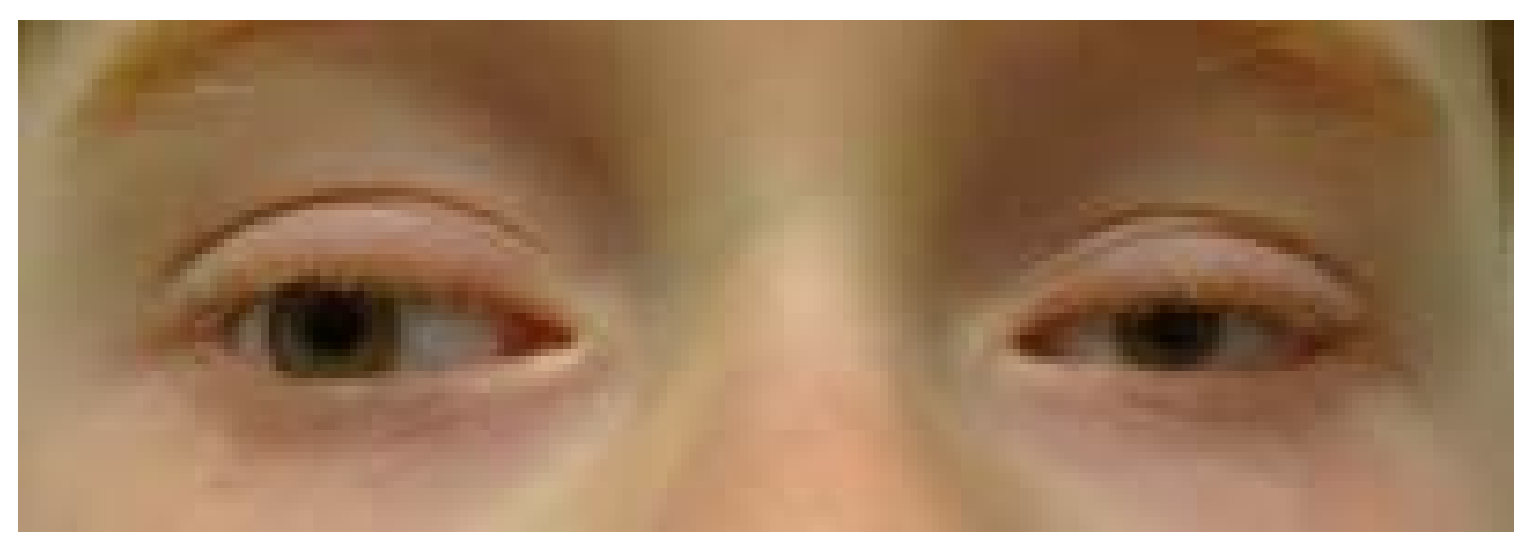

2.b-c.




Fig. 3 a. Facial view of a male with clinical anophthalmia, carrying a de novo PAX6 missense mutation. The patient is wearing bilateral clear prostheses as he has light perception, presumably from subconjunctival microphthalmic remnants. b-c. Right and left eyes, respectively, of a male diagnosed with bilateral microphthalmia, iris and optic disc coloboma, corneal opacity, bilateral congenital aphakia and primary glaucoma. The patient carries a missense variant in GJA8 (Ceroni et al. 2018)

3.a.

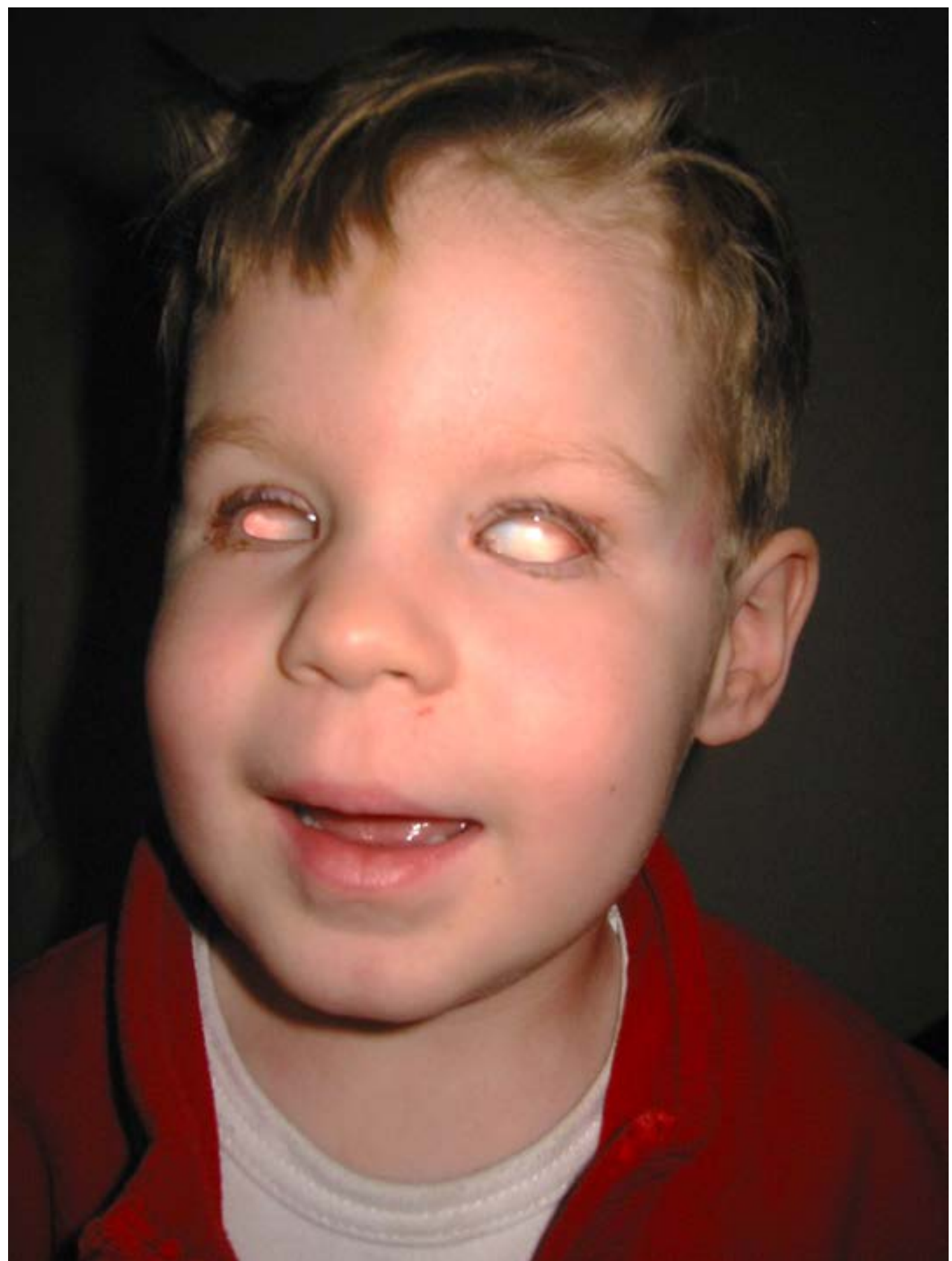


3.b-c.
